NBER WORKING PAPER SERIES

\title{
PAYROLL TAXES, FIRM BEHAVIOR, AND RENT SHARING: EVIDENCE FROM A YOUNG WORKERS' TAX CUT IN SWEDEN
}

\author{
Emmanuel Saez \\ Benjamin Schoefer \\ David Seim \\ Working Paper 23976 \\ http://www.nber.org/papers/w23976 \\ NATIONAL BUREAU OF ECONOMIC RESEARCH \\ 1050 Massachusetts Avenue \\ Cambridge, MA 02138 \\ October 2017
}

We thank David Card, Raj Chetty, Johan Egebark, Anders Forslund, Peter Fredriksson, Matthew Gentzkow, Lena Hensvik, Simon Jager, Lawrence Katz, Niklas Kaunitz, Patrick Kline, Tuomas Kosonen, Adriana Kugler, Magne Mogstad, Arash Nekoei, John Pencavel, David Sraer, David Stromberg, Jonas Vlachos, Danny Yagan, Eric Zwick, as well as numerous seminar and conference participants for helpful discussions and comments. Sam Karlin, Carl McPherson and Nina Roussille provided outstanding research assistance. We acknowledge financial support from NSF Grant SES-1559014; the Center for Equitable Growth at UC Berkeley, and FORTE Grant 2015-00490. The views expressed herein are those of the authors and do not necessarily reflect the views of the National Bureau of Economic Research.

NBER working papers are circulated for discussion and comment purposes. They have not been peerreviewed or been subject to the review by the NBER Board of Directors that accompanies official NBER publications.

(C) 2017 by Emmanuel Saez, Benjamin Schoefer, and David Seim. All rights reserved. Short sections of text, not to exceed two paragraphs, may be quoted without explicit permission provided that full credit, including $\odot$ notice, is given to the source. 
Payroll Taxes, Firm Behavior, and Rent Sharing: Evidence from a Young Workers' Tax Cut in Sweden

Emmanuel Saez, Benjamin Schoefer, and David Seim

NBER Working Paper No. 23976

October 2017

JEL No. H31,H32,J23,J31

\section{ABSTRACT}

This paper uses administrative data to analyze a large and long-lasting employer payroll tax rate cut from $31 \%$ down to $15 \%$ for young workers (aged 26 or less) in Sweden. We find a zero effect on net-of-tax wages of young treated workers relative to slightly older untreated workers, even in the medium run (after six years). Simple graphical cohort analysis shows compelling positive effects on the employment rate of the treated young workers, of about 2-3 percentage points, which arise primarily from fewer separations (rather than more hiring). These employment effects are larger in places with initially higher youth unemployment rates. We also analyze the firmlevel effects of the tax cut. We sort firms by the size of the tax windfall and trace out graphically the time series of firms' outcomes. We proxy a firm's windfall with its share of treated young workers just before the reform. First, heavily treated firms expand after the reform: employment, capital, sales, value added, and profits all increase. These effects appear stronger in creditconstrained firms, consistent with liquidity effects. Second, heavily treated firms increase the wages of all their workers - young as well as old - collectively, perhaps through rent sharing. Wages of low paid workers rise more in percentage terms. Rather than canonical market-level adjustment, we uncover a crucial role of firm-level mechanisms in the transmission of payroll tax cuts.

Emmanuel Saez

Department of Economics

University of California, Berkeley

530 Evans Hall \#3880

Berkeley, CA 94720

and NBER

saez@econ.berkeley.edu

Benjamin Schoefer

Department of Economics

University of California at Berkeley

530 Evans Hall \#3880

Berkeley,, CA 94720

schoefer@berkeley.edu
David Seim

Universitetsvägen 10 A, 10691 Stockholm

Stockholm University

david.seim@ne.su.se 


\section{Introduction}

Payroll taxes collect about $25 \%$ of total tax revenue in OECD countries, about as much as revenue from personal income taxes (OECD, 2016). Hence, payroll tax rates are often high, in excess of 30\% (OECD, 2017), potentially creating a large distortion. In recent decades, cuts to the employer portion of payroll taxes are often discussed as a policy lever to reduce labor costs of firms, particularly targeted towards workers facing high unemployment rates such as low earners, the young, or the elderly $\left.\right|^{1}$ The policy debate is framed as follows: the rationale for targeted payroll tax cuts is to boost employment for specific groups and business activity more generally; a potential drawback is that firm owners might instead just pocket the tax cut as a profit windfall. In the public economics literature, the received wisdom is that the incidence of payroll taxes - even if nominally paid by employers - ultimately falls on workers' net wages, leaving firms' gross labor costs unchanged $2^{2}$ This canonical incidence result is obtained in a standard competitive labor market model when aggregate labor demand is much more elastic than aggregate labor supply (see e.g., Fullerton and Metcalf, 2002).

In this paper, we re-examine this issue by exploiting a large, long lasting payroll tax cut for all young workers in Sweden. Our empirical findings starkly contradict the received wisdom, as we find a clear zero wage effect for the directly treated young workers compared to the slightly older ineligible control group, but sizable employment effects. These nonstandard market-level results may be due to wage frictions in the form of equity concerns that curb sharp differentiation of net wages between similar workers, especially within firms. Indeed, we uncover that firm-level mechanisms are critical in the ultimate incidence of payroll taxes and its transmission, exactly along the lines of the policy debate: rather than pocketing the windfall, firms use the cost reductions to expand their scale. Moreover, while we reject differentials in net market wages by eligibility status, individual firms do pass through the tax windfall into their employees' net wages across the board (i.e. spilling over to old and young), perhaps through rent sharing.

Sweden has a large, linear payroll tax rate of $31.4 \%$, with no floor or ceiling. The entire

\footnotetext{
${ }^{1}$ For example, France has sharply cut employer payroll taxes on low paid workers as a way to reduce the labor cost of minimum wage workers (see e.g., Piketty 1997 and Kramarz and Philippon, 2001). The United States has a history of more targeted employer credits for disadvantaged groups (see Katz 1998 for a survey and empirical analysis). During the Great Recession, the United States implemented broad-based hiring subsidies as well as debated employer payroll tax cuts (but ultimately implemented employee cuts), see US Congressional Budget Office (2010, 2011). Several European countries have experimented with payroll tax cuts for the young or the elderly (see e.g. OECD, 2017b). Bils and Klenow (2008) discuss employer payroll taxes as short-term stimulus. Singapore regularly cuts the employer payroll taxes during recessions to stimulate business activity.

${ }^{2}$ For example, these incidence assumptions are adopted in the official statistics on the distribution of US Federal taxes (US Congressional Budget Office, 2016).
} 
payroll tax is nominally paid by the employer. In 2007, a newly elected center-right government adopted a payroll tax cut targeted to young workers in two steps. On July 1st, 2007, the payroll tax rate was cut to $21.3 \%$ for workers turning 19-25 during the calendar year. On January 1st, 2009 , the payroll tax rate was further cut to $15.5 \%$ (a total cut of 16 points) and eligibility was raised to age 26. Hence, by 2009, the payroll tax rate on young workers was halved by the reform $\mathrm{S}^{3}$ The cut applied to both new and ongoing jobs. The motivation for the reform was to stimulate demand for young workers in light of high youth unemployment, as well as to boost business activity by reducing employer taxes.4 Administratively, the payroll tax cut was programmed into the government provided payroll tax software, which employers use for monthly payroll payments for each individual worker. Hence, take-up of the age-specific reform was immediate, salient and close to perfect.5 We analyze the payroll tax cut using populationwide Swedish administrative data linking employees to employers, and firm-level accounting data. Together, these features provide us with an ideal laboratory for our comprehensive study of payroll tax incidence and its transmission through market-level and firm-level mechanisms.

The first part of our empirical analysis focuses on the market level tax incidence on wages and the employment effects. We replicate the analysis in Egebark and Kaunitz (2013, 2017) and find that the payroll tax cut has zero effect on net-of-payroll tax wages of young treated workers relative to slightly older untreated workers: Average wages (measured as monthly full time equivalent salaries for all workers) are smoothly increasing with age across birth cohorts with no discontinuity whatsoever at the age cut-off where the payroll tax cut applies and in years after the reform is in place. Correspondingly, after the reform, we show that there is a sharp discontinuity in the labor cost (defined as earnings plus the payroll tax rate) at the age at which the tax cut applies in years after the reform. This simple contrast between wages pre- and post-tax provides compelling and transparent graphical evidence of full incidence on firms. This absence of wage effects on workers is broadly consistent with Skedinger (2014) and Egebark and Kaunitz (2013, 2017) who find zero or small positive wage effects depending on specifications using individual based Difference-in-Differences (DiD) regressions with controls (see our literature review below for a more complete discussion).

\footnotetext{
${ }^{3}$ Since the cut in payroll taxes for young workers was not paired with any reduction in social insurance benefits for young workers, it was a pure tax cut from the perspective of young workers and their employers (see Skedinger 2014 for a detailed discussion).

${ }^{4}$ The payroll tax cut was part of the center-right coalition's election promise in 2006 (e.g. Dagens Nyheter, August 12, 2006). It was enacted as a permanent tax change, although it was repealed in 2015-6 when a center-left new government was elected. Our data set ends in 2014 and hence we cannot study the repeal yet.

${ }^{5}$ This perfect take-up is in sharp contrast with many employer subsidies programs where firms have to apply and claim benefits (see e.g. Katz 1998 detailed discussion for US programs).
} 
We find positive effects on the employment rate of eligible younger workers, which after the reform increases by 2-3 points compared to slightly older ineligible workers. Again, we can obtain compelling graphical evidence of employment effects as employment to labor force ratios are very stable pre-reform at all ages and after-reform for unaffected older workers. They jump up from pre- to post-reform for young treated workers but remain stable for slightly older control workers. These results confirm the findings in Skedinger (2014) and Egebark and Kaunitz (2013, 2017), who find quantitatively similar employment results using individual based Difference-inDifferences (DiD) regressions with controls. Our key value-added relative to that earlier work is the transparent graphical evidence. We further show that the employment effects are mostly explained by fewer worker separations from jobs rather than entry into jobs. We also find much stronger employment effects in areas that have high initial unemployment rates, implying that the payroll tax cut was indeed most effective in areas where youth employment was most depressed.

In the standard model of tax incidence, any incipient labor cost differential among similar workers that are close substitutes in production (in our case: workers just below vs. above the age cut-off) triggers differential hiring/retention until the labor costs of young and slightly older workers are again equalized. Empirically, the differential hiring/retention channel appears present, but it does not impact relative wages. One possible explanation is that wages are rigid due to union bargaining agreements, which are indeed widespread in Sweden. Such union wage agreements specify wage floors by industry, occupation, and sometimes age as well. However, the absence of wage responses remains true even for higher wage earners who are above the union wage floors. More generally, we document that the full density distribution of young workers' labor costs, at all levels of earnings, shifts uniformly after the payroll tax cut. Another possibility is that wages are rigid due to implicit contracts whereby firms cannot change wages once the worker is on the job. However, we also do not find any evidence of wage differentials by age for new hires. Finally, employers might not be able to lower pay as workers age out of the payroll tax subsidy as wage cuts hurt morale (as in Bewley 2002). Hence, employers might be reluctant to offer higher wages to the young in the first place, although under such downward rigidity, wages would still increase in a noticeable, albeit attenuated, amount. Moreover, the median work spell for young Swedish workers is less than 2 years. In our view, the most likely explanation is that employers cannot discriminate net pay by age, not because of formal constraints, but perhaps because of fairness norms within the firm. In this setting, payroll tax cuts for the young can help alleviate these wage frictions. 
The second part of our comprehensive empirical analysis focuses on firms' behavior in response to the payroll tax cut, to understand why the standard incidence predictions are not borne out, and to cast further light on the ultimate incidence of the payroll tax cut and its transmission mechanisms. Our identification strategy exploits persistent between-firm variation in the share of young workers just before the reform. Firms with many young workers received a larger tax cut windfall and cost reduction and hence are more exposed to the reform ${ }^{6}$ Dividing firms into groups by pre-reform share young, it turns out that firms with a moderate share young are an excellent control group for firms with a large share young, as both types of firms move in parallel for a very wide range of outcome variables in pre-reform years and share similar pre-reform attributes (unlike zero or very small share young firms). Tracing out outcomes longitudinally pre- and post-reform allows us to provide simple and transparent graphical evidence of firms' responses. We obtain two main results.

First, we find that firms with a large share young grow faster and hire more workers after the reform (relative to firms with a moderate share young). Sales, value added, profits, capital assets, and employment all grow faster after the reform. Furthermore, we apply sample-split strategies to trace the firm-growth mechanisms. Firm effects are larger for firms more likely to be credit constrained according to standard proxies such as age, size measured by sales, or share of liquid assets in total assets. Therefore, these results are consistent with liquidity effects, whereby firms are limited in their growth due to credit constraints that the payroll tax cut helps alleviate. However, we also find positive growth effects in less constrained firms, either because the credit constraint proxies are inaccurate or because even unconstrained firms might respond to the tax cut, perhaps in response to lower marginal costs.7

Second, we document that firms most exposed to the tax cut also increase average net wages. To eliminate composition bias in those growing firms, we follow individual workers based on the firm they were working at just before the reform. We find that individuals working in a large share young firm experience faster wage growth after the reform even if these individuals are too old to directly have benefitted from the reform. This pattern is consistent with rent

\footnotetext{
${ }^{6}$ This empirical strategy was first used by Skedinger (2014), who focused on the retail sector. Egebark and Kaunitz (2017b) also use this strategy investigating the broader economy. As discussed in the literature review below in detail, we consider a much broader range of outcomes and mechanisms although we focus on a narrower set of firms to obtain better identification.

${ }^{7}$ Our research design does not allow us to distinguish between these two channels, but we can estimate very compellingly the combined effect using our longitudinal identification strategy. In principle, firm responses could be due to cash effects generated mechanically by the tax windfall itself. There is a large literature in corporate finance on how firms respond to cash windfalls, although compelling identification has been a challenge (see e.g. Hubbard, 1998 for a survey). Alternatively, marginal-cost effects from input cost reductions - young employees - may induce the scale effect in labor demand.
} 
sharing, whereby the payroll tax cut increases the profits of firms and part of these extra profits are distributed back to all workers (not just the tax cut eligible workers) 8 The firm-level mechanism of tax incidence contrasts with the standard model of payroll tax incidence, whereby the market mechanism would limit wage increases to young workers eligible for the payroll tax cut, and would be identical for all young workers irrespective of their firm. These firm-level wage effects would have been missed with a focus on worker-level market wages only, and would also be masked in aggregate macro studies of homogeneous payroll taxes 9

Our findings also imply that, at a macro level, the incidence of the payroll tax cut might still fall largely on workers collectively, even though it does not fall on the specific worker groups whose individual tax rate the reform targeted. Furthermore, we find that low earning employees benefit relatively more (in percentage terms) from the tax cut than high earners. This "collective tax incidence" appears progressive, in contrast with the public policy concern that wealthy employers pocket the tax windfall. These across-the-board wage increases at the firm level are also in line with our conjecture that within-firm pay equity concerns may have prevented sharp incidence in the market wage of young workers, and perhaps contributed to youth unemployment to begin with. In this context, an age-dependent employer payroll tax rate may help offset such wage frictions. 10

In Section 2, we review related literature. In Section 3, we describe the institutional setting, the payroll tax reform, and the data. In Section 4, we present the market level effects of the payroll tax cut on wages and employment. In Section 5, we present the firm level effects of the payroll tax windfall on hiring and business activity. In Section 6, we present the incidence effects on wages and rent sharing with the firm. We conclude in Section 7 with implications for policy and sketch a model that can account for our set of findings.

\section{Literature Review}

Our paper brings together issues of payroll tax incidence, employment subsidies for specific groups of workers, as well as the effects of taxes on business activity. We briefly review previous work on these topics.

\footnotetext{
${ }^{8}$ There is a valuable literature on how rents to firms are shared with workers. In particular, Van Reenen (1996) finds a positive effect of innovation on wages using a panel of UK firms. Fuest, Peich, and Siegloch (2017) also find that municipal corporate tax changes in Germany are partly shifted to workers' wages.

${ }^{9}$ Consistent with this, regional payroll tax cuts for all workers appear to affect net wages (see Section 2 ).

${ }^{10} \mathrm{An}$ age-specific employer payroll tax schedule is feasible because age is a fixed and easily observable attribute and therefore a suitable tag for differentiated tax rates. See Weinzierl (2011) for an application to age-dependent income taxes in a Mirrleesian framework.
} 
Payroll tax incidence. At the macro-level, the fact that the labor income share in national product is pretty stable both over time and across countries, in spite of large historical increases in payroll taxes, suggests that the incidence of payroll taxes is borne by workers in the longrun. There is a relatively small body of work analyzing payroll tax incidence exploiting payroll tax changes. Studies using time series variation within a country find mixed results (see e.g. Brittain, 1972, Hamermesh, 1979, Holmlund 1983). Studies using micro-data and payroll tax reforms have found incidence of employer payroll taxes shifted to employees (see Gruber 1997 for Chile, Cruces, Galiani, and Kidyba 2010 for Argentina, and Anderson and Meyer 1997, 2000 for US unemployment insurance payroll taxes). However, these findings contrast with recent micro evidence. Kugler and Kugler (2009) examined the effects of a large increase in payroll taxes in the 1990s in Colombia. They find that only between $14 \%$ to $23 \%$ of the payroll tax increase is passed to employees through reduced wages.11 Saez, Matsaganis, Tsakloglou (2012) use a cohort-based payroll tax increase in Greece and show that, even in the medium run, employers bear the burden of the employer level tax increase while employees bear the burden of the employee level tax increase, in contradiction with the conventional model of tax incidence, in which the statutory incidence is irrelevant. Bozio, Breda, and Grenet (2016) also find that large changes in employer payroll taxes are not passed on employees in the case of France even in the medium run, 5-7 years after the reform ${ }^{12}$ The non-standard results from these recent studies are consistent with our findings for Sweden.

Employment subsidies. There is a larger body of work evaluating the employment effects of various employment subsidy programs, often in the form of payroll tax cuts targeted to disadvantaged populations as many OECD countries have experimented with such policies ${ }^{13}$ Katz (1998) describes US wage subsidy policies for the disadvantaged, surveys the empirical literature, and pioneers a difference-in-difference approach similar in spirit to our market-level strategy in Section 4. He concludes that such wage subsidies can generate moderately positive employment effects for disadvantaged populations if administration is simple enough so that firms' take-up is high and the target group is broad enough to not be stigmatizing to potential beneficiaries. Neumark (2013) provides a more recent survey of hiring credits and also concludes

\footnotetext{
${ }^{11}$ They also find negative effects on formal employment, a finding consistent with the analysis of a subsequent payroll tax cut study in Colombia in 2014 by Kugler et al. (2017) and in Brazil by Scherer (2015).

${ }^{12}$ They find an incidence on workers only in the special case of supplementary pension contributions where payroll tax changes are tied to corresponding changes in pension benefits. They argue that, in such a case, the payroll tax is like a mandated benefit which allows employers to shift the incidence on employees.

${ }^{13}$ OECD $(2017,2017 b)$ compile and describe of all such policies in OECD countries.
} 
that they can increase employment but only if designed to be broad enough ${ }^{14}$ The Swedish payroll tax cut we analyze provides this ideal design: it is large, salient, administered with quasi-complete and automatic take-up, and targets all youth, so that our positive employment effects are fully consistent with the conclusions from these earlier surveys.

A number of recent studies have examined payroll tax cuts or subsidies targeting specific groups in European countries. Kramarz and Philippon (2001) show that permanent employer payroll tax cuts for minimum wage workers had a positive effect on employment by reducing separations (rather than stimulating hiring), consistent with our results. This minimum-wage context precludes wage incidence by construction, whereas we find zero direct wage effects even without formal wage floors. Cahuc, Carcillo and Le Barbanchon (2016) show that French shortterm subsidies for the newly hired but recently unemployed were effective during the Great Recession even though take-up was only around 25\%. They attribute these employment effects to rigid wages, again consistent with our findings. Kreiner et al. (2017) document employment effects of one large kink in teen minimum wages (at age 18) the Denmark.

Several studies have analyzed geographically targeted and temporary payroll tax cuts to stimulate employment in Nordic countries (Bohm and Lind, 1993 and Bennmarker, Mellander, and Ockert, 2009 for Sweden; Johansen and Klette 1997 and Gavrilova et al. 2015 for Norway; and Korkeamaki and Uusitalo, 2009 for Finland). The results are mixed but four out of these five studies find significant pass-through to wages, between $25 \%$ and $66 \%$, suggesting that wages in Nordic countries can be flexible and adjust to taxes. Only two of the five studies found significant (and fairly modest) employment effects. ${ }^{15}$ Our results differ from these results as we find zero direct wage effects, perhaps because a payroll tax cut affecting a full labor market (as opposed to the young only) allows firms to adjust wages across the board without facing pay equity constraints. Consistent with this explanation, Huttunen, Pirttila, and Uusitalo (2013) find that a payroll tax cut targeting older workers in Finland had no effects on wages 16

Firms and tax incentives. The effect of taxation on business activity looms very large in the public policy debate yet there is relatively little empirical work using well-identified

\footnotetext{
${ }^{14}$ Yet another survey by Marx (2001) provides international evidence and concludes: "Relatively generous measures with a relatively broad scope and involving a substantial subsidy or a reduction in contributions generally generate a greater response."

${ }^{15}$ Mansson and Quoreshi (2015) also use geographical variation of payroll tax cuts in Sweden to look at firms effects and find positive effects on firms' profits followed by positive effects on wages later on.

${ }^{16}$ In contrast to our results though, they do not find any positive employment effects, perhaps because the subsidy was temporary or because the old are more difficult to employ than the young. Consistent with this explanation, in the context of Spain, Elias (2015) found positive employment effects of payroll tax cuts targeted to the young (30 or less) but no effects of payroll tax cuts targeted to the old (45 or more).
} 
empirical designs on this important question 17 Chetty and Saez (2005) show that the large 2003 US dividend tax cut had a strong positive effect on dividend payments but Yagan (2015) compellingly shows that this dividend surge was not accompanied by any increase in real business activity such as investment or employee compensation. Zwick and Mahon (2017) show that US temporary tax incentives for investment had a positive effect on subsidized investment for small firms, particularly when the policy generates immediate cash flow, consistent with credit constraints. Our study shows compelling tax responses of firms' real business activity along a wider range of outcomes and in the medium run.

Corporate tax incidence on wages. There is a large literature on whether the incidence of the corporate income tax falls on labor using the standard incidence model with general equilibrium factor price effects. Credible identification is a challenge (see Auerbach 2006 for a survey). A few recent studies however have focused on the incidence of the corporate tax on wages through wage bargaining within firms. In the US context, Felix and Hines (2009) find that unionized wage premia are larger in states with lower corporate taxes. In the EU context, Arulampalam et al. (2012) also find that, everything else equal, companies with low corporate tax liabilities tend to pay higher wages. Most compellingly, Fuest, Peich, and Siegloch (2017) analyze municipal corporate tax rate changes in Germany and find that about 50\% of the incidence falls on workers' wages, with low-skilled, young and female employees bearing a larger share of the tax burden. Our collective wage incidence results that wage incidence favors low earners echo their findings.

Earlier work the Swedish Payroll Tax Cut for the Young. Several studies have also analyzed the same payroll tax cut for the young and its effects on both individual workers (comparing workers by age) and firms (comparing firms by fraction young workers) as we do in this paper. Our analysis builds upon these previous studies. We replicate some of these earlier results and extend the analysis in a number of directions described below.

Wage incidence effects. Bennmarker, Calmfors, and Seim (2013) focus solely on wages and find no effects. Skedinger (2014) focuses on the retail sector only and finds no effect on wages. Egebark and Kaunitz (2013, 2017) show graphs by age and time period showing no effect on wages (Figure 4 in Egebark and Kaunitz, 2017). Their individual-level DiD regression with controls analysis shows modest positive effects on wages. Our analysis in Section 4 replicates these findings using a purely graphical analysis with no controls, and zooming in on monthly

\footnotetext{
${ }^{17}$ See Hassett and Hubbard (2002) for a survey of the earlier work on this question.
} 
cohorts. In addition, we look at wages inclusive of payroll taxes to saliently show that the payroll tax incidence is $100 \%$ on employers with no effect at all on wages (see Figures 2 and 3 ) and we analyze wage densities to show that the incidence is uniform across the wage distribution (see Figure 5).

Youth employment effects. Skedinger (2014) finds small positive effects on hiring and employment over the period 2007-2011 in the retail sector. Egebark and Kaunitz (2013, 2017) start with a standard graphical difference-in-difference approach plotting employment rates by age and year relative to full population (their Figures 3 and 5). However, they conclude that the graphical analysis per se is not fully compelling in this context 18 Therefore, they use individuallevel DiD regression with controls for their estimation. They find significant employment effects in 2007-2008 and 2010-2012 (but no effect in 2009). In our graphical analysis, we look at employment rates within the labor force (instead of within population). Such graphs display excellent parallel trends so that we can provide a very simple and compelling graphical demonstration of employment effects (see Figure 6, top panel). Even though we use a somewhat different measure of employment, the quantitative employment effects we find are similar in magnitude to the regression based estimates of Egebark and Kaunitz (2013, 2017). We also look at heterogeneity across areas by pre-reform unemployment level ${ }^{19}$

Firm outcomes. Skedinger (2014) pioneered the empirical analysis comparing firms with large share young vs. small share young. He finds that firms more exposed to the payroll tax cut saw their profits increase. Egebark and Kaunitz (2017b) also analyze the effects of the payroll tax reform on various firm outcomes in 2007 and 2008, they find a positive effect on gross investment but no significant effects on value added per worker and operating profits. Our firm level analysis builds and expands upon these two studies. We consider narrower but closer control and treatment groups and we use simple longitudinal graphical evidence where we can successfully and transparently test the parallel trend assumptions in four years pre-reform and trace outcomes up to 2013 more than five years after the reform. We find clear positive effects on a wider range of outcomes measuring firm activity, and we look at heterogeneous effects by

\footnotetext{
${ }^{18}$ Egebark and Kaunitz (2017) state on page 15: "In its simplest form, DiD uses the evolution of the control group over time as a measure of how the treatment group would have evolved, had the intervention not taken place. Figure 5 demonstrates that, in the present context, this is too strong an assumption. Inspecting the evolution of employment in the period before the reform (2001-06), it is clear that individuals of different ages differ in the degree of employment cyclicality, with younger workers tending to display larger cyclical variations."

${ }^{19}$ Egebark and Kaunitz $(2013,2017)$ present a number of interesting heterogeneity analyzes as well. They find zero employment effects for immigrants or the unemployed, and larger effects for the very young and low education individuals. Egebark (2016) analyzes the effects of the payroll tax cut on self-employment. He finds no effects on the extensive margin but evidence of positive effects on the intensive margin due to substitution from wage earnings to self-employment earnings (findings that we replicate in appendix Figure A6 .
} 
credit constraint proxies. We also follow individuals (instead of firms) to cast light on collective rent sharing and its distribution across wage deciles.

\section{Institutional Setting and Data}

In this section, we first discuss the institutional setting of the payroll tax in Sweden and the payroll tax cut reform. Next, we present the data we use for the analysis.

\subsection{Payroll Tax Cut for Young Workers in Sweden}

Swedish payroll tax. In Sweden, the entirety of the payroll tax on earnings is nominally paid by employers and the tax is proportional to wage earnings with no exemption and no cap. The payroll tax rate is uniform across industrial sectors and covers all employers public and private 20 The top series in the solid line in Figure 1. Panel (a) depicts the normal payroll tax rate from 2004 to 2017. The normal tax rate has been quite stable around 31-32\% over this period. Payroll taxes fund various benefits (such as pension, sickness, work injury, etc.) with some imperfect link between the generosity of benefits and the level of taxes paid (see Skedinger, 2014).

Young workers payroll tax cuts. The second series in dashed line in Figure 1, Panel (a) depicts the preferential payroll tax rate for young workers. In 2007-9, a new center-right coalition government implemented a payroll tax cut targeted toward young workers in two steps. The explicit aim of this reform was to fight youth unemployment, which had risen in previous years, and was perceived in the public debate to be excessively high. The payroll tax cut was intended to be permanent.

In 2007, the first step lowered the payroll tax rate by 11.1 points from $32.42 \%$ (main rate in 2007) down to $21.32 \%$ for workers aged 19 to 25 . The reform was first mentioned in October 2006. The bill for this reform was voted by parliament on March 15, 2007, and took effect on July 1, 2007. It started to apply for earnings paid out on or after July 1st, 2007 to all workers turning 19 to 25 during the calendar year. To be precise, in 2007, the payroll tax cut applied to workers born in 1982-1988 on all their earnings paid on or after July 1st. In 2008 (the first full year), the payroll tax cut applied to all workers born in 1983-1989 on the totality of their 2008 earnings, etc.

\footnotetext{
${ }^{20}$ Negotiated agreements between employers and unions generate sometimes extra payroll fees on top the standard payroll tax discussed here. Skedinger (2014) provides more details.
} 
In 2009, the second step further lowered the payroll tax rate down to $15.49 \%$ and increased eligibility to all workers turning 26 or less during the calendar year (instead of 19-25 in the first step). Eligible young workers tax rate was therefore 15.9 points lower than the main rate of $31.42 \%$ (as of January 1st, 2009 and after). The bill for this second reform was voted by parliament on September 25, 2008 and started to apply on January 1st, 2009 (Government Bill 2008/09:7). To be precise, in 2009, the payroll tax cut applied to all workers born in 1983 or later on the totality of their 2009 earnings; in 2010, the payroll tax cut applies to all workers born in 1984 or later, etc.

Hence, a worker's only determinant of eligibility for a full calendar year is year of birth (and not actual age when the earnings are received), assessed against a rolling window of eligibility birth years. For a given year, our analysis is always based on birth-year cohorts: age is always defined as year of observation minus birth year - regardless of whether the person has actually reached her birthday or not during the year.

To summarize, by January 1st 2009, the payroll tax on young workers was halved from $31.4 \%$ (main rate) to around $15.5 \%$. Importantly, these payroll tax cuts for the young did not generate any reduction in the benefits of young workers. Hence, the payroll tax cut for the young can be considered as a pure tax cut from the perspective of the young and their employers.

Implementation and take-up. The payroll tax is administered by employers using government provided software. The bottom panel in Figure 1 illustrates the reporting of monthly earnings and payroll taxes by employers by showing the government-provided software for a 2013 snapshot. Every month, employers specifically type in the earnings paid to employees born in the different cohorts, and the program displays the applicable cohort-specific tax rate and automatically calculates the payroll taxes due, ensuring almost perfect, immediate take-up. Employers always know the birth year of their employees as employees systematically provide their social security number, which includes the birth year, when starting an employment spell. Earnings for employees born in 1948-1986 are reported in box 55 and face the normal tax rate of $31.42 \%$. Earnings for employees born in 1987 or after are reported in box 57 and face the lower $15.49 \%$ tax rate. Hence, the very simple administrative procedure, which requires no specific application for firms or workers, ensures very high take-up. In terms of enforcement, firms additionally have to send annual individual earnings reports (similar to US W2 forms) to the tax administration. Therefore, the tax administration can do an ex-post reconciliation to check whether the payroll tax paid by employers over the year matches the theoretical payroll tax 
based on individual earnings reports. In case of discrepancies, the tax administration can send letters to help correct mistakes. From our conversations with the tax administration, mistakes were fairly rare. This suggests that take-up was close to $100 \% 21$

Other contemporary reforms. The newly elected 2006 government implemented three additional reforms in 2007 that could also affect employment: an Earned Income Tax Credit was implemented, the maximum duration of temporary labor contracts was extended from 1 to 2 years, and payroll taxes were cut sharply (and temporarily) for people unemployed or disabled for at least one year. These three reforms are discussed in detail in Skedinger (2014). These reforms do not create a sharp discontinuity by age (although young workers are relatively more likely to benefit from the first two reforms) and hence do not invalidate our identification design.

Repeal in 2015-16. The left-wing opposition parties were against this payroll tax cut from the start. They lost the 2010 election but won the 2014 election on September 14. Therefore, in 2015, the new center-left government abolished the payroll tax cut for young workers. Their reasoning for the abolition was that the reform was costly and the benefits in terms of reducing youth unemployment were debatable. The lower payroll tax rate for the young expired in three steps on May 1, 2015, August 1, 2015 and June 1, 2016, as depicted in the top panel of Figure 1. The bill was passed on March 25, 2015 following a proposal put forward on October 7, 2014, just after the election.

After June 1, 2016, young workers again face the normal tax rate. Hence, the payroll tax cut lasted 9 years (and 6.5 years in its strongest form). Since our data set ends in 2013, we cannot yet analyze the effects of the repeal. Studying whether the effects of the repeal are symmetric to the effects of the tax cut will be interesting (in light of compelling new evidence of asymmetric responses to tax increases vs. decreases by Benzarti et al. 2017) and is left for future research.

Wage setting in Sweden. The Swedish labor market is to a great extent regulated and monitored in collective bargaining agreements (CBAs). An estimated 90 percent of all wage earners are covered by CBAs, with slightly lower figures for the private sector (Medlingsinstitutet, 2015). These agreements are typically renegotiated every three years and they define the rules for wage bargaining. Many CBAs also prescribe a fall-back wage increase, but these are

\footnotetext{
${ }^{21}$ Many work subsidy programs have low take-up (and hence possibly low impact) because of administrative application costs for employers or stigma costs for beneficiaries. See Katz (1998) and Neumark (2013) for a survey and detailed discussions.
} 
only operationalized in case the local bargaining between the employer and its employees fails (Fredriksson and Topel, 2010).

Fredriksson and Topel (2010) categorize CBAs by the influence that local bargaining parties have on wage determination. They conclude that $36 \%$ of all employees are covered by agreements where wages are bilaterally bargained between employer and employee (in some cases there are guaranteed minimum wage-increases). Another $57 \%$ are covered by agreements in which increases in total labor costs at the firm level are pre-determined centrally, but the allocation of those increases are determined in local negotiations. Only $7 \%$ have wage increases entirely set by the central agreement; this figure includes workers bound by the minimum wages. Therefore, the degree of bilateral bargaining in wage-setting is high.

Even though most employees' wages are set locally, centrally determined wage increases are more common in the lower part of the wage distribution. Sweden has no legislated minimum wage, but CBAs prescribe minimum wages that differ both across CBAs and within CBAs by age, experience (time spent working in the industry), tenure (time spent working in the firm) and education. In our robustness checks, we will investigate (but ultimately rule out) such union wage floors as the explanation for the absence of effects on wages.

\subsection{Administrative Data}

We use several administrative data registers at both the individual- and the firm-level, collected by Statistics Sweden for both individuals and firms.

Worker data. The basis of our individual-level analysis is the population of all Swedish residents (as of December 31 each year) aged 16 and above for years 1990-2013. We obtain annual earnings and employment spells for this population using the complete matched employeremployee records available for all years 1985-2013, with unique individual and firm identifiers. For each spell, these data record annual wage payments and months worked ${ }^{22}$

We also add a number of outcome and demographic variables to the individual-level population at the annual level. From the Income Tax Register, we retrieve self-employment earnings and total wage earnings. From the Integrated Database for Labour Market Research (various administrative records compiled by Statistics Sweden), we obtain the level of education, unemployment history (days registered with the unemployment insurance agency as well as unemployment insurance received), gender, year and month of birth.

\footnotetext{
${ }^{22}$ These data are used to administer the social security and income tax systems in Sweden.
} 
We also link to this baseline population a matched employer-employee data set that covers worker-level wages, occupational codes and hours of work, for a very large sample of firms. The data set covers all public sector employees and around $50 \%$ of private sector workers, using the Structure of Earnings Survey ${ }^{23}$ The information is collected annually during a measurement week (in September-November) for all workers employed for at least one hour during that week. The wage concept refers to the full-time equivalent wage, including all fixed wage components, piece-rate and performance pay and fringe benefits ${ }^{24}$

Firm data. The starting point for the firm-level analysis is the population of firms that are active at some point during 2003-2013. For these firms, we retrieve income statements and balance sheet information at the yearly level, collected by the Tax Agency and administered by Statistics Sweden.25 These records must be reported by all firms, even though not all components are relevant for tax purposes.26

The unit of observation is the firm. However, in some instances, Statistics Sweden aggregates the firm-level information from the Tax Agency to the level of the corporate group and assigns a (weighted) average to each firm. Our baseline analysis sample therefore focuses on firms that are not part of a corporate group.

\section{Market Level Effects on Wages and Employment}

In this section, we first analyze the effects of the payroll tax reform on cohort-specific wages to determine the incidence of the payroll tax. Then we turn to the analysis of employment effects, again by cohort. We naturally use two definitions of wage earnings. First, we define gross wage earnings (sometimes abbreviated to gross wages) as wage earnings plus the employer payroll tax. Gross wage earnings are the total labor cost that employers pay for a given worker, including taxable fringe benefits.27 Second, we define net wage earnings (sometimes abbreviated to net

\footnotetext{
${ }^{23}$ The sample is a stratified random sample of firms, with larger weights on larger firms. All firms with more than 500 employees are included. Our wage results are robust to reweighting the wage sample to match the industry- and the firm-size distribution of the total population of employees.

${ }^{24}$ Fringe benefits are taxable and therefore recorded by the employer.

${ }^{25}$ For some firms, the financial year is not the same as the calendar year. Statistics Sweden adjusts the income and balance sheet information for these firms to match the calendar year. To be precise, for a firm with financial year June-May, calendar year $t$ 's values are $5 / 12$ of financial year $t-1$ 's values and 7/12 of year $t$.

${ }^{26}$ Using the raw files from the Tax Agency, Statistics Sweden verifies basic accounting identities and if they do not hold, Statistics Sweden either imputes values (for small businesses), collects the annual reports, or approaches the firms with surveys. In our baseline analysis sample (described in detail in Section 5), $1.33 \%$ of observations are corrected using one of those methods and our results are robust to excluding these corrected records.

${ }^{27}$ Non-taxable fringe benefits are very small in Sweden.
} 
wages, or even just wages) as wage earnings net of employer payroll tax. It is the concept used for computing payroll taxes and is also the standard reference for compensation negotiations and contracts. There are no employee-level payroll taxes in Sweden, but there is an income tax assessed on net wage earnings (as well as on additional sources of income) with withholding at source, so that the worker's take-home paycheck is typically less than net wage earnings.

\subsection{Standard Competitive Model}

Before we start the empirical analysis, it is useful to recap the expected effects in a standard competitive spot market model, where the market wage is determined such as aggregate labor supply equals aggregate labor demand. This model underpins the incidence of the payroll tax in the public economics literature.

In this standard competitive spot market model, treated workers slightly below the age cutoff are naturally almost perfect substitutes for control workers slightly above the age cut-off. Suppose we start from a pre-reform equilibrium where these two groups are paid the same wage (and the same labor costs as payroll taxes are equal across age groups). When the payroll tax cut is introduced, the treated workers become cheaper to employers. Hence, employers hire more treated workers (and lay off control workers). With upward sloping labor supply, these employment effects bid up the wage of treated workers until the labor costs of the two groups are again equalized. Hence, in the new equilibrium, there cannot be a discontinuity in labor costs at the age threshold, but there is a discontinuity in wages equal to the payroll tax differential between the two groups. The tax differential is borne entirely by treated workers' wages (relative to control workers).

The payroll tax reform stimulates employment of treated workers. In this case, the incidence is always $100 \%$ on employees because the labor demand for young workers is effectively infinitely elastic as young workers are perfect substitutes for slightly older workers at the discontinuity. Obviously, this benchmark is a vast simplification of how the labor market works in practice. There are frictions and costs in recruiting, training, and laying-off workers that make the labor demand less than infinitely elastic (although similar results would still hold). There might be wage rigidities, either institutional or norm based, preventing employers from differentiating wages based on age, or adjusting wages as workers age out of the payroll tax cut. We will discuss all these elements in more detail after we examine the empirical evidence. 


\subsection{Effects on Wages}

To test the implications of the standard model, we evaluate whether net wages vs. gross wages are discontinuous by age around the eligibility threshold after the reform. By definition, both wage concepts cannot be continuous after the reform so looking at both earnings concepts is a powerful and transparent way to tease out where the incidence falls. ${ }^{28}$ If gross wages paid by firms remain continuous, the incidence is entirely on workers' net wages. If net wages remain continuous, then firms experience a full pass-through into the relative labor costs of young treated workers.

Figure 2 depicts net wages (in Panel (a)) and gross wages (in Panel (b)), averaged by age for different time periods. The sample is all employees in the Structure of Earnings Survey, which covers all industrial sectors for the month of September (or October-November) for each year (see Section 3.2 for more details). 29 The wage is defined as the full-time equivalent contracted monthly wage, measured in September-November, CPI-deflated and converted to US dollars (8.9 SEK/USD as of 4/18/2017). We use this measure to abstract from effects on hours worked 30 We consider the following time periods: 2002-4 and 2005-6 are the pre-tax reform periods; 20078 is the period affected by the first step of the reform (up to age 25) 2009-11 and 2012-3 are the periods affected by the second step of the reform (up to age 26). The two dashed vertical lines depict the age thresholds under which the payroll tax cuts apply in 2007-8 and 2009-14 respectively. Recall that age denotes end-of-calendar-year age, which determines eligibility for the full calendar year.

Net wages. Panel (a) in Figure 2 shows that net wages are smoothly increasing with age and across years before the reform. Importantly, net wages during the reform years do not exhibit any discontinuity whatsoever at the age cut-off where the payroll tax cut applies, neither before nor after the reform ${ }^{32}$ In other words, wages of treated young workers do not adjust at all in response to the reform (relative to slightly older, ineligible workers). Note that even in 2012-3, there does not appear to be any incidence on net wages, even in the medium-term, 5-6 years

\footnotetext{
${ }^{28}$ Previous evaluations of the Swedish payroll tax cut by Skedinger (2014), Egerbark and Kaunitz $(2013,2017)$ typically examine solely net wages.

${ }^{29}$ All of our wage results are robust to sample restrictions to only private sector workers or including both private and public sector workers. We therefore show results for all sectors.

${ }^{30} \mathrm{All}$ of our wage results are robust to instead considering monthly earnings from the tax records.

${ }^{31}$ The reform started applying in July 1st, 2007 so that it fully applies in September-November 2007.

${ }^{32}$ The wage is increasing in age reflecting standard age, experience and tenure effects on wages. Our graphical finding of the smoothness of the wage profile during the reform years replicates the findings of Egebark and Kaunitz (2017), who present a similar graph (their Figure 4) of wages by age using only years 2006, 2008, 2011 and focusing exclusively on net wages.
} 
after the reform.

Gross wages. Panel (b) in Figure 2 visualizes the corresponding effects on gross wages (labor costs), which consist of net wages plus the age-specific payroll tax rate in the given year. Before the reform, labor costs evolve smoothly across the eligibility thresholds. After the reform, there emerges a sharp, immediate discontinuity in average gross wages at the age threshold of the tax cut. This directly implies that the reform lowered relative labor cost of younger workers one to one, in the short as well as the medium run, even 5-6 years into the reform.

Hence, the two panels combined show very clearly that the payroll tax cut has no effect on net-of-payroll tax wages of young treated workers relative to slightly older untreated workers. The incidence is entirely on firms' labor costs.

This finding of full incidence on firms goes starkly against the prediction of the standard model discussed above, which predicts no discontinuity in gross wages but a discontinuity in net wages. To our knowledge, the net and gross wage graphs combined with the sharp tax rate discontinuity among comparable workers are the simplest and most transparent evidence to date that employer payroll taxes do not get shifted to employees as predicted by the standard theory ${ }^{33}$ For this clean inference, the crucial features of the reform we study are that it was long-lasting, large, salient, applied to all young workers (not just new hires), had full, automatic take-up, and generated a sharp prediction since workers are nearly perfect substitutes around the age cutoff.

Regression results. Table 1 displays regression results on the incidence of the payroll tax, based solely on the aggregate cohort-year time series as depicted in the figures. We use the following basic difference-in-differences (DD) specification to estimate the treatment effect of the reform $(\gamma)$ :

$$
w_{a t}=\alpha_{a}+\beta_{t}+\gamma \cdot 1\left(a \leq a_{\text {eligible }}\right) \cdot 1\left(t \geq t_{\text {reform }}\right)+\varepsilon_{a t}
$$

where $a=20, . ., 32$ denotes 13 age categories, $t$ denotes the 5 time periods $(2002-4,2005-6$, 2007-8, 2009-11, 2012-13), $w_{a t}$ is the gross or net average wage outcome for age $a$ and period $t$, $1\left(a \leq a_{\text {eligible }}\right)$ is a dummy for age below the eligibility cut-off, and $1\left(t \geq t_{\text {reform }}\right)$ is a post-reform

\footnotetext{
${ }^{33}$ Saez, Matsaganis, and Tsaklogou (2012) also find that employers bear the employer portion of payroll taxes using a cohort based payroll tax reform in Greece. Bozio, Breda, and Grenet (2017) also find employer payroll tax changes in France are borne by employers. But in both cases, the evidence is not as simple and compelling, as the tax differential in Greece or France applies only above an earnings threshold while it applies to the totality of earnings in the Swedish case we study here. Other payroll tax studies that we reviewed in Section 2 typically focus solely on net wages.
} 
dummy. $\varepsilon_{a t}$ is the error term. $\gamma$ is the coefficient of interest on the interaction age eligibility and post-reform; it denotes the treatment effect of the reform. Wages are again expressed in real US dollars and form the unit of the coefficients.

Panel A provides the estimates corresponding to Figure 2. In column (1), we focus on shortrun effects (2007-2008 vs. pre-reform) so that we use the three periods (2002-4, 2005-6, 2007-8), $a_{\text {eligible }}=25$ and $t_{\text {reform }}=2007$. Hence, the regression is based on 39 observations (13 ages 20-32 times 3 periods) and we report conventional OLS standard errors. In column (2), we focus on medium-run effects using instead four periods (2002-4, 2005-6, 2009-11, 2012-13) and hence excluding the period 2007-08 when the reform is not fully phased in. In this case, $a_{\text {eligible }}=26$ and $t_{\text {reform }}=2009$.

Consistent with the graphs, we find large effects on gross wages and very small effects on net wages. Tax incidence can be measured as the fraction of the payroll tax cut that benefits the employer, that we call the pass-through to firms. It is computed as the gross wagecoefficient divided by the gross-wage coefficient net of the net-wage coefficient. Standard errors are computed using the delta-method. We find a pass-through of $100 \%$ in both the short and long run 34

Monthly cohorts. Figure 3 replicates Figure 2 but zooms into cohorts defined by month and year of birth instead of year of birth. For comparison with Figure 2, for any given year $t$ when the wage is measured, monthly birth cohorts are translated into monthly age bins as of end of year $t$. For example, 27 in 2009 means being born in January 1982 (and ineligible for the tax cut). $26+11 / 12$ in 2009 means being born in December 1983 and thus eligible for the tax cut. The top panel depicts net wages (monthly wage earnings net of payroll taxes). The bottom panel depicts gross wages (i.e. gross of payroll taxes). The top panel shows that the wages are continuous at the age thresholds, except for small school-year effects already present pre-reform and also away from the reform age threshold 45 In contrast, the bottom panel shows that the gross wage is discontinuous at the eligibility thresholds. Therefore, these results confirm the earlier findings from Figure 2, Corresponding estimates are provided in Table 1, Panel B, and are even closer to $100 \%$ pass-through to employers than our annual based estimates.

\footnotetext{
${ }^{34}$ Egebark and Kaunitz $(2013,2017)$, using individual-level DiD regressions with controls, find small positive effects on wages in the order of 1-2\% and often statistically significant. Their results would be consistent with a modest pass-through to workers of around $10 \%$ of the tax cut. Our simpler graphical analysis suggests an even lower pass-through, consistent with no wage effects at all.

${ }^{35}$ The school system is based on calendar year of birth (and hence people born in December of year $t$ are in general 1 year more advanced in their career path than people born in January of year $t+1$ ).
} 
Wage setting institutions. One possible explanation for full pass-through to firms is that wages are rigid due to union bargaining agreements that are indeed widespread in Sweden. Such union wage agreements specify wage floors by industry, occupation, and sometimes age (see Section 3 for more details) ${ }^{36}$ If young workers' prevailing net wages are constrained by the wage floor (in the sense that the equilibrium wage for young workers would be lower absent the union wage floor, and labor supply would be rationed), then the payroll tax cut simply reduces labor costs. But as long as the post-reform net wages remain above the equilibrium wage, the incidence of the payroll tax cut would still fall fully on firms. More generally, wages could be rigid due to implicit contracts, whereby the firm promises a specific set of wage increases over time contingent on various outcomes 37 Such contracts may be incomplete and hence not contingent on possible payroll tax reforms, explaining why firms do not adjust wages in response to the payroll tax cut.

Top wage quintile. Figure 4 tests this possible explanation by repeating the analysis of net wages as in Figure 2, top panel, but focusing on two specific subsamples. The top panel displays the average wage within the top $20 \%$ of the wage distribution conditional on age and year. This group is unlikely to be affected by the binding union negotiated wage floors. Yet, we do not see any discontinuity arising after the reform even in this subsample. The corresponding regression based estimates are reported in Table 1, Panel C. They show a pass-through to firms of $91 \%$ in the short-run and $97 \%$ in the medium-run. This implies that binding union wage floors cannot explain our findings.

New jobs. The bottom panel of Figure 4 shows the average wage for new hires. New hires are defined as having a new firm identifier (again for the month of September) as the main employer relative to the previous year. It includes both job-to-job transitions as well as new hires among previously non-employed individuals. These new hires are not affected by implicit wage contracts by definition. Yet, even for this subsample, we do not see any discontinuity arising after the reform. The corresponding regression estimates are reported in Table 1, Panel D. They show a pass-through to firms of $101 \%$ in both the short- and the medium-run, as high as in the overall sample. This implies that standard implicit contracts cannot explain our findings

\footnotetext{
${ }^{36}$ However, a close examination of these wage agreements shows that no age specific provisions targeting workers eligible for the payroll tax cut were made after the reform takes place. This suggests that the payroll tax cut for young workers did not factor in the bargaining outcome of unions and employers. Alternatively, this provides another illustration of the lack of net-wage incidence.

${ }^{37}$ There is a large literature in labor economics on such optimal incentives contracts with career concerns (see e.g., Rosen 1985, Malcomson 1999 for surveys).
} 
either.

Wage distributions. To provide a nonparametric view of incidence across the wage distribution as well as to further explore whether pass-through to firms could be explained by rigidities or wage floors, we next look at pre-tax and post-tax wage densities in Figure 5. The figure depicts the monthly wage earnings densities for young workers (aged 22-24) affected by the payroll tax cut and slightly older workers (aged 27-29) not affected by the payroll tax cut pre-reform (pooling years 2002-2006) and post-reform (pooling years 2009-2013). The top panel depicts the densities for net wages, the bottom panel for gross wages. In each period, both treatment and control group wages are deflated by a common index factor for each year based on the mean annual wage for the control group (ages 27-29).

The top panel of Figure 5 shows that the post-reform wage densities of the young treated workers lie on top of the pre-reform densities of that age group. Hence the absence of passthrough to workers is pervasive throughout the wage distribution, rather than just for the mean wages and the top quintile. Importantly, the net wage densities do not change from pre-reform to post-reform for the slightly older control group either, which validates our strategy of assessing potential shifts in the wage distribution. Correspondingly, the bottom panel of Figure 5 shows that the gross wage density is shifted uniformly from pre-reform to post-reform for young treated workers.

Finally, the density graphs also imply that the incidence results cannot be due to union bargained minimum wage floors. To formally assess the impact of minimum wages on the estimated incidence, we retrieve digitized information on wage floors for blue-collar workers during 2009-2013 at the level of the collective bargaining agreement and year 38 Using industry and occupation codes, we match the wage floors to individual workers. Based on the workers in ages 22-24 with recorded minimum wages, we compute the 20th and 80th percentiles of minimum wages in 2009-2013 (as there are many minimum wages in Sweden based on industry, occupation, and tenure, see Section 3 for details). The top panel depicts the location of those reference wages as vertical lines and even the wage density substantially above the minimum wages for young workers is unaffected by the reform. This graph also shows that the vast majority of young workers are paid above the minimum wage.

\footnotetext{
${ }^{38}$ We thank Anders Forslund, Lena Hensvik, Oskar Nordström Skans and Alexander Westerberg for providing these data.
} 
Long-term jobs vs. spot markets. Another potential explanation for the zero net-wage incidence points to the long-term nature of real-world employment relationships, whereas the conceptual framework applies to a spot market for labor. Some young employees will age out of the payroll tax cut over the course of the job. Indeed, it has been documented extensively by Bewley (2002) that employers believe that they cannot easily cut nominal wages as this has deleterious effects on morale and hence productivity of workers 39

Ex post, it would attenuate the scope for wage cuts as workers age across the threshold, and, anticipating this, employers would attenuate wage increases for the young ex ante.

However, a substantial fraction of young Swedish workers have short employment spells and hence would not be expected to ever age out of the payroll tax cut on the job, which we document in Appendix Figure A1 by plotting various percentiles of job length by age of hiring for individuals newly hired in 2000. It shows that the median spell length of young hires (aged 20-24) is less than two years. Hence, many such young workers could in principle be hired at higher wages.

Even for workers that are expected to age out of eligibility, such downward wage rigidity would merely attenuate initial pass-through to workers, not eliminate it entirely, as incidence can be spread across a smooth wage 40 In our context, even a constant wage would exhibit a noticeable bump: even the barely-eligible median worker will spend at least one full calendar year - i.e. on average half of her two-year tenure - in the low-tax regime (since the eligibility criteria apply to cohorts by birth-year rather than daily age; consider the monthly cohorts in Figure 3); thus the cut lowers around half of her present-value labor costs.

In Appendix Figure A2, we empirically investigate whether net wages exhibit incidence in high turnover industries, in which shorter job spells should attenuate dynamic concerns associated with long-term jobs 41 The top panel replicates our original net-wage analysis of Figure 2 separately for high-turnover industries, and the bottom panel does so for low-turnover industries. Even in the high-turnover industries, net wages exhibit no discontinuity around the

\footnotetext{
${ }^{39}$ For the United States, Campbell and Kamlani (1997) document that $84 \%$ of employers deem a series of a higher wages followed by a cut more demoralizing than having paid the final low wage for the entire period. The specific question (8, on p. 779 ) refers to a $10 \%$ cut, almost exactly the wage cut required by our scenario $(12 \%)$. The specific question is: "A. Assume that for the past five years, you paid wages that were $10 \%$ lower than the wages you actually paid. [... B. Assume that for the previous four years, you had paid the same wages that you actually paid, and then cut wages by $10 \%$ in the current year. [...] In which situation would you expect workers' effort and morale to be worse?"

${ }^{40}$ Elsby (2009) and Shimer (2004) present variants of these arguments in non-tax contexts.

${ }^{41}$ Our turnover measure is the average job duration of new job spells. We compute the mean duration of new jobs in 2000 for workers aged 20-25, within each of our coarsest industry measure (10 industries). We then split industries by the median average job duration (weighted by 2000 employment).
} 
age eligibility threshold during the reform years. This result is perhaps not surprising in light of the stability of the wage distribution we previously documented in Figure 5. But it does suggest that while turnover is already high among young workers, our incidence results hold up in subsamples even closer to a spot labor market.

Therefore, the absence of tax incidence on wages cannot be explained solely by the concern that all young hires will age out of the payroll tax eligibility on the job and that long-term jobs would mask tax incidence.

Summary. Our findings are not the mechanical consequence of union bargained wages, implicit labor contracts, or downwardly rigid wages on the job. They may reflect a deeper social norm about wage setting that manifests itself as a form of wage rigidity preventing employers from cross-sectionally discriminating pay by age among similar workers, perhaps within firms. Our evidence on firm-level rent sharing in Section 6 is consistent with such a phenomenon. In any case, our findings starkly contradict the standard model, which would predict 100\% payroll tax incidence on workers at the age discontinuity. As employment is the channel through which incidence is passed on to workers in the standard model, we next turn to employments effects.

\subsection{Effects on Employment}

Overall employment effects. Our wage results described above imply that young eligible workers are cheaper to employers than slightly older ineligible workers. In the period 2009-2014, the payroll tax rate cut for young workers lowered their labor cost by $12.1 \% .42$ Effectively, an employer would save $12.1 \%$ of labor costs if she could switch from an ineligible older worker (say aged slightly above 26) to an eligible young worker (aged 26 or less), given the lack of net wage incidence. As these two groups of workers should be close substitutes, profit maximizing firms should want to hire more eligible workers or put more effort in retaining eligible workers (relative to ineligible workers). Indeed, this is the economic mechanism that eventually equalizes gross wages across treated and control groups in the standard competitive model. Even if wages are rigid, the employment effects should still manifest as long as firms care about labor costs when making their hiring decisions 43

\footnotetext{
${ }^{42}$ The tax rate for young workers is $15.49 \%$ while the normal rate is $31.42 \%$, hence a reduction of labor costs of $(31.42-15.49) /(100+31.42)=12.1 \%$.

${ }^{43}$ The labor demand condition implies that $\frac{M P L_{y}}{M P L_{o}}=\frac{\left(1+\tau_{y}\right) w_{y}}{\left(1+\tau_{o}\right) w_{o}}$ between young and older workers. For example with CES production and given our finding that wages remain unchanged and approximately identical, this implies $\frac{\gamma_{y} n_{y}^{\alpha-1}}{\gamma_{o} n_{o}^{\alpha-1}}=\frac{1+\tau_{y}}{1+\tau_{o}}$, where $\alpha$ is the CES substitution parameter and $\gamma_{i}$ denotes skill weights. See our model in the Appendix for the full analysis.
} 
To analyze this, we examine first the employment rate in the labor force by age group and over time using the individual annual earnings data (see Section 3 for details). The employment rate is defined as the ratio of all employees to the labor force. The employees numerator is defined as all residents who are employed with annual wage earnings above a small annual threshold ${ }_{44}^{44}$ The labor force denominator is defined as all residents who are either (i) employed with annual wage earnings above a small annual threshold or (ii) unemployed (defined as having registered with the Unemployment Office at any point during the year).

The top Panel (a) of Figure 6 depicts the employment rate by age and time periods. Age and time periods are defined as in Figure 2 above. We exclude the period 2007-08 when the tax reform was not yet fully phased in 45 Two important findings emerge from the top panel. First, the two pre-reform periods 2002-4 and 2005-6 show virtually superposed series with the fraction of employees increasing smoothly with age from around $77 \%$ at age 20 to $93 \%$ at age 35 . This suggests that time trends are parallel pre-reform. Second, the employment rate is substantially higher in the post-reform periods of 2009-11 and 2012-13 but only for the treated groups aged 20 to 26 . At ages 21-25, the employment rate is about 3 points higher in 2009-11 (relative to 2002-6) and about 4 points higher in 2012-13. In contrast, the employment rate is virtually the same in 2009-11 and 2012-13 (relative to 2002-6) at ages 28 and above. Particularly striking is the fact that in 2012-13, the employment rate is actually higher at age 25 than at ages 27-28, in sharp contrast with the steadily increasing employment rate pattern by age before the reform. This simple graphical approach provides perhaps the most compelling causal evidence to date of employment effects of targeted employer payroll tax cuts. ${ }^{46}$

Table 2 provides the corresponding estimates using a basic difference-in-differences regression based on the graphical output following the specification of equation (1). We consider the 4 periods 2002-04, 2005-06, 2009-11, 2012-13 (always excluding period 2007-08 when the reform was only partially phased-in) and 16 age groups 20 to 35 . All regressions are run on just $16 \times 4=64$ aggregate cohort-period observations and we use conventional OLS standard errors. Column (1) reports the effect expressed in percentage points while column (2) translates this effect into an elasticity estimate (using the fact that the payroll tax cut reduces labor costs

\footnotetext{
${ }^{44}$ The small annual threshold is equal to $\$ 4,940$ in 2012 (and adjusted for inflation in other years). This small annual threshold corresponds approximately to working at $20 \%$ of full-time a full year at the minimum wage in the restaurant sector. Appendix Figure A3 compares our employment and unemployment measures Swedes aged 20-34 with official statistics based on the labor force survey and shows that they line up fairly well.

${ }^{45}$ The relative by-age employment rates show a treatment effect similar to the later years, but we see a large parallel upward shift for all cohorts in these months due to an aggregate expansion.

${ }^{46} \mathrm{Katz}$ (1998) first provided similar graphical evidence of employment effects of hiring subsidies (but the series were noisier due to smaller sample size).
} 
by $12.1 \%$ ). We estimate an effect of 2.1 percentage points with an implied elasticity of .21 . Although employment effects are very significant, they still translate into a relatively modest elasticity, consistent with the previous findings of Egebark and Kaunitz $(2013,2017)$ who used individual-level DiD regression with controls.

The employment response we have uncovered is likely due to labor demand effects rather than labor supply effects because the net wage of eligible young workers does not increase (our first result), so that the labor supply channel does not operate.

Robustness. Appendix Figure A4 provides robustness tests to our findings from the top panel of Figure 6. In the top panel of Figure A4, we add students to the labor force denominator. In the bottom panel, we show employment effects when varying the earnings threshold for defining employees (keeping the labor force constant). Both graphs show that the employment effects we have obtained are robust to these alternative definitions. This finding also implies that the composition of newly created jobs, in terms of total earnings, did not decline. Row 2 in Table 2 reports the estimates when adding students to the labor force, showing only a minor effect on the size of the estimate.

Importantly, we use the employment to labor force ratio (instead of the employment to population ratio) because as there is no wage effects on workers from our previous analysis, there is no reason to expect strong labor supply participation responses from people outside the labor force joining the labor force by looking for a job. Two pieces of evidence presented graphically in the appendix confirm this assumption.

First, Appendix Figure A5 shows that there are no visible effects of the reform on the labor force to population ratio. However, the series for the labor force to population ratio are noisier and the pre-trends are not as parallel as for the employment to labor force ratio. As a result, there is less confidence that the labor force to population is unaffected by the reform. The regression-based analysis presented in Table 2 actually shows a small negative effect of -.96 points and is barely significant. Table 2 displays an employment to population effect of 1.4 percentage points (an elasticity of .23), similar in magnitude to the effects on the employment to labor force ratio but much less precisely estimated.

Second, we also show in Appendix Figure A6 that self-employment earnings respond only modestly to the tax cut. These results replicate the earlier findings of Egebark (2016). As self-employment earnings are typically much more responsive to taxes than wage earnings, this further suggests that supply side responses are very modest. 
Two caveats should be noted. First, the employment rates vary in level with the business cycle. In particular, the employment rate was much higher in 2007-8 relative to all other years for all age groups so that the 2007-8 employment data cannot easily be used to evaluate the effects of the reform on employment. In contrast, the employment rates at ages 28-35 are very close across all four other periods, providing us much stronger confidence that the higher employment rates at younger ages are indeed reform driven. Second, the labor force denominator only includes individual with earnings (employees) above a modest threshold or individuals who are formally registered as unemployed at any time during the year. It is possible that individuals not in our denominator could still be in practice looking for work even if not formally registered with the unemployment office.

Heterogeneity by local unemployment rate. The stated goal of the policy was to reduce youth unemployment because of a perception among policy makers that youth unemployment was excessively high. In 2006, just before the reform, there was wide variation across Sweden's 21 regions in youth unemployment. Appendix Figure A7 provides a map of Sweden showing youth unemployment rates by quintiles (weighted by labor force size). Regions in the lowest quintile of youth unemployment rates had rates in the range 10.5-12.4\% while regions in the highest quintile had youth unemployment rates in the range 20-23.3\%, i.e. about twice as high. Hence, a natural question is whether the payroll tax cut is more effective at stimulating employment in regions where the unemployment rate is higher, and hence presumably furthest away from its efficient level.

The bottom panel of Figure 6 depicts the pre- vs. post-reform employment rates by age (as we did in the top panel) but separately for bottom quintile regions (in dark red) and top quintile regions (in lighter red) in terms of youth unemployment rate in 2006. To reduce clutter in the graph, we consider only a single pre-period of 2005-06 and a single post-period of 2012-13. The graph shows that the employment effects of the payroll tax cut appear much larger in the high unemployment regions - for many cohorts in excess of 5 percentage points off a smaller initial base - than in the low unemployment regions.

Formal employment effect estimates by quintiles of local youth unemployment in 2006 are presented in Table 3. Column (1) reports the average local youth unemployment rate in each quintile. Within each quintile, we follow the methodology from the first row of Table 2 to estimate employment effects. We regress employment to labor force ratio on period dummies, age dummies and the interaction of the post-reform dummy and a payroll tax cut eligibility 
dummy (ages 20-26). We show the estimated employment effects in column (2) of Table 3. The table shows that the employment effects are monotonically increasing with the local youth unemployment rate, from 1.0 percentage points in the bottom quintile up to 3.4 percentage points in the top quintile. Comparing columns (1) and (2), we can see that employment effects are increasing even relative to the local initial unemployment rate as the employment effect in the bottom quintile is $9.3 \%$ of the unemployment in 2006 in the bottom quintile but $16.0 \%$ of the unemployment in 2006 in the top quintile. Hence, besides replicating our nation-wide analysis across subregions, these results show that the payroll tax cut subsidy appears noticeably more effective in high unemployment regions, consistent with the stated goal of the policy.

Are wage effects different across these areas? In principle, with low unemployment rates, it might be difficult for employers to find young workers, perhaps leading to the biding up of their wage more in line with the canonical equilibrium predictions of tax incidence. Column (3) shows the estimates of the pass-through of the payroll tax cut to firms by the local unemployment rate following the method from Table 1. Estimates are slightly above $100 \%$ for all quintiles. Hence, there is no evidence that pass-through estimates are lower in low unemployment rate regions.

One concern about the differential employment effects we have uncovered is that regions with high initial youth unemployment rate might naturally mean-revert over time, leading the employment rate of youth to increase relative to regions with low youth unemployment rate even absent the reform. To address this concern, we generate a placebo analysis where we again split Swedish regions into quintiles, but do so based on 2002 unemployment rates. We then estimate employment effects comparing years 1998-2002 to years 2003-2006 (i.e., before the start of the reform). Column (4) in Table 3 displays the unemployment rates in each quintile, and they are roughly comparable in level and variation to the unemployment rates from the real experiment in column (1). However, the placebo employment effects presented in column (5) are all small (less than 0.5 percentage point in absolute value) and insignificant. In particular, the difference in placebo employment effects between the top quintile and the bottom quintile is less than 1 percentage point and insignificant (relative to 2.4 points and highly significant in the real experiment).

Hiring vs. separations. Are the employment effects we have uncovered due to more hiring of young individuals (inflow into employment) or fewer separations of young employees (outflow)? In other words, did unemployment spells shorten, or did employment spells become longer? To analyze this question, we break down the employment effects into worker- 
level unemployment-to-employment transition rates ("hiring" or the "job finding rate") and employment-to-unemployment transition rates ("separations").

We construct the transition rates by measuring the share of unemployed individuals in year $t-1$ who are employed in year $t$ (unemployment-to-employment transition rate $\rho^{U \rightarrow E}$ ) as well as the share of employed individuals in year $t-1$ who become unemployed in year $t$ (employmentto-unemployment transition rate $\rho^{E \rightarrow U}$ ).

With long-term employment relationships and unemployment, (un-)employment rates are pinned down by these transition rates: $\frac{E m p}{\mathrm{LF}}=\frac{\rho^{U \rightarrow E}}{\rho^{U \rightarrow E}+\rho^{E \rightarrow U}}$, which is one minus the unemployment rate. Shifts in the employment rate are accounted for by the transition rates as $d \log \left(\frac{\mathrm{Emp}}{\mathrm{LF}}\right)=$ $\left(1-\frac{\mathrm{Emp}}{\mathrm{LF}}\right) \cdot\left(d \log \left(\rho^{U \rightarrow E}\right)-d \log \left(\rho^{E \rightarrow U}\right)\right)$.

The age-specific employment effects are depicted in the top panel of Figure 7. This graph simply shows the difference in employment rates by age from pre-reform (2002-2006) to postreform (2009-2013) using the series depicted in the top panel of Figure 6 ${ }^{47}$

The bottom panel of Figure 7 decomposes these age-specific employment effects by plotting the effect on the log of the job finding rate (unemployment-to-employment transition rate) and on the log of the separation rate (employment-to-unemployment transition rate) separately by age. Table 2 presents the corresponding estimates.

Together (multiplied by the unemployment rate) the two rates indeed account for the employment effects. The bottom Panel in Figure 7 show that about $80 \%$ of the employment effects from the top Panel are due to a reduction in the separation rate of young workers, which falls by $22 \%$, and that about $20 \%$ of the employment effects from the top panel are due to an increase in the hiring rate of young unemployed workers, which increases by around 5\%.48 This decomposition suggests that employers respond to the payroll tax cut for young workers primarily by retaining such workers or by offering longer jobs, and only marginally by hiring specifically young workers. Perhaps this is due to the fact that hiring cannot be differentiated by age as easily as retention of existing workers. Moreover, these findings implies the average job quality for young treated workers increased in terms of duration, and that firms did not increase layoffs as workers age across the eligibility threshold. These turnover dynamics would be masked in net employment effects but occupy the policy discourse, particularly with marginal and temporary hiring subsidies that may incentivize churn (e.g. Katz 1998).

\footnotetext{
${ }^{47}$ Egebark and Kaunitz $(2013,2017)$ also analyze heterogeneity of estimates by age. Our results are broadly consistent with theirs.

${ }^{48}$ Recall that the employment rate increases by around $2.5 \%$ for the young. Table 2 reports the corresponding percentage point estimates for the pooled treatment effect.
} 
Summary. Exploiting the sharp discontinuity around the eligibility threshold, our graphical evidence has documented that the payroll tax cut increased the employment rate by 2 percentage points exactly among the targeted worker groups. Moreover, we find the employment effects (even in percentage points) to be largest in areas with initially high youth unemployment, although treatment effects are present in all regions. We do not find evidence that those new jobs came at the expense of job quality for the treated young workers; in fact, we found that $80 \%$ of the employment rate increase was accounted for by longer employment relationships, rather than shorter unemployment spells. Neither did we find spikes in layoffs or sharply reduced hiring for slightly older ineligible workers, suggesting no negative spillovers. These positive employment effects combined with zero net-wage effects are puzzling to the standard tax incidence framework that relies on a competitive labor market: high labor demand elasticities and low labor supply elasticities predict small (close to zero) employment effects (and pass-through into net wages, with gross wages unaffected) 49 While this collection of market-level findings may appear consistent with wage rigidities, our investigations clarify that formal wage setting institutions in Sweden or even conventional downward wage rigidity cannot explain the incidence into gross wages. In light of these nonstandard results at the market level, we next explore the role of firm-level mechanisms as potential transmission channels of tax incidence.

\section{$5 \quad$ Effects on Business Growth}

Our market-level results presented in Section 4 contradict the standard public economics view. The payroll tax cut does not lead to higher wages for young workers, and hence translates fully into reduced labor costs for employers. Employers respond to the lower labor costs by employing more young workers, primarily by retaining them longer (rather than hiring them more). As firms are the beneficiaries of the payroll tax cut, an interesting question that arises and is indeed discussed in the public debate is whether firms just pocket the windfall from the tax reduction, or whether they use it to expand business activity. This question can be seen as a further investigation of the incidence effects of the payroll tax cuts.

We address this question using firm-level variation in exposure to the payroll tax cut generated by pre-existing, persistent age composition of their workforce. Firms with a large share of

\footnotetext{
${ }^{49}$ In fact, the standard framework would infer a 0.22 labor demand elasticity with respect to labor costs (see Table 2 and an infinite labor supply elasticity (given the zero net wage increase). Since we find larger responses at the separation margin, we believe that the overall employment elasticity does not reflect the underlying structural substitution parameters since search for new hires may not sharply discriminate by age. Some models predict high Frisch elasticities for youth labor supply (Rogerson and Wallenius, 2009), although our evidence overall points towards labor demand driven adjustment of employment and rationed youth labor supply.
} 
young workers benefit from a larger payroll tax cut windfall than firms with few young workers. Therefore, it is possible to do a longitudinal analysis based on firms' pre-reform share of young workers. This empirical strategy was first developed by Skedinger (2014) for the retail sector. Egebark and Kaunitz (2017b) also use this strategy to analyze all industries. We build upon these previous contributions by defining narrower but more comparable treatment and control groups. We provide compelling graphical evidence with pre-trends, including the medium run, and also analyze a broader range of outcomes and mechanisms, as discussed in Section 2 .

Mechansim: cash injection vs. marginal cost reduction. The response of firms to the payroll tax cut should depend on their share of young workers pre-reform through two potential channels. First, the payroll tax cut generates a larger cash flow windfall to firms with many young workers. If firms are credit constrained, such a cash windfall could lead firms to expand and in particular hire and invest more. We call this channel the cash channel. It arises from the cash injection from inframarginal workers. Second, the payroll tax cut lowers the overall marginal cost of production by reducing the cost of one production input, namely young eligible workers. This marginal-cost effect is stronger for firms whose production function leads them to always want to employ many young workers. We call this channel the (marginal) cost channel, akin to the scale effect in labor demand.

A given firm's pre-reform labor cost share of young treated workers is a good proxy for both the youth intensity of their production process as well as the cash injection from the tax windfall 50 Hence, our research design does not allow us to estimate separately these two effects, although we investigate whether the effects are stronger for firms more likely to be credit-constrained. Our main specifications estimate the combined effect of the cash channel and the cost channel using our longitudinal identification strategy.

Finally, unlike in the market-level investigations of employment, our firm-level design does not permit us to investigate substitution from old to young workers separately from scale effects. This is because our firm-level identification is constructed directly from a given firm's share of young workers (in 2006), and we find that this share young measure moreover exhibits mean revision that would mask all potential substitution patterns.

\footnotetext{
${ }^{50}$ For the cost channel, the cost share (rather than raw employment share) of one input (the young) would precisely pin down the elasticity of overall marginal cost to a change in that input's price (our payroll tax cut) with CES production, and therefore the scale effect. For the cash channel, payroll (rather than employment) share young also pins down the cash effect because it depends on the dollar magnitude of the price reduction.
} 


\subsection{Empirical Strategy and First Stage}

Our empirical strategy exploits the fact that there is considerable between-firm variation in share of young workers pre-reform which generates firm-level variation in treatment intensity. We consider a balanced panel of firms active in every single year from 2003 to 2013 51 We include firms with more than 3 employees in each year 52 We consider only for-profit corporations domestically owned, hereby excluding sole proprietorships, partnerships, as well as all firms in the public and the nonprofit sector. Financial companies are not part of the data produced by Statistics Sweden and hence cannot be included in our analysis either. We also exclude firms that are part of a corporate group as Statistics Sweden sometime imputes values for such firms (see Section 3.2).

We split the balanced panel of firms into five groups based on their share young, which we define as the share of total wage earnings paid to young workers aged 19-25 in 2006. As young workers tend to be paid less than older workers, our share young is typically below the fraction of employees who are young. ${ }^{53}$ The five groups are defined as the four (unweighted) quartiles of firms with positive share young, and a mass of firms with precisely zero young share ${ }^{54}$

Figure 8 illustrates our source of between-firm variation: pre-reform firm-level share young in 2006. The top panel depicts the density distribution of share young in 2006. The spike at zero represents the $22.6 \%$ of firms which have a share young of exactly zero. The bottom quartile is depicted in green, the middle two quartiles in red, and the top quartile in blue. The share young distribution has a long tail with substantial variation within the top quartile. We will sometimes exploit this additional variation by further breaking down the top quartile into a top $1 / 8$ and the next $1 / 8$. Correspondingly, as there is less first stage variation in the middle of the distribution, we group together the middle two quartiles. To summarize, we call the bottom group that includes firms with zero young workers and firms in the bottom quartile (in green on Figure 8), the low share young, we call firms in the two middle quartiles group (in red on Figure 8), the medium share young, and we call the top quartile group (in blue on Figure 8), the

\footnotetext{
${ }^{51}$ We show below that our results are robust to considering an unbalanced panel of firms and that the reform did not have an effect on firms' survival. We also follow individual workers in some of our analyses regardless of whether they still work for their initial employer, or whether their initial employer still operates.

${ }^{52}$ This is because we do not weight firms by size, which would render the series noisier due to the large number of very small firms with zero, one, two, or three employees. We have also checked that our results are robust to weighting firms by employment size, in which case, the more than 3 employees condition is not necessary. We prefer to use unweighted estimates for simplicity of presentation.

${ }^{53}$ Since payroll tax rates were homogeneous in 2006 , net and gross wage shares were identical.

${ }^{54}$ Slightly more than one fifth of firms $(22.6 \%)$ in our sample have a zero share young. As a result our split is very similar to splitting all firms, including those with zero share young, into five quintiles. Our results are also robust to defining quartiles by weighing firms by number of employees.
} 
high share young. We split the top quartile group into two equally sized groups: the very top group called the very high share young and the next group called the fairly high share young.

Critical to our empirical design is the persistence of share young across years. We explore this in the bottom panel of Figure 8, which depicts the average share young in each year for each of the three groups of firms. The spike/trough pattern around 2006 is due to mean reversion: firms with high share young in 2006 tend to have lower share young before and after. Conversely, firms with low share young in 2006 tend to mean revert up before and after. Most important, there is substantial persistence in the share young across years, and hence proportionate persistence in the 2006 tax windfall received by firms through subsequent years. We will trace these persistent effects in our design. While we do not explicitly estimate IV effects, this persistence graph presents the "first stage" of our strategy.

Table 4 provides further statistics as of 2006 on the three groups of firms depicted in Figure 8. Statistics for each of the three groups (low, medium, high) are reported in each of the three columns (1), (2), (3). Two points are worth noting. First, firm statistics are not widely different across the three groups. Second, the top two groups in columns (2) and (3) are relatively more similar to each other than to the bottom group in column (1). In particular, the top two groups have very similar average firm size measured either in terms of full-time employees or sales. As our analysis will show, the top two groups have very close pre-reform parallel trends for a very wide range of outcomes. In contrast, the pre-trends for the bottom group are not quite as well aligned. Furthermore, as the bottom panel of Figure 8 showed, there is a much larger first stage difference between the top two groups than between the bottom two groups. Hence, our empirical analysis will compare the top two groups and not use the bottom group.

The difference in fraction of payroll young in 2006 between the high share young group and the medium share young group is 19.8 points. As the payroll tax cut reduces labor costs of the young by $12.1 \%$, this means that the tax windfall differential is $2.4 \%$ of total payroll initially. As a fraction of payroll, the tax windfall tapers off and is reduced by about half in the post-reform years for 2009-2013 relative to 2006 due to mean reversion. In 2006, the difference between the very high share young (and the medium share young) is 27.1 points while the difference between the fairly high share young (and the medium share young) is 12.5 points (see Appendix Figure A8, Panel (a)). Hence, we should expect differences in outcomes between the very high share young and the medium share young to be about twice as large as the differences between the fairly high share young and the medium share young. 


\subsection{Firm-Level Results}

Methodology. We generally consider two groups as in Figure 8. (1) firms in the middle two quartiles of share young in 2006 (medium share young) and (2) firms in the top quartile of share young in 2006 (high share young). We plot the time series of average outcomes for these two groups of firms from 2003 (the first year we have comprehensive firm data) to 2013 (the latest year available). For each firm, we normalize outcomes relative to year 2006, i.e. $y_{f, t} / y_{f, 2006}$, where $y_{f, t}$ is outcome $y$ of firm $f$ in year $t$. We then compute the straight average of these normalized firm-level outcomes for each of the two firm groups in each year 55 Denoting by $\bar{y}_{h, t}$ and $\bar{y}_{m, t}$ these average normalized outcomes in year $t$ for the high share young group (h) and medium share young group $(m)$, we then simply plot the two time series $\bar{y}_{h, t}, \bar{y}_{m, t}$ for $t=2003, . ., 2013$. For additional variation, we will further sometimes split the high share young top quartile group into 2 equally sized subgroups, the top $1 / 8$ (very high share young) and the next $1 / 8$ (fairly high share young) and we construct the corresponding time series $\bar{y}_{v h, t}, \bar{y}_{f h, t}$ for the very high $(v h)$ and fairly high $(f h)$ share young groups.

The corresponding quantitative effects are estimated based solely on these time series of group aggregates, using the following basic DD-specification and conventional OLS standard errors:

$$
\bar{y}_{g, t}=\alpha_{t}+\beta_{g}+\gamma \cdot 1(t>2006) \times 1(g=h)+\varepsilon_{g, t},
$$

where $g=h, m$ denotes the group (high share young vs. medium), $t$ denotes the year, $\alpha_{t}$ denotes year dummies and $\beta_{g}$ group dummies. The coefficient $\gamma$ on the interaction term post-reform times high share young group is the coefficient of interest. $\varepsilon_{g, t}$ is the error term. Because the reform is only partially phased-in in 2007 and 2008, we exclude these years from the regressions and hence $t$ runs from 2003,.., 2006 and 2009,.., 2013, i.e., 9 years of data. With two groups, this regression is based just on 18 observations. However, as pre-trends are very parallel and effects generally very stable across post-reform years, even these basic regressions with conventional OLS standard errors deliver precise results. The firm-level regression results are presented in Table 5. Column (1) reports the DD effects comparing the high vs. medium share young firms. We also run the regressions contrasting the fairly high share young group versus the medium share young, and regressions contrasting the very high share young group versus the medium share young. These estimates are calculated exactly as above by just replacing the group $h$ by group $v h$ (or group $f h$ ). These additional results are reported in columns (2) and (3) of Table 5.

\footnotetext{
${ }^{55}$ We take and report unweighted averages for simplicity. Our results are robust to considering weighted averages, where for example we weight each firm by 2006 employment.
} 
The graphical analysis discussed below is a critical element to provide compelling and transparent causal evidence of the payroll tax cut on firms. We view the regression results as simply a way to quantify the treatment effects already identified in the graphical analysis, and their precision $\sqrt[56]{6}$

Firm-level employment effects. We measure employment at the firm level by the number of workers receiving annual wage earnings from the firm above the same low threshold of $\$ 4,940$, as in Section 4.357 The effects on employment are depicted in Figure 9. In the top panel, we compare firms with medium share young (in red dashed line with squares) to firms with high share young (in solid very dark blue line with circles). In the bottom panel, we further split the high share young group into the very high share young (in long dashed light blue circles) and the fairly high share young (in dotted dark blue circles).

Three important results stand out from Figure 9. First, both panels show that there is a parallel trend in the growth of employees before 2006 across groups. Recall that they line up at 1 in 2006 by normalization. Therefore, assuming that absent the reform the parallel trend would have continued, seems like a reasonable assumption. It is the critical identification assumption needed for our simple DD empirical strategy.

Second, after the reform, firms with a higher share young in 2006 experience a faster growth of employees. The top panel shows that the differential effect builds in 2007-2009 when the reform is phased in and seems stable from 2010-2013 at about 4-5\%. Note that the two series remain very parallel after 2009 but with a clear (and hence stable) level effect. The fact that the change happens exactly when the reform starts and that it stabilizes after 2010 strongly suggests that this effect is indeed reform driven.

Third, the bottom panel shows that this faster growth is quantitatively related to the initial share young in 2006. The differential effect for the very high share young group (relative to the medium share young group) is about 2.5 times larger than the differential effect for the fairly high share young group (again relative to the medium share young group). This additional "dosage" effect is roughly proportional to the difference in first stage treatment intensity mentioned above. This gives us further confidence that the effects we uncover are indeed causally driven by the payroll tax cut.

Corresponding regression estimates of the implied treatment effect are provided in Table 5 ,

\footnotetext{
${ }^{56}$ In this way, we extend and build upon the previous contributions by Skedinger (2014) and work by Egebark and Kaunitz (2017b), whose firm-level analyses solely report individual level DiD regression results.

${ }^{57} \mathrm{We}$ also investigated effects on the number of workers that appear on the payroll of the firm and effects are similar.
} 
top row. Comparing high share young vs. medium share young firms, the payroll tax cut boosts employment by $4.6 \%$, a precisely estimated effect with a standard error of .3\% (based on an OLS regression with just 18 group-aggregated observations). This employment growth differential is with respect to a $2.4 \%$ initial differential in average labor costs that the reform induces between these two firm groups. Splitting the top group into two, we estimate an employment effect for fairly high vs. medium share young at a somewhat smaller $2.8 \%$, and the employment effect for very high vs. medium share young is higher at $6.5 \%$.

Firms' business activity. We repeat in Figure 10 the analysis presented in Figure 9 top panel but instead of considering employment growth, we consider four alternative outcomes in each of the 4 panels that capture firms' business activity: (a) total assets (this includes the book value of tangible and intangible capital assets as well as the market value of financial assets), (b) total sales (annual gross proceeds from all sales), (c) value added (sales minus all purchases of intermediate goods and capital goods), (d) profits (defined as earnings before interest and taxes (EBIT)). For Panel (d), as profits can be negative, we normalize profits by value added in the firm in 2006 and then adjust the two series multiplicatively so that they are normalized to 1 in 2006 58 All four outcomes are obtained from the firms' balance sheet and income statement data used for the administration of the business tax. All four panels show that the two groups of firms have parallel pre-reform trends and the group with high share young (and hence largest cost reduction and tax windfall) experiences faster growth in assets, sales, value added, and profits after the reform.

The graphs show that parallel trends are particularly good for total assets and sales, pretty good for profits, and decent (but not perfect) for value added, which should determine the confidence about the respective effects. But even for value added, the opening up after the reform is considerably larger than the gap in parallel trends before the reform. Therefore, the evidence shows that the payroll tax cut for employers was successful in boosting business activity along a number of dimensions 59 Note that sales and value added effects could be due in part to producing and selling larger quantities, and in part to selling at higher prices. We unfortunately cannot distinguish between volume effects and price effects with our data. ${ }^{60}$ But

\footnotetext{
${ }^{58}$ That is, we normalize firm $f$ 's profits in year $t, \pi_{f, t}$, by its 2006 value added, $V A_{f, 2006}$, to obtain $\pi_{f, t} / V A_{f, 2006}$. We then average this ratio across all firms in a given group $g$ in year $t$, as our normalized average $\bar{\pi}_{g, t}$. We then plot the time series of $\bar{\pi}_{g, t} / \bar{\pi}_{g, 2006}$ on Figure 10 . Panel (d). It is equal to one for $t=2006$.

${ }^{59}$ Table 5 shows that the effects on employment are similar in magnitude to the effects on assets reveals, which suggests that the capital/labor ratio stays fairly constant.

${ }^{60}$ There is volume and average-price data for a smaller sample of manufacturing firms. Unfortunately, the sample size we have is too small to obtain reliable results on price effects. Furthermore, the price data are
} 
since employment as well as assets (our measure includes productive capital) expand, it is very likely that real sales increase as well.

Corresponding estimates are provided in Table 5, rows 2 to 5. The regression results in column (1) show effects in the range of 3 to $6 \%$, and precisely estimated. The table also shows that effects are systematically larger (and about twice as high) when comparing very high share young to medium share young (in column 3) relative to comparing fairly high share young to medium share young (in column 2). This provides further confirmation that the results we uncover are indeed driven by the payroll tax cut. The corresponding graphs showing the very high and fairly high groups time series are presented in Appendix Figure A8.

Firm survival. The tax cut could have affected survival of firms. This is an outcome of interest in its own right. However, such effects would also render our sample of a balanced panel of firms (2003-2013) endogenous to the reform. We address this question in Figure 11. For this exercise, we now consider all firms present in 2006 and operating with more than 3 workers in 2006, regardless of whether they operate in other years (or whether they have more than 3 workers when they operate). Firms are naturally assigned zero values for employment, sales, profits, etc. in years in which they do not operate. We then compare firms with a high share young in 2006 to firms with a medium share young in 2006, as we did for our benchmark analysis.

Panel (a) of Figure 11 plots the fraction of firms operating in each group for years 2003 to 2013. By definition of the sample, this fraction is equal to one in 2006. It can be lower than one before 2006 as some firms have not started yet; it can be lower than one after 2006 as some firms might cease to operate after 2006. The Figure shows that firms with a high share young are substantially less likely to have operated before 2006 (relative to firms with a medium share young). In other words, high share young firms in 2006 are younger. Panel (a) also shows that high share young firms are slightly less likely to survive after 2006 than firms with medium share young. However, rather than a causal effect of the reform, this differential exit rate post-reform of high share young firms may be due to the fact that recently created firms tend to have both lower survival rates and higher shares of young workers 61

Therefore, to analyze compellingly whether the reform affects survival, we reweight firms in the medium share young group to align their 2006 firm-age distribution to the high share

revenue divided by quantity, rather than eliciting actual micro unit prices.

${ }^{61}$ Intuitively, the reform would be expected to help high share young firms survive. Hence it should have pushed survival of high share young firms up in relative terms. That is why the differential survival we observe in Panel (a) is certainly due to differences in firms characteristics and not due to the reform. 
young group, using the non-parametric methods in DiNardo, Fortin, and Lemieux (1996) (DFL reweighting). We do so by partitioning each group into 8 firm-age based subsets and reweighting each subset so that, after reweighting, the fraction of firms in each age subset is equal across the two groups. We then plot again fraction of firms operating in each group for years 2003 to 2013 in Panel (b) of Figure 11. Panel (b) shows that, after this age based DFL reweighting, the survival curves align perfectly both pre- and post-reform. The pre-reform alignment is expected by definition of DFL reweighting by age in 2006. The post-reform alignment then suggests that the reform has actually no effect on survival of high share young firms. That is, all of the exit effect was purely compositional with regards to firm-age differences. This absence of survival effects justifies our use of the balanced panel for our main results. It also implies that the payroll tax cut affected firm outcomes only at the intensive scale margin, but not at the extensive margin 62

Unbalanced panel. It is also possible to estimate firm effects using the full sample of firms from Figure 11 (regardless of whether they operate in all years) and compare the two groups after DFL reweighing by age as done in Panel (b). This exercise is presented in Appendix Figure A9, where we trace out firm outcomes for employment, sales, profits, and value added relative to 2006 in four separate panels. In this case, non-operating firms are assigned zero values. Therefore, this analysis is fully robust to endogenous survival effects. Figure 11 shows that, thanks to DFL reweighing by firm-age, pre-trends are very well aligned for all outcomes (less so for the noisier variable of profits).

After the reform, these unbalanced, DFL-reweighted graphs also show that firms with high share young expand employment, sales, value added, and profits growth 63 This effect therefore confirms our main specification using the balanced panel of firms. In the end, we prefer to use the balanced panel of firms active in all years 2003-2013 rather than this full sample because the balanced panel approach does not require any DFL reweighting, making the analysis simpler and more transparent.

Changing the base year. All our results are based on dividing firm by share young in 2006. Selecting the treatment group based on 2006 generates a kink in the first stage around year 2006 due to mean reversion as we saw from Figure 8. One potential concern is that this first stage

\footnotetext{
${ }^{62}$ We cannot credibly investigate firm entry in response to the policy as employment structure at entry is endogenous to the reform.

${ }^{63}$ As expected from the entry/exit findings, without DFL reweighing, pre-trends for most outcomes are not parallel, hereby invalidating our key parallel trend assumption as we saw in Panel (a) of Figure 11.
} 
kink could translate into a kink in other outcomes, hereby generating a spurious effect around 2006. In Appendix Figure A10, we show side-by-side that both pre-reform parallel trends and effects after 2006 survive if we instead select firms into the treatment vs. control groups based on 2003 (instead of 2006).

\subsection{The Role of Credit Constraints}

Our empirical analysis has shown strong effects of the payroll tax cut on employment and business growth across the board, suggesting that the tax windfall boosts the economic activity of the firms which receive it due to their workforce age structure. Theoretically, firms that are particularly constrained in their access to external finance (debt or equity) should be particularly responsive to the cash effect of payroll tax cut (but less constrained firms may still be affected through the cost effect we discussed above). Indeed, the literature in corporate finance has provided substantial evidence that cash windfalls matter for firms' growth perhaps due to credit constraints (see e.g., Fazzari, Hubbard, and Petersen, 1988 for a classic study) ${ }_{64}^{6}$ In the case of the Swedish reform we examine, the payroll tax cut applied to all (young) workers rather than new hires only (as e.g. with hiring subsidies that other studies have examined), which may be part of the reason for the significant effects we find in the aggregate and on the firm level. Indeed, the policy discourse often loosely refers to the resources the payroll tax cut may free up for reinvestment in capital and labor, rather than the standard marginal-cost channel that would apply to marginal hiring subsidies.

To understand whether credit constraints play a role in the firm-level effects we have uncovered, we follow a split-sample strategy by dividing the firms in 2006 by various proxies for financial constraints that have been used in the corporate finance literature (see e.g., Farre-Mensa and Ljunqvist 2016). Since theories of financial constraints consider firms to be constrained in their input choices, we consider two outcomes: (1) employment and (2) total assets (which include productive capital inputs). The results are presented in Table 6 and the corresponding time series graphs are presented in Appendix Figures A11 and A12.

Table 6 displays the effects of the payroll tax cut on employment (Panel A) and total assets (Panel B) for financially constrained and less constrained ("unconstrained") firms. We always compare firms in the high share young group to firms in the medium share young group but we also divide each of these two groups by financial constraint proxies. Column (1) divides

\footnotetext{
${ }^{64}$ Schoefer (2016) applies this cash channel to labor costs in labor demand in the context of wage rigidity, and proposes a Slutsky identity of labor demand that features the cash channel as a financial analogue of the standard scale effect from marginal costs.
} 
firms above and below median age in 2006 as young firms are much more likely to be creditconstrained. Column (2) divides firms into above vs. below median of liquid assets / total assets in 2006 as firms with fewer liquid assets are much more likely to be credit-constrained. Finally, column (3) divides firms into above vs. below median sales in 2006 as small firms are much more likely to be credit-constrained. The table shows the DD estimates for unconstrained firms and for constrained firms as well as the F-test and the associated p-value for the null of equal effects across constrained firms and unconstrained firms. The graphical evidence in Appendix Figures A11 and A12 shows that the identification is compelling in the sense that pre-tends are systematically parallel (even for these additional subsamples), and a clear gap opens up right at the time of the reform and remains stable from 2010 to 2013.

Two key lessons emerge. First, in all six cases, the employment and asset growth effects on firms more likely to be credit-constrained are larger than for firms less likely to be creditconstrained. However, only two of these six differences are statistically significant. Second, all 12 estimates of treatment exposure by share young are positive and significant, implying that all subgroups experience an effect driven by the payroll tax cut. Therefore, these results are consistent with the credit constraint channel, although they certainly do not prove credit constraints as the sole driver of the effects. But since our firms contain small firms (rather than the frequently studied U.S. publicly traded firms), possibly many firms in the "unconstrained" control group may be financially constrained too, rather than unconstrained. Another issue is that the available credit constraints proxies might not be very accurate and misclassify firms (see Farre-Mensa and Ljunqvist (2016) for a discussion of these issues in the corporate finance literature).

A concern is that the heterogeneous effects by financial constraints are simply driven by a larger difference in the share young across firms with a high and a medium share young in 2006. Panel $\mathrm{C}$ of Table 6, however, shows that financial constraints are not systematically correlated with the 2006-share of the payroll to young workers. The difference in share young in 2006 between treated and control firms is almost constant across financially constrained and unconstrained firms, irrespective of the financial proxy, at around 19-20\%, which is the difference in the main analysis (Table 5).

\section{Benchmarking the implied cash effects to existing dollar-for-dollar estimates in the}

literature. A full model and assessment of the financial channel is beyond the scope of this paper and limited by the strong effects we find even for firms that our imperfect proxies classify as 
less constrained. However, in the Appendix, we evaluate our firm-level findings quantitatively by investigating whether the size of our treatment effect for the average firm could be entirely and exclusively rationalized by a credit constraints channel. Our benchmarks are existing estimates of the dollar-for-dollar sensitivity of capital (investment) to cash flow from the corporate finance literature. While our sample and particular design differ from existing U.S. analyses with publicly traded, very large firms, our back of the envelope calculation suggests that our effects are of the same order of magnitude, and that the cash channel could play an important role in the firm-level effects. Specifically, our effects would correspond to a $\$ 0.1-\$ 0.5$ effect on capital stock per dollar of tax windfall, which spans the range of existing estimates for the investment cash flow sensitivity for the average U.S. Compustat firm (see e.g., Fazzari, Hubbard, and Petersen (1988) for a classic study). The financial channel is therefore quantitatively plausible.

\section{Rent Sharing at the Firm Level}

In Section 4.2, we documented strong market-level evidence against the standard prediction of full incidence on workers' net wages for directly treated young workers. The underlying conceptual framework is a frictionless labor market equilibrium that pins down one single marketclearing wage for each worker group. There is a growing body of evidence in labor economics that points to the role of individual firms in setting wages and in generating wage dispersion between similar workers, which may emerge in frictional labor markets (see e.g. Card, Cardoso, Heining and Kline (2016)). For our context of a tax windfall, we are particularly motivated by evidence of wages reflecting rents shared between the firm and the workers - after all, our non-standard results imply that firms do experience labor cost reductions and thus receive tax windfalls. It is thus natural to investigate whether some of those rents might have been shared with the workers that happened to have been employed at those firms. Next, we therefore investigate the firm-level effect of exposure to the windfall on wages at those firms. We first investigate average wages, but then move to eliminate potential composition biases by following individual workers based on their pre-reform employer.

\subsection{Firm-Level Average Net Wages and Gross Wages}

We first apply our firm-level strategy from Section 5 to investigate how firms' average earnings per worker diverge in response to differentials in the tax windfall. We distinguish three firm-level per worker wage related concepts: pre-tax average earnings inclusive of the payroll tax (gross wage earnings), and its two components: post-tax average earnings net of the payroll tax (net 
wage earnings) and the payroll taxes paid per worker.

Figure 12 presents the graphical evidence. In each panel, we again compare firms with high share young vs. firms with medium share young in the balanced panel of firms operating in each year 2003 to 2013 with more than 3 employees in each year. Panel (a) depicts the evolution (relative to 2006) of the average net wage earnings per worker in the firm. Panel (b) depicts the evolution (relative to 2006) of the average payroll taxes per worker in the firm. Panel (c) depicts the evolution (relative to 2006) of the average gross wage earnings per worker in the firm (i.e., the labor cost per worker paid by the employer). Importantly for our causal inference, pre-trends for all those variables are parallel between the different firm types.

The intriguing fact of Figure 12 is shown in Panel (a): firms with a high share young (and hence the largest average-payroll reduction as well as the largest tax windfall) experience a faster increase in net wage earnings per worker. Panel (b) confirms that they do benefit in form of a lower payroll tax payment per worker. But Panel (c) clarifies that the increase in net wages is so large that their gross wage payments - inclusive of payroll taxes - per worker actually do not differentially fall.

Taken together, these three variants of labor costs suggests that the windfall payroll tax cut allows, or leads, firms to pay higher wages on average but that, thanks to the payroll tax cut, the labor cost per worker does not increase (but also does not decrease) on average.

Corresponding estimates are provided in Table 5, column (1). Quantitatively, average net wage earnings increase by $1.9 \%$ in high share young firms (relative to medium share young firms). In contrast, the effect on average gross wage earnings per worker is only .33\%. The reduction in payroll taxes paid per worker is estimated at 4.4\%. In columns (2) and (3), we again split the high share young into two groups and find again much larger effects for the very high share young group in column (3) than for the fairly high share young group in column (2) (see Appendix Figure A8 for the graphical time series evidence). Interestingly, the effects on labor costs are very close to zero for both groups so that firms in the very high share young can increase net wages per worker by $2.4 \%$ (instead of $1.3 \%$ for the fairly high share young group).

Therefore, these results suggest that at the firm level, part of the tax cut is passed on to workers in the form of higher wage earnings, and that the payroll tax cut generates betweenfirm earnings divergence. Next, we explore this phenomenon further by conducting a matched employer-employee longitudinal analysis of individual earnings (instead of firms). 


\subsection{Individual-Level Wage Responses to Firms' Tax Windfalls}

One concern with the firm-level analysis is that the composition of workers may change for the treatment group post-reform. After all, our evidence in Section 5 shows that treated firms expand across the board, in particular in employment (Figure 9); and, we know that the share of young workers mean-reverts moderately (Figure 8, Panel (b)). If these new workers differ in their characteristics, they could drive up or down the average wages in the firms through composition effects.

To address this issue, we create a matched employer-employee version of our firm- and worker-level data to conduct an individual-level analysis that follows workers over time. Instead of following firms, we now follow individual workers, grouping them by their 2006 employer (i.e. just before the reform), again using the split of firms by their share young as of 2006 as in Section 5. We then trace out these individual worker-level outcomes from 1999 to 2013, regardless of whether they switch firms or drop out of employment (in which case their wage earnings are zero) 65 Our sample is workers aged 25-60 as of 2006 matched to our firm sample from Section 5 (but before or after 2006 these workers may work for firms outside of that firm sample). We pick this prime-aged worker group because they are old enough to have interpretable pretrends. And, none of these workers will ever be directly affected by the payroll tax cut, as they are too old to benefit from it when the tax cut is implemented in 2007 (for workers aged 25 or less) and in 2009 (for workers aged 26 or less), rendering any wage effect consistent with rent-sharing patterns of the tax windfall.

The results on average net wage earnings (i.e., exclusive of the payroll tax) are presented in Figure 13. The Figure depicts the evolution (relative to 2006) of the average wage earnings per worker group (i.e. 2006 firm group) for all individuals aged 25-60 as of 2006. In the top panel, we consider two groups of individuals: (1) individuals working in a medium share young firm in 2006 and (2) individuals working in a high share young firm in 2006. In the bottom panel, we further split the high share young group into two subgroups: (2a) individuals working in a fairly high share young, (2b) individual working in a very high share young. In both graphs, we DFL reweight by 5 year $\times$ gender cells to control for the age structure across groups. DFL reweighting is necessary because the age distribution of workers is different across the two groups of firm by construction of the groups. Because of strong age effects in the profile of individual earnings growth (see Figure 2), the pre-trends could not be parallel without DFL reweighting (and would differ post-reform even absent a treatment effect). However, with DFL reweighting,

\footnotetext{
${ }^{65}$ The panel is almost perfectly balanced, as international migration and deaths are the only attrition sources.
} 
the pre-trends are close to perfectly parallel in both groups, i.e. raw pretrend differences were entirely due to age composition differences ${ }^{66}$

Three findings are worth noting. First, in both panels, pre-trends are very parallel giving us confidence that our difference-in-difference design is credible. Second, the top panel shows that individuals working in 2006 (just before the reform) in a firm with a large share young (and hence largest tax windfall) experience a faster increase in earnings after the reform. Third, the bottom panel shows that this positive individual earnings effect is larger yet for individuals working in firms with a very high share young than for individuals working in firms with a fairly high share young. This suggests that the wage effects we uncover are indeed driven by the payroll tax cut. Using exactly the same design, we show in appendix Figure A13 that there is no effect on likelihood of working and likelihood of working with the same 2006 employer. This implies that there was no extensive margin employment responses and that the individual earnings effects we uncover are due to intensive responses.

The earnings estimates are provided in the first row of Table 7 where we consider all workers aged 25-60. Following our standard approach, Column (1) compares the high share young group to medium share young group and finds a positive individual earnings effect of $2.6 \%$, a highly significant effect. This effect is similar in size to the average net-wage effect of $1.9 \%$ that we documented at the firm-level in Figure 12 and Table 5. In Columns (2) and (3), we again split the high share young into two groups and find again much larger effects-about twice as high-for the very high share young group in column (3).

These results imply that workers did benefit from the tax windfall their immediate employer received. Quantitatively, our individual-level wage effect lines up with the predicted reduction in average (or total) labor costs the high share young firm would experience over the medium share firms absent a wage response: $2.4 \%$. As a result, our cross-sectional results reveal full pass-through of firm's idiosyncratic exposure to the tax windfall onto (all) workers' net wages.

The sources of the wage effect. Our individual-level wage strategy differs from the firmlevel perspective on average wages not only by removing composition bias. By allowing for job mobility and nonemployment in our intent-to-treat design based on workers' 2006 employer, our design also allows workers to potentially benefit from the windfall by moving up the job ladder, or through lower unemployment risk. In additional checks, we find that stayers with the original employer drive the wage effect and that the intensive margin of earnings is dominant.

\footnotetext{
${ }^{66}$ We have more pre-reform years than in our previous firm level analysis. This is because individual earnings data start earlier than firm-level balance sheet data, and we only use firm-level data in 2006 for this exercise.
} 
We do not find any effect on the extensive margin of nonemployment: pre- and post-trends of the fraction of workers with positive earnings as an outcome variable are the same for both groups (Appendix Figure A13, Panel (a)). In consequence, we find that the intensive-margin treatment effect on average earnings conditional on employment is similar to the unconditional one (Appendix Figure A14, Panel (a)). Which employers drive this intensive-margin effect? When we restrict the earnings observations to only include stayers with the 2006 employer, the data exhibit the original treatment effect on worker earnings (Appendix Figure A14, Panel (b)). Relatedly, there is no treatment effect on the fraction of individuals staying with their 2006 employer as an outcome variable (see Appendix Figure A13, Panel (b)). In summary, these results complete our picture that indeed, the annually recurring payroll tax cut windfall has persistently raised wages of the workers present in the heavily exposed firms.

Rent sharing? Which mechanism may explain the wage effect at the firm level? Recall that none of the sampled workers aged 25-60 in 2006 ever benefit directly from the payroll tax cut as it applies only to workers aged 25 or less in $2007-8$ and 26 or less in 2009 and after. That is, we find that at the firm level, tax incidence spills over to workers ineligible for the tax cut 67 Larger tax windfalls (from larger share of young workers pre-reform) appear to lead firms to offer (or workers to demand) wage increases to their employees collectively, not just the young workers who trigger the windfall. This evidence is consistent with rent sharing of windfalls within the firm and consistent with earlier empirical evidence obtained in other (non payroll tax) contexts that we reviewed in Section 2. Our study differs from existing research in that we have a within-firm group of workers that we can cleanly identify as an unaffected group except for spillovers from rent sharing. In contrast to our market-level analysis from Section 4 , which showed that eligible workers' market wage did not benefit specifically and differentially, our firm-level evidence for rent sharing reveals that workers do benefit, collectively, from the payroll tax cut.

Next, we probe deeper into the collective tax incidence effects by considering heterogeneity by age and heterogeneity by initial earnings level within the firm, and then explore effects on various percentiles of the earnings distribution (instead of considering only the average earnings

\footnotetext{
${ }^{67}$ Kline et al. (2017) find positive effects of successful patenting on workers' wages using US matched employeremployee data for the cohort present at the patent approval only. This pattern is in line with performance-pay contracts. Our context differs in that the tax windfall benefits workers that are not directly treated (too old to ever be directly eligible themselves), and yet in the individual level design, we still document wage effects particularly for those older workers. Rather than performance pay contracts, our findings are therefore consistent with rent sharing mechanisms.
} 
as we have done here).

Heterogeneity by age. In Figure 12, we considered all workers aged 25-60. We now split this sample into 4 age groups: 25-30, 31-40, 41-50, 51-60 and estimate effects for each sub-age group. The graphical evidence for these 4 groups is presented in Appendix Figure A15. The figure shows that pre-trends are parallel for each of the 4 groups and that positive effects arise just after the reform. The corresponding DD estimates are presented in rows 2-5 of column (1) of Table 7. All age groups except the oldest group 51-60 display significant earnings effect on the order of 3\% and highly significant. The oldest group 51-60 estimate is smaller (.5\%) and not statistically significant. Columns (2) and (3) report the effects of comparing the medium share young groups to the fairly high share young group and the very high share young group. Again, the effects are systematically larger for the very high share young group. In that case, even the older group 51-60 displays a significant effect although fairly small in magnitude (1.2\%). These results suggest that the collective incidence happens broadly and is not limited to workers most closely resembling the young treated group along the age dimension.

Heterogeneity by earnings rank within the firm in 2006. Next, we split the sample by relative earnings groups within their 2006 employer. More specifically, we consider two groups: workers with 2006 earnings above the firm median in 2006 ("high earners") and workers with 2006 earnings below the firm median in 2006 ("low earners"). We focus on workers aged 31-40 to compare workers in a single broad age cohort. Figure 14 depicts the average earnings in workers at high vs. medium share young firms in 2006 for high earners in the top panel and low earners in the bottom panel. Pre-trends are parallel in both panels, and particularly so for lower earners in the bottom panel. Interestingly, the percent effects on earnings appear to be much larger - about twice as large - for lower earners than for higher earners ${ }^{68}$ This is confirmed in the last two rows of Table 7, which provide the corresponding estimates on wage earnings: $4.1 \%$ for lower earners, and $1.8 \%$ for higher earners, both highly significant and precisely estimated so that the two estimates are clearly statistically different. Again, columns (2) and (3) show that these differential effects between low and high earners are much stronger when using the very high share young group rather than the fairly high share young group. These within-firm

\footnotetext{
${ }^{68}$ Note that selecting workers based on their position within the firm in 2006 creates visible mean reversion patterns. High earners experience a sharp increase in earnings in 2006 and a stagnation in earnings in 2007. Conversely, low earners experience a slow increase in earnings in 2006 and a sharp increase in earnings in 2007. Fortunately, these mean reversion effects are identical for the high share young group and the medium share young so that the credibility of the empirical design is not affected.
} 
results suggest that the collective incidence of the payroll tax cut on wages is progressive within firms. Firms use the tax windfall to increase wages of non-eligible workers and increase wages of lower earners relatively more (in percentage terms). This evidence of progressive distribution of windfalls within firms is consistent with the analysis of Pencavel (1991, pp. 73-77).

Effects on the earnings distribution. To cast further light on the distributional aspects of the collective tax incidence results, we come back to our initial design from Figure 13, Panel (a), but look at effects for other moments of the earnings distribution besides the mean (as we did in Figure 13). Instead, we now look at various percentiles: P20,..,P90 but we otherwise follow exactly the same methodology. We follow individual workers employed in high share young vs. medium share young firms as of 2006 (and aged 25-60 in 2006) and regardless of whether individuals change jobs as in Figure 13 . We again DFL reweight by 5 year $\times$ gender cells. Estimates for deciles P20,P30,..,P90 are presented in Table 8, column (1). The estimates are monotonically decreasing across deciles (the P90 estimate is only very slightly above P80). Hence the effects of the payroll tax cut on individual earnings (as a percentage of 2006 earnings) are highest for the lowest earners and decreasing across the percentile distribution, implying that the rent sharing of the payroll tax cut is progressive across the distribution of individual earnings.69 Using estimates of earnings levels at each percentile (as of 2006), the percentage effects we find suggests that the absolute dollar gains are also progressive: they are about constant for percentiles P20, P30, P40, and P50 and somewhat decreasing above P50. This evidence of progressive distribution of windfalls across the wage distribution is consistent with prior work on unions (see e.g., Card 1996 and Card, Lemieux, and Riddell, 2004).

As an additional placebo test, we repeat the analysis assuming that the reform took place in 2003 and comparing earnings in 1999-2002 vs. 2004-2006 (always before the actual reform happened). The corresponding estimates are reported in column (2) of Table 8. This placebo test displays no significant wage effect for any percentile. There is no indication that the placebo effects are decreasing across percentiles; if anything, they are slightly increasing, although this increase is not statistically significant. This placebo result suggests that the progressive gradient is a causal effect of the reform.

Labor and capital shares. How did the total effect of the tax windfall - including its effect on business activity and rent sharing - shift the share of labor and capital in value added? To

\footnotetext{
${ }^{69}$ The corresponding graphical evidence for each percentile is presented in Appendix Figure A16. All graphs show parallel pre-trends and clear effects opening up at the time of the reform. It is clear from the Figures that effects for lower percentiles are significantly larger than for higher percentiles.
} 
ballpark this distributional outcome, our longitudinal design suggests a simple calculation based on treatment effect estimates in Table 5. The highly exposed firms' total net wage bill increased by around $6.5 \%$, compared to the control firms. ${ }^{70}$ Value added increased by $6.1 \%$. The labor share therefore appears to have been fairly stable in response to the tax windfall 71

Summary. Our finding of firm-level collective tax incidence contrasts with the standard model of payroll tax incidence, whereby the market mechanism would limit wage increases to young workers eligible for the payroll tax cut, and would be identical for all young workers irrespective of their firm. These firm-level wage effects would have been missed with a focus on worker-level market wages only. They would also be masked in aggregate macro studies of homogeneous payroll taxes, where market-level incidence through standard mechanisms would be observationally equivalent to our firm-level transmission mechanism. While our study is naturally limited to the particular payroll tax cut in Sweden for young workers, our cuts of the data (inframarginal workers at heavily vs. moderately exposed firms) do suggest an alternative transmission mechanism of payroll tax incidence into the rent component of wages, besides the canonical market-wage adjustment.

The firm-level wage effects are consistent with rent sharing, whereby the payroll tax cut increases the profits of firms and part of these extra profits are distributed back to all workers (not just the tax cut eligible workers), with an intra-firm wage-equity constraint. A strength of our design is that we have used the eligibility features of the reform to identify workers that we know have never been directly affected by the policy, and yet benefit from its firm-level windfall through spillovers. Previous studies typically use firm-level shocks (industry rents, patents, or other shifters of productivity) without clean markers for directly vs. indirectly affected workers within the firm.

\section{Conclusion}

Summary. Our paper provides a comprehensive analysis of a large employer payroll tax cut targeted to young workers in Sweden. The payroll tax cut was effective in reducing youth

\footnotetext{
${ }^{70}$ The count of workers increased by $4.6 \%$ (Table 5). Net per-worker wage rates increased by an additional 1.9\%. (In Table 5 we document a $1.9 \%$ wage effect tracking a simple average net wage. Table 7 matched this effect at $2.6 \%$ when we adjusted for composition, which would move towards $1.9 \%$ due to the progressive effect we uncovered in the bottom columns of that Table. Moreover, the $1.9 \%$ simple wage effect includes the composition changes appropriate for the value added calculation.)

${ }^{71}$ While profits increased by $8.1 \%$, profits are a leveraged variable and only capture one component of the capital share (see Table 4 for firm descriptives).
} 
unemployment. Rather than the canonical market mechanisms, we have found that within-firm mechanisms are crucial for the ultimate incidence of the policy intervention onto labor market outcomes, as well as its transmission mechanisms.

On the market level, we have obtained two main results on wage and employment effects. First, in contrast to the standard model of tax incidence, the payroll tax cut has zero effect on net-of-tax wages of young treated workers relative to slightly older untreated workers, implying that employers do not adjust wages based on age in response to the tax reform, perhaps because wage frictions curb sharply age-specific wage differentiation. Hence, the labor cost of younger workers falls relative to other workers. Second and related, we find large positive employment effects for directly treated young workers. These results are consistent with the earlier results by Egebark and Kaunitz $(2013,2017)$. Together, this evidence rejects the standard tax incidence model that would have predicted full incidence into net wages, and small employment effects. The employment effects are also largest in areas with high youth unemployment to start with, and largely work by lengthening employment relationships. This suggests that targeted payroll tax cuts could potentially be a powerful instrument to fight inefficiently high unemployment, in line with earlier findings in the literature (Katz, 1998; Neumark 2013).

Next, we have analyzed the firm-level effects of the payroll tax cut by comparing firms with many vs. fewer young workers just before the reform, where firms with many young workers receive a larger tax cut windfall. We have obtained two results on firm-level effects. First, firms with large share young grow faster after the reform: employment, sales, value added, profits, and capital assets, all grow faster. These effects appear stronger in firms more likely to be credit-constrained, consistent with liquidity effects. Second, firms getting larger tax windfalls increase the wages of all workers (young and old) after the reform. Wages of low-paid workers grow by more. This suggests that the payroll tax cut benefits workers collectively (rather than only the directly treated young workers' market wages) and indirectly through rent sharing (rather than through market wage adjustment). Hence, our paper highlights the key role of firms in understanding the labor market effects of payroll taxes.

What model can account for the facts? We have explained in detail why our empirical findings cannot be reconciled with the standard model of competitive spot labor markets. One parsimonious refinement can explain most of our empirical findings: a wage equity constraint within firms. We develop this model formally in the Appendix but it can be described informally as follows. It is a competitive model where firms use both young and old workers for production. 
But they are constrained to pay the same net-of-payroll tax wages to young and old workers. This constraint creates involuntary unemployment among the young (their equilibrium wage should be lower than the old absent the constraint because their productivity is lower). In that context, a payroll tax cut for the young offsets the inefficiently high net wage, and hence reduces unemployment among the young - consistent with our market level results. It also benefits both young and old workers' wages in equilibrium - consistent with our findings that wages in general increase following the tax cut. Furthermore, we can also obtain the key results from our firm-level analysis by introducing two types of firms: (1) firms whose production leads them to hire mostly young workers and (2) firms which use mostly old workers; the pay equity concerns constrain wages within each firm but not across firms. ${ }^{72}$ In this extension, we obtain the following two additional results. First, the youth-intense firms expand more (across the board) following a payroll tax cut for the young than the old-intense firms. Second, the wages of all workers (young and old) in youth-intense firms increase by more than wages in firms which use mostly old workers. Without the pay-equity constraints, the model exactly nests the neoclassical benchmark and recovers all incidence predictions of the standard model - yet does not match the empirical evidence we documented. Moreover, the model with pay equity constraints implies that payroll tax cuts targeted at the non-rationed worker group (the old) need not be effective in reducing unemployment among the rationed group (the young).

While the model has an insider/outsider flavor (Lindbeck and Snower, 1986; Blanchard and Summers, 1986), our evidence (progressive rent-sharing effects; the irrelevance of formal wage frictions) points to the behavioral pay-equity constraints of Akerlof and Yellen (1990) and Bewley (2002) as a plausible underlying mechanism.73 Our empirical findings for wage compression complement growing survey evidence for the role of within-firm pay equity constraints. ${ }^{74}$

\footnotetext{
${ }^{72}$ Heterogeneity in workers' tastes for employer types ensures positive labor supply to the lower-paying firms.

${ }^{73}$ Alternative possibilities to rationalize our results are production complementarities, monopsony, or wage bargaining. Neoclassical complementarity effects appear unlikely because of mean-reversion in the share young, such that older workers actually become more abundant in the high share young firms after 2006. Standard bargaining models, even with multi-worker firms (e.g. Stole and Zwiebel (1996)), would not feature wage effects from pure cash windfalls (let alone progressive ones), but are only sensitive to changes in workers' real marginal products. In monopsony mechanisms (Manning, 2003), growing firms move up a firm-specific labor supply curve. But even in tight labor markets, we found employment increases for young workers without wage effects. Our parsimonious model with the pay-equity constraint features a monopsony-like wage channel for the old, which stands in for a richer, less tractable rent-sharing mechanism. Lazear (1989) provides a theory of compression of wage residuals, whereas our findings suggest wage compression across the clear and salient observables of age or tax status.

${ }^{74}$ Galuscak et al. (2012, Table 1) survey 15 European countries (excluding Sweden) to document rigid internal pay structures, particularly in slack labor markets and for new hires. Agell and Lundborg (1995, Tables 1 and 3) document the role of internal pay equity in Swedish manufacturing firms, and Campbell and Kamlani (1997, questions 5 and 6) and Blinder and Choi (1990, p. 1006) do so for the United States. Card et al. (2012) document employee dissatisfaction to information treatments about pay inequality.
} 
Policy consequences. What are the policy consequences of our findings? First, targeted employer payroll tax cuts could be a useful tool to fight inefficiently high unemployment, which is particularly costly for young workers 75 Payroll tax cuts can be targeted to groups with particularly high unemployment rates (such as the young, depressed geographical areas, or lower paid workers), as has been done in actual policy practice. Some particular features of the tax cut we study may underlie its effectiveness. It was employer borne, salient, administered in a way to ensure near-perfect, immediate and automatic take-up, it targeted young workers but was encompassing (i.e. applied not just to new hires out of unemployment or a subset), it was intended to be permanent, and it was large.76

Unlike cuts to minimum wages or union wage floors, an employer payroll tax cut lowers labor costs without lowering workers' take-home wages. Although such payroll tax cuts reduce government revenue, the cost per job created is not a meaningful statistic, as revenue can be recouped by increasing other taxes in a distributionally neutral way while preserving the beneficial employment effects. Second, there might be positive employment and business activity effects beyond the effects on the targeted population as firms most exposed to the tax cut increase hiring of all workers (and their wages), and thus in turn payroll tax payments. However, it is possible that such business gains could come at the expense of other firms. Hence, the general equilibrium effects are challenging to estimate. Third, the actual distributional incidence is actually much more complex than originally thought both according to the public finance workhorse model and the policy discourse. In the Swedish case we have analyzed, lower paid workers seem to have benefited disproportionately from the tax cut. Fourth, we found dramatic heterogeneity in the effectiveness of the tax cut by local unemployment and correspondingly heterogeneous costs, and scope to more narrowly target the policy.

The policy was pitched by proponents - who passed the bill when elected - as a way to stimulate employment among the young and business activity in general. It was criticized by opponents - who ultimately repealed the tax cut in 2015 when elected - as being too costly relative to the number of jobs created and a give-away to employers. Our qualitative findings align more with the former view than the latter, as our results show that there were positive employment effects among the youth, particularly so in regions with high youth unemployment

\footnotetext{
${ }^{75}$ Kahn (2010) and Oreopoulos et al. (2012) document the long-term costs of entry into slack labor markets for young workers. The standard competitive model does not have inefficiently high unemployment. Our wage equity constraint within firms as in our theoretical model in the Appendix, is one particular price friction that triggers inefficient involuntary youth unemployment. More generally, search and matching models can have inefficient unemployment (see e.g., Landais, Michaillat, Saez (2017) for an attempt to measure the gap between efficient and inefficient unemployment in US data).

${ }^{76}$ Katz (1998) discusses many of these features as important factors in the effectiveness of wage subsidies.
} 
rates. Furthermore, our results also show that the tax cut stimulated business activity and was in part redistributed back to workers, and particularly so to lower paid workers. Hence, employers did not just pocket the tax cut. A complete quantitative cost-benefit analysis is challenging as our difference-in-difference analysis cannot uncover all general equilibrium effects on older workers. However, the evidence we present paints a positive picture of the potential of targeted employer payroll tax cuts as powerful policy levers to reduce youth unemployment. 


\section{References}

Agell, Jonas, and Per Lundborg. 1995. "Theories of pay and unemployment: survey evidence from Swedish manufacturing firms." Scandinavian Journal of Economics 97.2, 295307.

Akerlof, George, and Janet Yellen. 1990. "The fair wage-effort hypothesis and unemployment." The Quarterly Journal of Economics 105.2, 255-283.

Anderson, Patricia, and Bruce D. Meyer. 1997. "The Effects of Firm Specific Taxes and Government Mandates with an Application to the US Unemployment Insurance Program," Journal of Public Economics 65, 119-145.

Anderson, Patricia, and Bruce D. Meyer. 2000. "The Effects of the Unemployment Insurance Payroll Tax on Wages, Employment, Claims and Denials," Journal of Public Economics 78, 81-106.

Arulampalam, W., M. P. Devereux, and G. Mani. 2012. "The Direct Incidence of Corporate Income Tax on Wages." European Economc Review 56 (6), 1038-1054.

Auerbach, Alan J. 2006. "Who bears the corporate tax? A review of what we know." In J. Poterba ed. Tax policy and the economy 20, 1-40.

Bennmarker, H., Calmfors, L. and Larsson Seim, A. 2013. "Earned income tax credits, unemployment benefits and wages: Evidence from Sweden," IFAU Working Paper 2013:12, Uppsala.

Bennmarker, H., E. Mellander, and B. Ockert 2009. "Do Regional Payroll Tax Reductions Boost Employment?" Labour Economics 16 (5), 480-89.

Benzarti, Youssef, Dorian Carloni, Jarkko Harju, and Tuomas Kosonen. 2017. "What Goes Up May Not Come Down: Asymmetric Incidence of Value Added Taxes," Working paper. Bewley, Truman F. 2002. Why Wages Don't Fall During a Recession. Cambridge, MA: Harvard University Press.

Bils, Mark, and Pete Klenow. 2008. "Further Discussion of Temporary Payroll Tax Cut during Recession(s)." unpublished working paper.

Blanchard, Olivier and Lawerence Summers. 1986. "Hysteresis and the European unemployment problem, NBER Macroeconomics Annual 1, 15-78.

Blinder, Alan and Don Choi. 1990. "A shred of evidence on theories of wage stickiness." Quarterly Journal of Economics 105(4), 1003-1015.

Bohm, P., and Lind, H. 1993. "Policy evaluation quality-a quasi-experimental study of regional employment subsidies in Sweden." Regional Science and Urban Economics 23, 51-65.

Bozio, Antoine, Thomas Breda, and Julien Grenet. 2017. "Incidence of Social Security Contributions: Evidence from France," Paris School of Economics Working Paper.

Brittain, John. 1972. The Payroll Tax for Social Security, (Washington, DC: Brookings Institution).

Cahuc, Pierre, Stéphane Carcillo, and Thomas Le Barbanchon. 2014. "Do Hiring Credits Work in Recessions? Evidence from France." IZA Discussion Paper No. 8330.

Campbell, Carl, and Kunal Kamlani. 1997. "The reasons for wage rigidity: evidence from a survey of firms." Quarterly Journal of Economics 112.3, 759-789. 
Card, David. 1996. "The Effects of Unions on the Structure of Wages: A Longitudinal Analysis." Econometrica 64, 957-979.

Card, David, Joerg Heining, and Patrick Kline. 2013. "Workplace Heterogeneity and the Rise of West German Wage Inequality", Quarterly Journal of Economics 128(3), 967-1015. Card, David, Joerg Heining, Ana Rute Cardoso, and Patrick Kline. 2016. "Firms and Labor Market Inequality: Evidence and Some Theory", Journal of Labor Economics forthcoming.

Card, David, Thomas Lemieux, and W. Craig Riddell. 2004. "Unions and wage inequality." Journal of Labor Research 25(4), 519-559.

Card, David, Alexandre Mas, Enrico Moretti, and Emmanuel Saez. "Inequality at work: The effect of peer salaries on job satisfaction." American Economic Review 102(6), 29813003.

Chetty, Raj, and Emmanuel Saez. 2005. "Dividend Taxes and Corporate Behavior: Evidence from the 2003 Dividend Tax Cut." Quarterly Journal of Economics 120(3), 791-833.

Chodorow-Reich, Gabriel, Laura Feiveson, Zachary Liscow, and William Gui Woolston. 2012. "Does State Fiscal Relief During Recessions Increase Employment? Evidence from the American Recovery and Reinvestment Act." American Economic Journal: Economic Policy 4(3), 118-145.

Cruces, Guillermo, Sebastian Galiani, and Susana Kidyba. 2010. "Payroll Taxes, Wages and Employment: Identification through Policy Changes." Labour Economics 17(4), 743-749.

Dagens Nyheter. 2006. "Reinfeldt vill skrota arbetsgivaravgifter för unga." August 12.

DiNardo, J., Fortin, N.M., Lemieux, T., 1996. "Labor Market Institutions and the Distribution of Wages, 1973-1992: a Semiparametric Approach." Econometrica 64 (5), 1001-1044.

Egebark, Johan. 2016. "Effects of Taxes on Youth Self-Employment and Income.', IFN Working Paper No. 1117.

Egebark, Johan and Niklas Kaunitz. 2013. "Do Payroll Tax Cuts Raise Youth Employment?", IFAU Working Paper No. 2013:27.

Egebark, Johan and Niklas Kaunitz. 2017. "Payroll Taxes and Youth Labor Demand", IFN Working Paper No. 1001, 2014 (revised June 2017).

Egebark, Johan and Niklas Kaunitz. 2017b. "Payroll Taxes and Firm Performance", IFN Working Paper No. 1175.

Elias, Ferran. 2015. "Labor demand elasticities over the life cycle: Evidence from Spain's payroll tax reforms." Columbia University PhD thesis.

Elsby, Michael. 2009. "Evaluating the economic significance of downward nominal wage rigidity. Journal of Monetary Economics, 56(2), 154169.

Farre-Mensa, Joan and Alexander Ljunqvist. 2016. "Do Measures of Financial Constraints Measure Financial Constraints?" Review of Financial Studies 29(2): 271-308.

Fazzari, Steven M., R. Glenn Hubbard, and Bruce C. Petersen. 1988. "Financing Constraints and Corporate Investment." Brookings Papers on Economic Activity 1, 141-206.

Felix, R. Alison, and James R. Hines. 2009. "Corporate taxes and union wages in the 
United States." NBER Working Paper No. 15263.

Fredriksson, Peter, and Robert H. Topel. 2010. "Wage determination and employment in Sweden since the early 1990s: Wage formation in a new setting." In R. Freeman, B. Swedenborg and R. Topel eds., Reforming the Welfare State: Recovery and Beyond in Sweden. (Chicago: University of Chicago Press), 83-126.

Fuest, Clemens, Andreas Peichl, and Sebastian Siegloch. 2017. "Do Higher Corporate Taxes Reduce Wages? Micro Evidence from Germany", forthcoming American Economic Review.

Fullerton, Don and Gilbert E. Metcalf. 2002. "Tax incidence," in: A. J. Auerbach and M. Feldstein (eds.), Handbook of Public Economics, Volume 4, chapter 26, 1787-1872 (NorthHolland: Amsterdam).

Galuscak, Kamil, Mary Keeney, Daphne Nicolitsas, Frank Smets, Pawel Strzelecki, and Matija Vodopivec. "The determination of wages of newly hired employees: Survey evidence on internal versus external factors." Labour Economics 19 (5): 802-812.

Gavrilova, Evelina, Floris Zoutman, Arnt-Ove Hopland, and Jarle Moen. 2015 "Who Pays for the Payroll Tax? Quasi-Experimental Evidence on the Incidence of the Payroll Tax." Working Paper.

Government Bill 2008/09:7. 2008. "Kraftfullare nedsättning av socialavgifter för unga", Ministry of Finance, Stockholm.

Gruber, Jonathan. 1997. "The Incidence of Payroll Taxation: Evidence from Chile," Journal of Labor Economics 15, S72-S101.

Hamermesh, Daniel S. 1979. "New Estimates of the Incidence of the Payroll Tax," Southern Economic Journal 45, 1208-1219.

Hassett, Kevin A., and R. Glenn Hubbard. 2002. "Tax Policy and Business Investment." In Handbook of Public Economics Vol. 3, edited by Alan J. Auerbach and Martin Feldstein, 1293-1343. Amsterdam: Elsevier.

Holmlund, Bertil. 1983. "Payroll Taxes and Wage Inflation: The Swedish Experience," Scandinavian Journal of Economics 85, 115.

Hubbard, R. Glenn. 1998. "Capital-Market Imperfections and Investment." Journal of Economic Literature 36(1), 193-225.

Huttunen, Kristiina, Jukka Pirttila, and Roope Uusitalo. 2013. "The Employment Effects of Low-Wage Subsidies." Journal of Public Economics 97, 49-60.

Johansen, F., and Klette, T.J. 1997. "Wage and employment effects of payroll taxes and investment subsidies." Statistics Norway Discussion Paper No. 194.

Kahn, Lisa. 2010. "The long-term labor market consequences of graduating from college in a bad economy." Labour Economics 17.2, 303-316.

Katz, Lawrence F. 1998. "Wage subsidies for the disadvantaged", in Freeman, Richard B.; Gottschalk, Peter (eds.). Generating jobs: How to increase demand for less-skilled workers. (New York, NY, Russell Sage Foundation), 21-53.

Kline, Patrick, Neviana Petkova, Heidi Williams, and Owen Zidar. 2017. "Who Profits from Patents? Rent-sharing at Innovative Firms", Working paper. 
Korkeamaki, O. and R. Uusitalo. 2009. "Employment and Wage Effects of a Payroll Tax Cut: Evidence from a Regional Experiment." International Tax and Public Finance 16, 753-772.

Kramarz, Francis and Thomas Philippon. 2001. "The Impact of Differential Payroll Tax Subsidies on Minimum Wage Employment," Journal of Public Economics, 82 (1), 115-146.

Kreiner, Claus, Daniel Reck, and Peer Skov. 2017. "Do Lower Minimum Wages for Young Workers Raise their Employment? Evidence from a Danish Discontinuity." Working paper.

Kugler, Adriana and Maurice Kugler. 2009. "Labor Market Effects of Payroll Taxes in Developing Countries: Evidence from Colombia," Economic Development and Cultural Change 57, 335-358.

Kugler, Adriana, Maurice Kugler, and Luis Omar Herrera 2017. "Do Payroll Tax Breaks Stimulate Formality: Evidence from Colombias Reform," NBER Working Paper No. 23308.

Landais, Camille, Pascal Michaillat, and Emmanuel Saez. 2017. "A Macroeconomic Approach to Optimal Unemployment Insurance: Applications." forthcoming American Economic Journal: Economic Policy.

Lazear, Edward. 1989. "Pay equality and industrial politics." Journal of Political Economy. 97(3), 561-80.

Lindbeck, Assar and Dennis Snower. 1986. "Wage setting, unemployment, and insideroutsider relations," American Economic Review, 76(2), 235-239.

Malcomson, James M. 1999. "Individual Employment Contracts." in (Eds. Ashenfelter, Orley and David Card) Handbook of Labor Economics, Volume 3B, Chapter 35, 2291-2372 (North-Holland: Amsterdam).

Manning, Alan. 2003. "Monopsony in Motion: Imperfect Competition in Labor Markets, Princeton University Press: Princeton, NJ.

Mansson, Jonas, and A. Shahiduzzaman Quoreshi. 2015. "Evaluating regional cuts in the payroll tax from a firm perspective." The annals of regional science 54(2), 323-347.

Marx, Ive. 2001. "Job subsidies and cuts in employers' social security contributions: The verdict of empirical evaluation studies." International Labour Review 140(1), 69-83.

Medlingsinstitutet 2015. "Avtalsrörelsen och lönebildningen år 2015." Medlingsinstitutet, Stockholm.

Neumark, David. 2013. "Spurring Job Creation in Response to Severe Recessions: Reconsidering Hiring Credits." Journal of Policy Analysis and Management 32(1), 142-71.

OECD. 2016. "Revenue Statistics 1965-2015" (Paris: Organisation for Economic Cooperation and Development).

OECD. 2017. "Taxing Wages 2017" (Paris: Organisation for Economic Cooperation and Development).

OECD. 2017b. Employment database-Labour market policies and institutions, (Paris: Organisation for Economic Cooperation and Development).

Oreopoulos, Philip, Till Von Wachter, and Andrew Heisz. 2012. "The short-and 
long-term career effects of graduating in a recession." American Economic Journal: Applied Economics 4.1, 1-29.

Pencavel, John H. 1991. Labor Markets under Trade Unionism: Employment, Wages, and Hours. (Cambridge, MA. Basil Blackwell).

Piketty, Thomas. 1997. "La Redistribution Fiscale face au Chômage", Revue Française d'Economie, 12, 157-201.

Pissarides, Christopher A. 2000. Equilibrium Unemployment Theory. 2nd edition, Cambridge, MA: MIT Press.

Rogerson Richard and Johanna Wallenius. "Micro and Macro Elasticities in a Life Cycle Model with Taxes." Journal of Economic theory. 144(6), 2277-92.

Rosen, Sherwin. 1985. "Implicit Contracts: A Survey," Journal of Economic Literature 23(3),1144-1175.

Saez, Emmanuel, Manos Matsaganis and Panos Tsakloglou. 2012. "Earnings Determination and Taxes: Evidence from a Cohort Based Payroll Tax Reform in Greece," Quarterly Journal of Economics 127(1), 493-533.

Scherer, Clovis. "Payroll tax reduction in Brazil: Effects on employment and wages." ISS Working Paper Series/General Series No. 602.

Schoefer, Benjamin. 2016. "The Financial Channel of Wage Rigidity, Working Paper.

Shimer, Robert. 2004. "The consequences of rigid wages in search models, Journal of the European Economic Association, 2(2-3), 469-479.

Skedinger, Per. 2014. "Effects of Payroll Tax Cuts for Young Workers," in eds. Michael Rosholm and Michael Svarer, Nordic Economic Policy Review: Consequences of youth unemployment and effectiveness of policy interventions 1 , Norden.

Stole, Lars and Jeffrey Zwiebel. 1996. "Intra-firm bargaining under non-binding contracts, The Review of Economic Studies, 63(3), 375-410.

Congressional Budget Office. 2010. "Policies for Increasing Economic Growth and Employment in 2010 and 2011. " January.

Congressional Budget Office. 2011. "Policies for Increasing Economic Growth and Employment in 2012 and 2013." November.

US Congressional Budget Office. 2016. "The Distribution of Household Income and Federal Taxes, 2013", US Congressional Budget Office report, Washington DC.

Weinzierl, Matthew. 2011. "The surprising power of age-dependent taxes, The Review of Economic Studies, 78(4), 1490-1518.

Yagan, Danny. 2015. "Capital Tax Reform and the Real Economy: The Effects of the 2003 Dividend Tax Cut." American Economic Review 105 (12): 3531-63.

Zwick, Eric and James Mahon. 2017. "Tax Policy and Heterogeneous Investment Behavior," American Economic Review 107(1): 217-48. 
Figure 1: Payroll Tax in Sweden: Tax Rate and Administration

(a) Preferential payroll tax rate for young workers

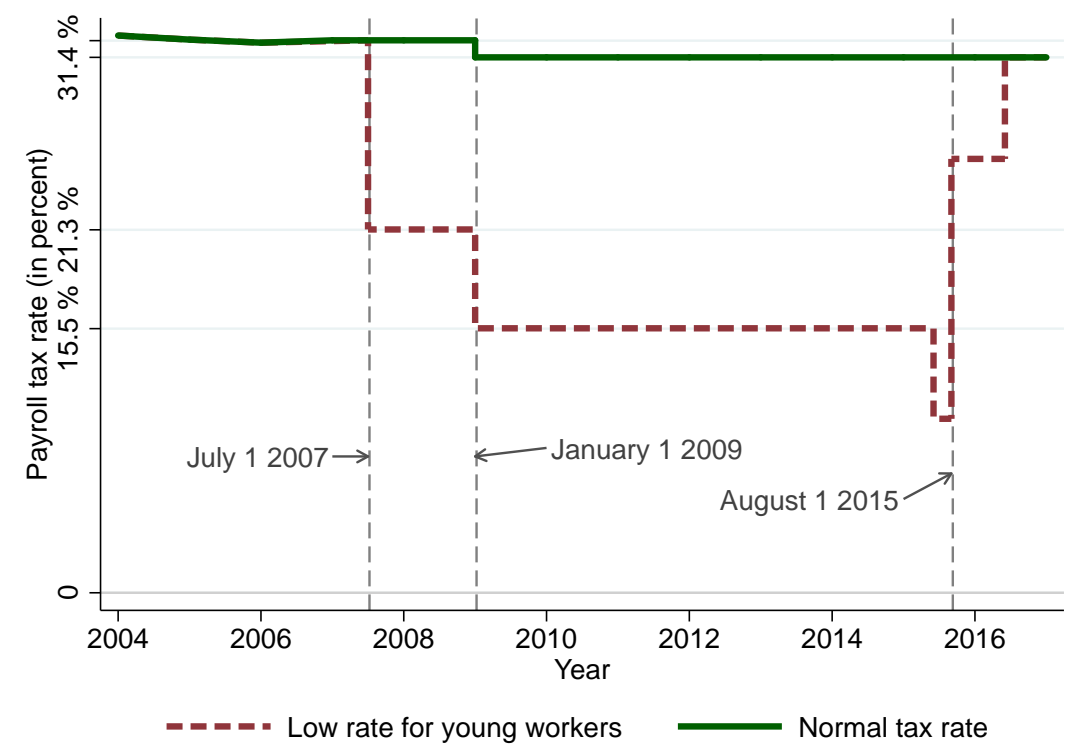

(b) Payroll tax software for employers

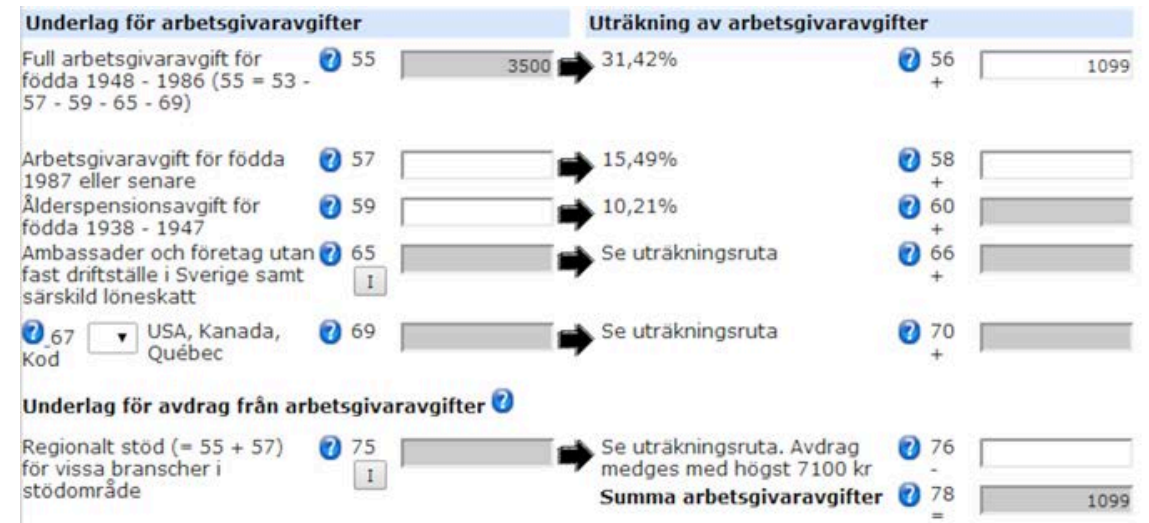

Notes: The top panel depicts the normal payroll tax rate (solid line) and the lower rate for young workers (dashed line) in Sweden over time. The payroll tax rate in Sweden applies to the totality of earnings and is nominally fully paid by employers. The first reform lowered the payroll tax rate for earnings received on or after July 1, 2007 for all workers turning 19 to 25 during the calendar year. The second reform further lowered the tax rate for earnings received on or after January 1, 2009 for all workers turning 26 or less during the calendar year. The reform was repealed in three steps on May 1, 2015, August 1, 2015, and on June 1, 2016. In the first step, the tax rate was actually lowered for workers aged 23 and below (remained $15.49 \%$ for ages $24-25$, and increased to $31.42 \%$ for workers aged 26). In the second step, all workers aged 25 and less had their taxes increased to $25.46 \%$ and finally, in June 2016, they were increased to the normal rate of $31.49 \%$. The bottom panel illustrates the reporting of monthly earnings and payroll taxes by employers for year 2013, by depicting a snapshot of the government-provided software. Employers specifically type in the wage payments made to employees born in different cohort categories and the program automatically calculates the payroll taxes due, ensuring almost perfect take-up. Earnings for employees born in 1948-1986 are reported in box 55 and face the normal tax rate of $31.42 \%$. Earnings for employees born in 1987 or after are reported in box 57 and face the lower $15.49 \%$ tax rate (a lower rate of $10.21 \%$ applies to older workers born in 1947 or earlier in box 59, which is not part of this study). 
Figure 2: The Effect of the Payroll Tax Cut on Average Wages by Annual Cohorts

(a) Monthly net wage (wage earnings net of the payroll tax)

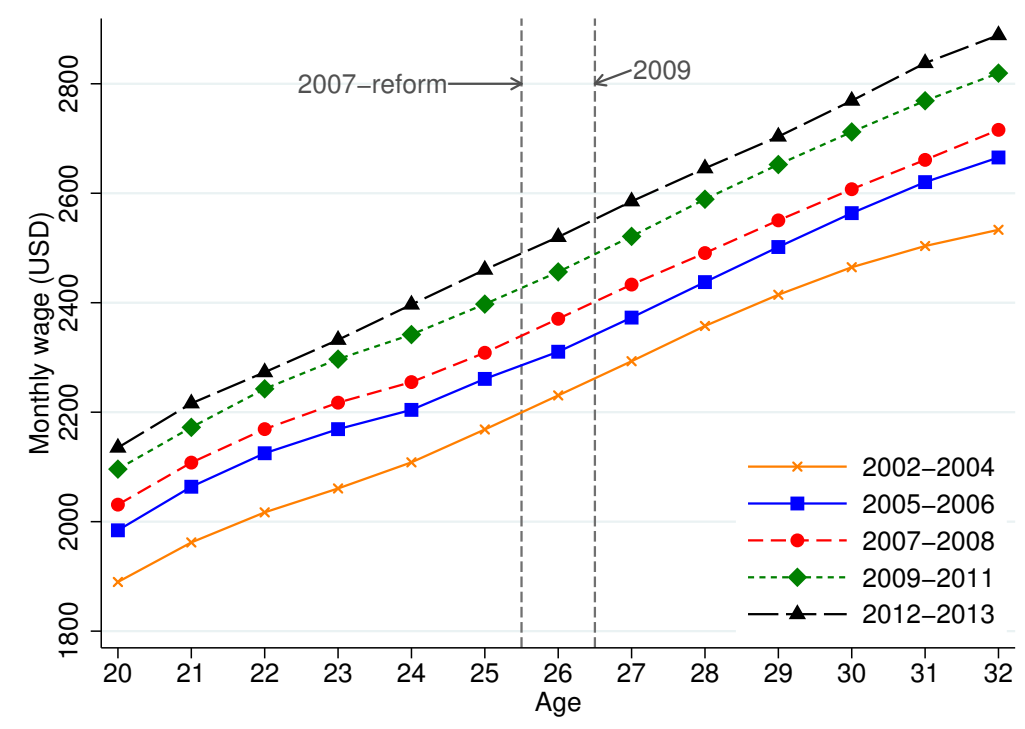

(b) Monthly gross wage (wage earnings gross of the payroll tax)

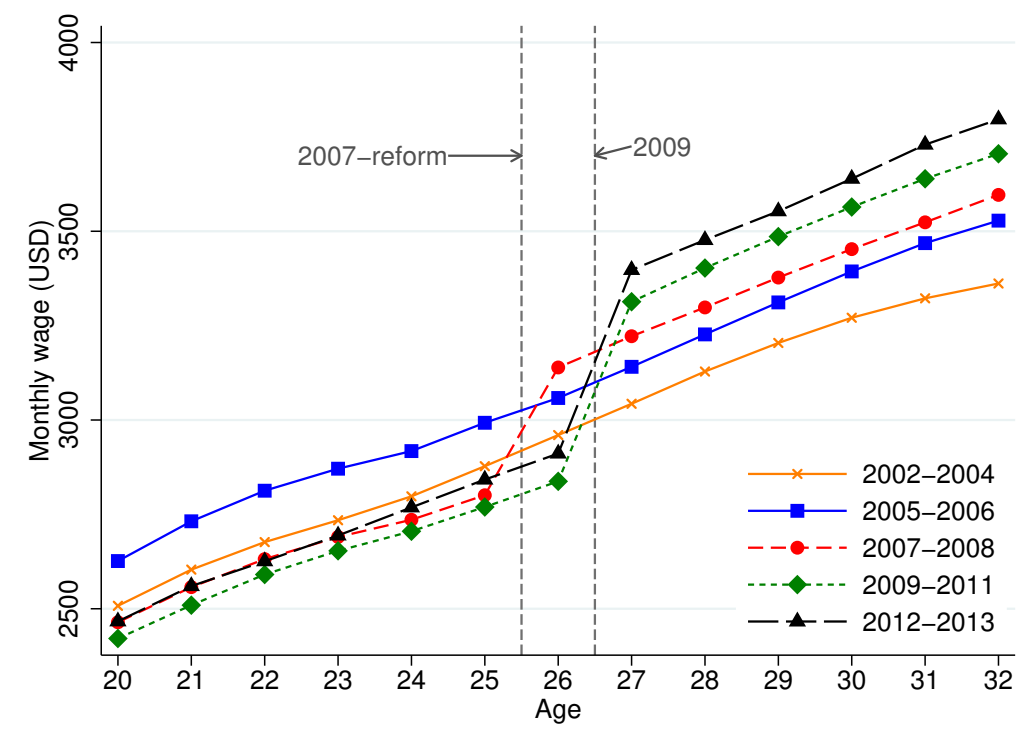

Notes: This figure depicts the average monthly wage in Sweden by age for different time periods using the Structure of Earnings Survey data for wage earners. The survey measures wages mostly for the month of September (with some measurements in October and November). The top panel depicts net wages defined as monthly wage earnings net of payroll taxes. The bottom panel depicts gross wages defined as monthly wage earnings gross of payroll taxes. The wage is defined as the full-time equivalent contracted monthly wage. It is adjusted for inflation (base-year 2003) and converted to US dollars using an exchange rate of 8.9 SEK/USD (as of 4/18/2017). Age is defined as the age turned during the calendar year, which is the relevant concept for the payroll tax cut. The two dashed vertical lines depict the age thresholds under which the payroll tax cuts apply in 2007-08 and 2009-14 respectively. The sample includes all employees in the Structure of Earnings Survey which covers all industrial sectors (see Section 3.2 for more details). The top panel shows that net wages are continuous at the age thresholds and the bottom panel shows that gross wages are discontinuous. This implies that employers do not adjust wages by age in response to the payroll tax cut even in the medium-term 5-6 years after the reform. Corresponding estimates are provided in Table 1. 
(a) Monthly net wage by month of birth

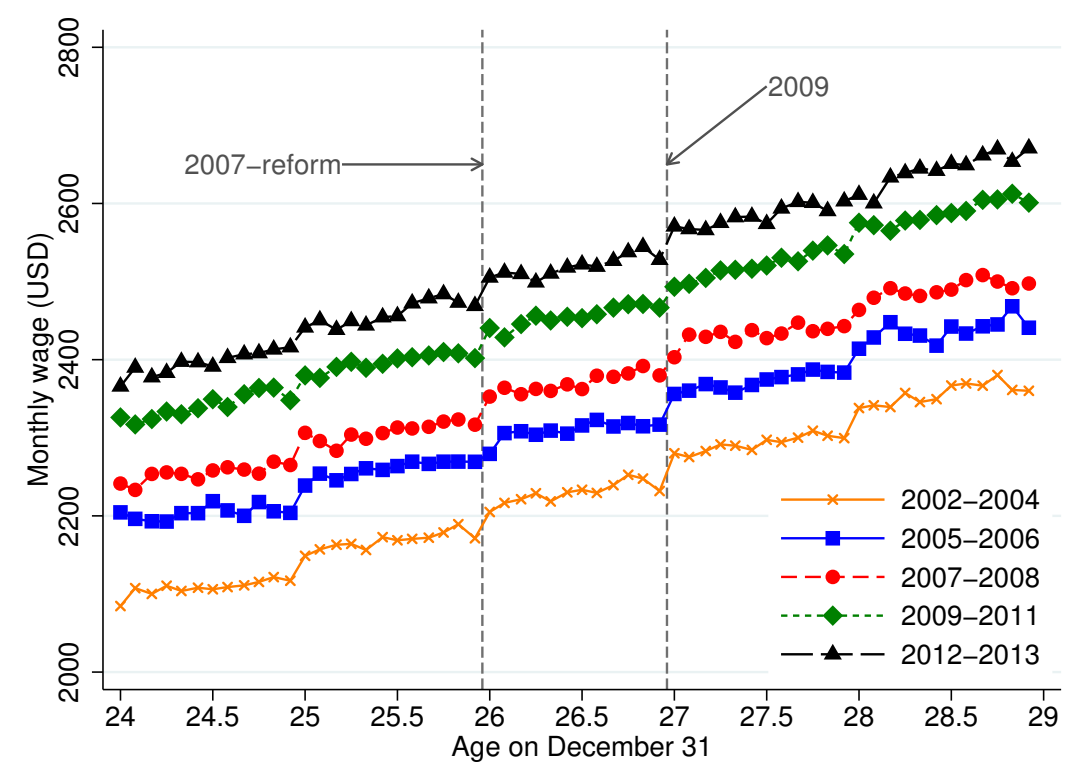

(b) Monthly gross wage by month of birth

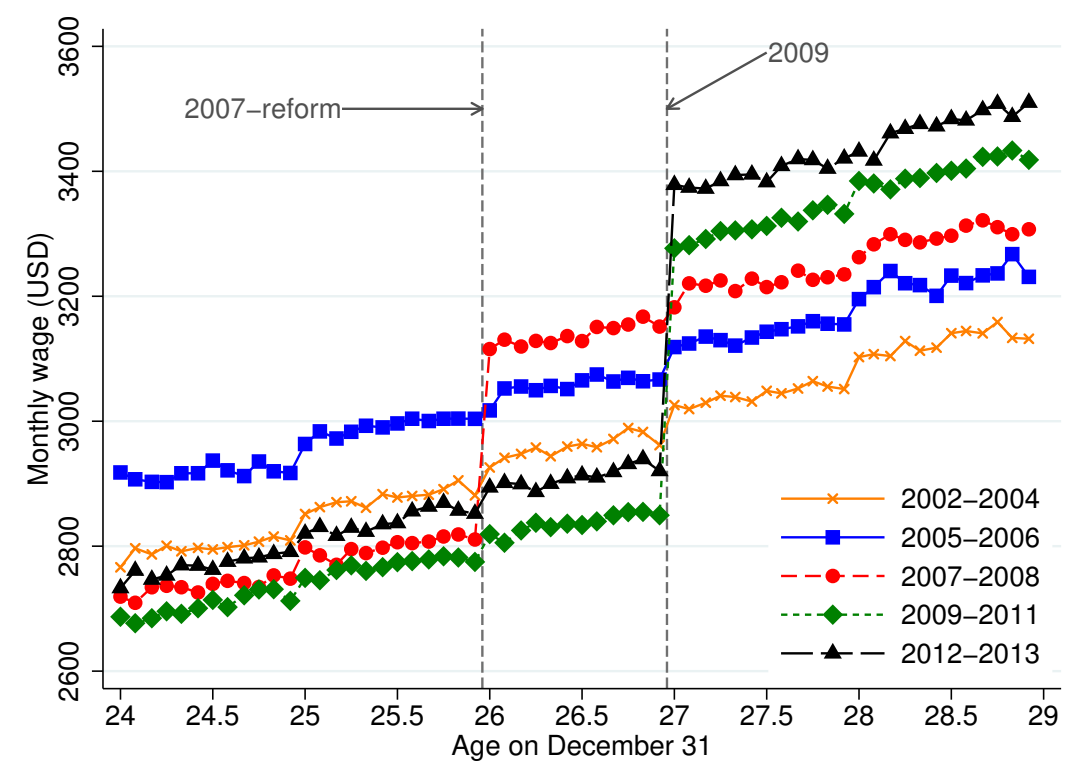

Notes: This figure replicates Figure 2 but zooming in by month of birth instead of year of birth. For comparison with Figure 2 , for any given year $t$ when the wage is measured, monthly birth cohorts are translated into monthly age bins as of end of year $t$. For example, 27 in 2009 means being born in January 1982 (and not eligible for the tax cut). 26+11/12 in 2009 means being born in December 1983 and eligible for the tax cut. The top panel depicts net wages defined as monthly wage earnings net of payroll taxes. The bottom panel depicts gross wages defined as monthly wage earnings gross of payroll taxes. The two dashed vertical lines depict the age thresholds under which the payroll tax cuts apply in 2007-08 and 2009-14 respectively. The top panel shows that the wages are continuous at the age thresholds. There are small positive discontinuities at each year threshold as the school system is based on calendar year of birth (and hence people born in December of year $t$ are in general 1 year in advance in their career path relative to people born in January of year $t+1$ ). The bottom panel shows that the gross wage is discontinuous at the tax reform age thresholds. Corresponding estimates are provided in Table 1. 
(a) Top $20 \%$ of the wage distribution

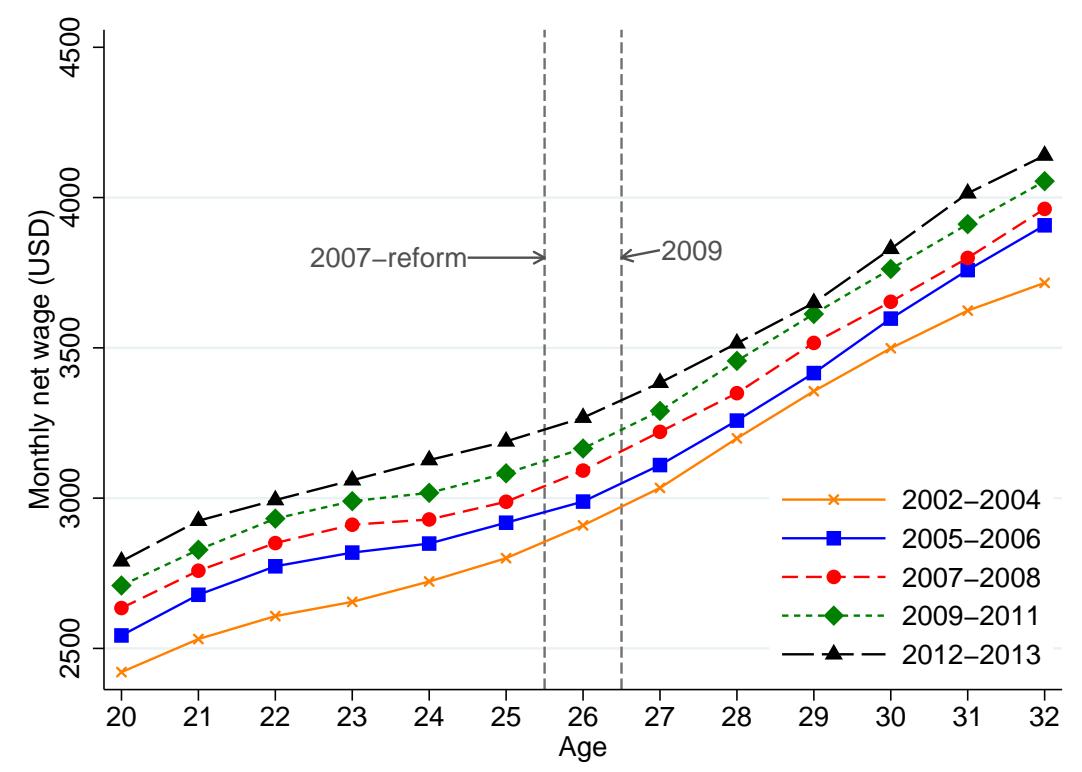

(b) New hires and job switchers

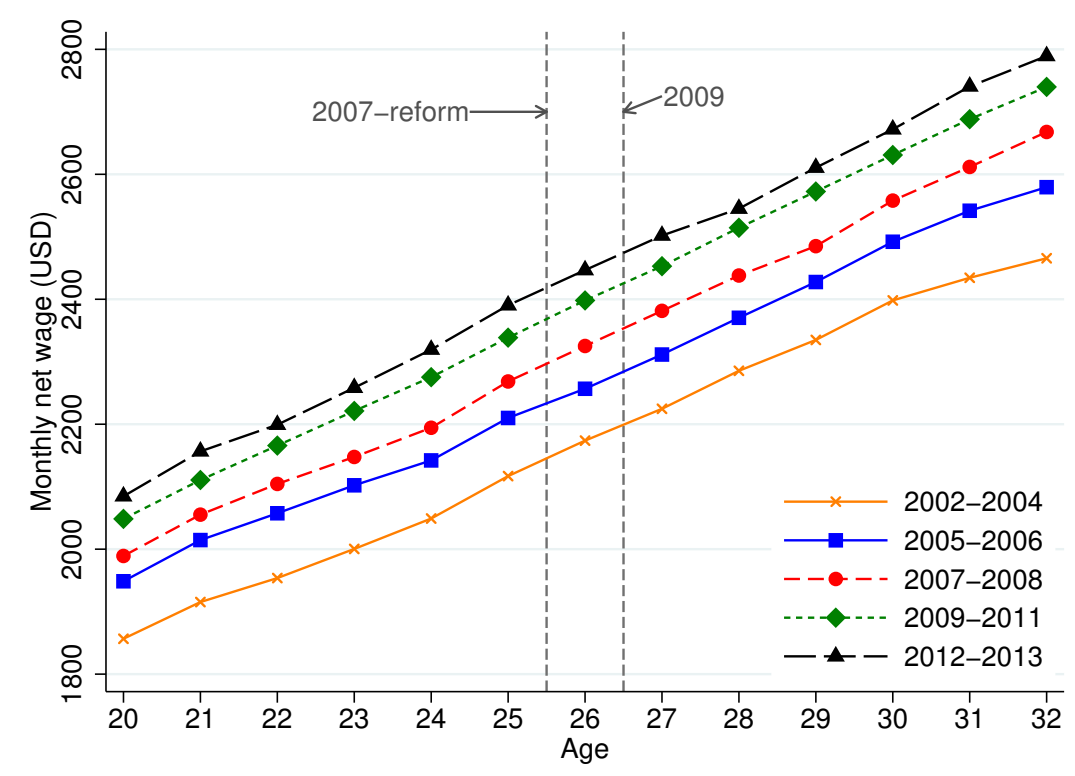

Notes: This figure depicts the average monthly net wage (i.e., exclusive of the payroll tax) in Sweden by age for different time periods using the Structure of Earnings Survey data generally for the month of September (with some measurements in October and November) of each year. We consider two specific subsamples. The top panel displays the average wage within the top $20 \%$ of the wage distribution conditional on age and year. This top group is not affected by the union negotiated wage floors. The bottom panel shows the average wage (measured in September) for new hires or job switchers, defined as having a new firm identifier as the main (i.e., highest paying) employer relative to September of the previous year. It includes both job-to-job transitions as well as new hires among the non-employed. Both wage series are inflation adjusted (base-year 2003) and converted to USD using an exchange rate of $8.9 \mathrm{SEK} / \mathrm{USD}$ (as of 4/18/2017). Both graphs show no discontinuity in wages at the age thresholds implying that the absence of incidence on workers is not due to union bargained wage floors (top panel) or rigid wages within a job spell (bottom panel). Corresponding estimates are provided in Table 1. 


\section{Figure 5: Net and Gross Monthly Wage Earnings Densities}

(a) Monthly net wage earnings (exclusive of payroll tax)

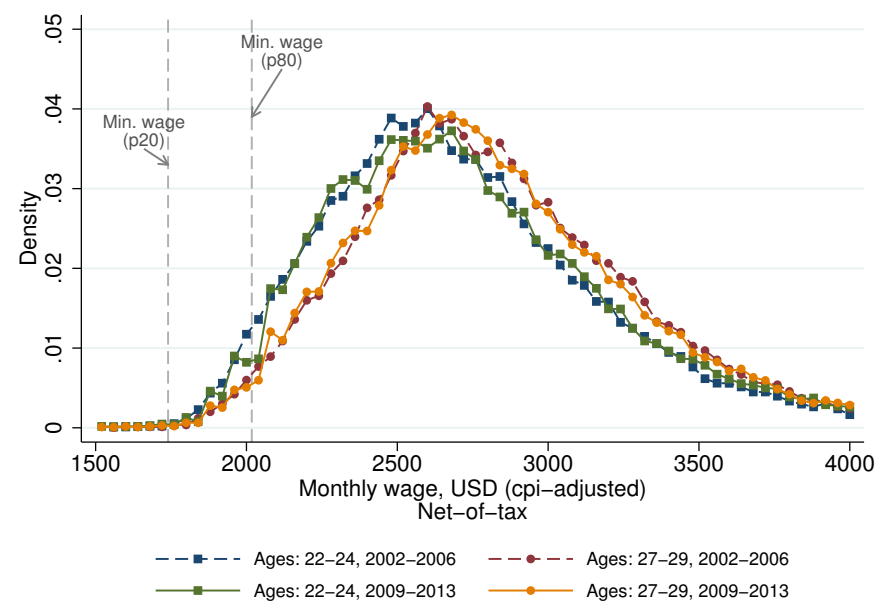

(b) Monthly gross wage earnings (inclusive of payroll tax)

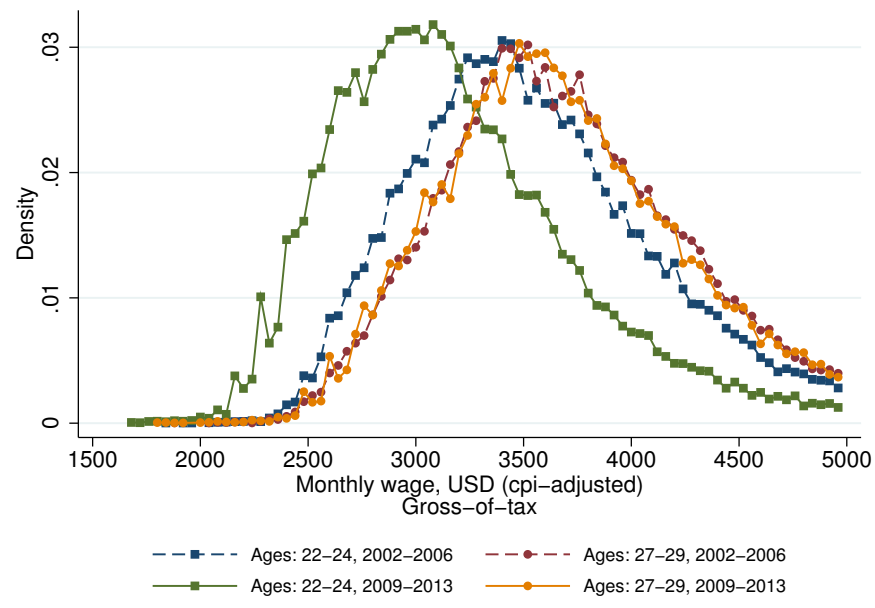

Notes: This figure depicts the monthly wage earnings densities for young workers (aged 22-24) affected by the payroll tax cut in (in squares) and for slightly older workers (aged 27-29) not affected by the payroll tax cut (in circles) both pre-reform (pooling years 2002-2006 in dashed lines) and post-reform (pooling years 2009-2013 in solid lines). The top panel depicts the densities for net wages. The bottom panel depicts the densities for gross wages. Wage earnings densities are measured typically in September (and sometimes October-November). Wages are adjusted for annual wage growth by first constructing a wage index based on the older individuals. Using this index, we deflate all workers' wages to 2013 values. The top panel shows that the net wage earnings densities do not change from pre-reform to post-reform both for young treated workers and for the control slightly older workers. In particular, even the earnings density substantially above the minimum wages for young workers is unaffected. The top panel depicts in vertical lines the 20th and 80th percentiles of minimum wages (as there are many minimum wages in Sweden based on industry, occupation, and tenure). This shows that the vast majority of young workers are paid above the minimum wage. The bottom panel correspondingly shows that the labor cost density is shifted uniformly from pre-reform to post-reform for young treated workers. 
Figure 6: The Effect of the Payroll Tax Cut on Employment

(a) Employees to labor force ratio

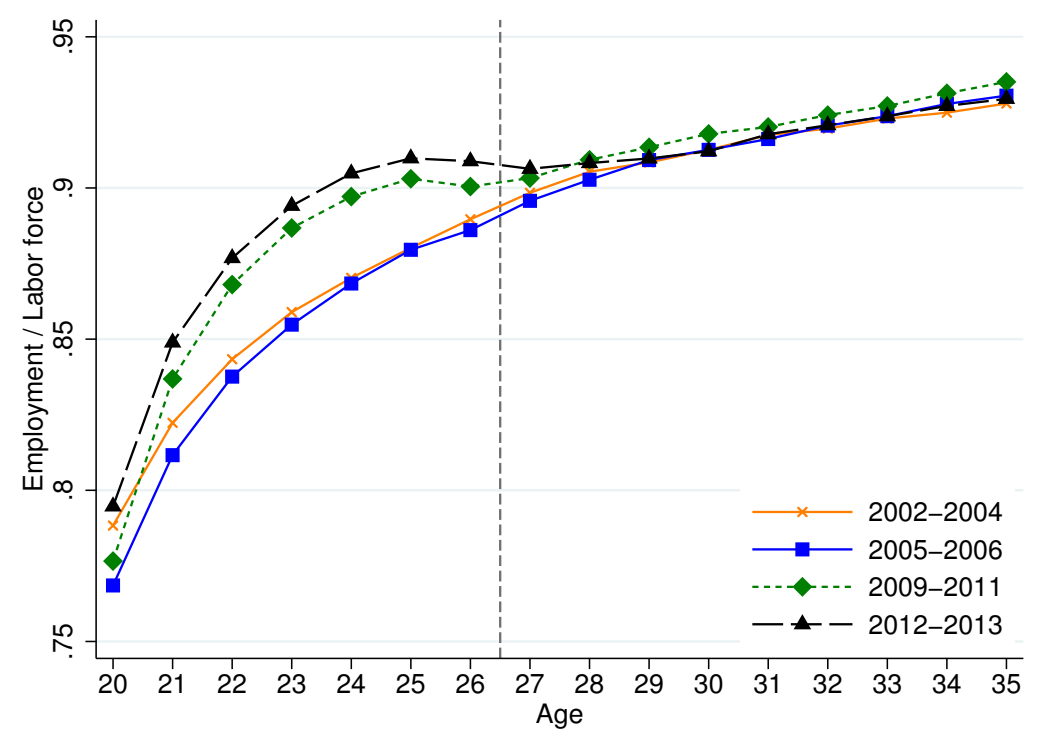

(b) Employees to labor force ratio: high vs. low unemployment regions

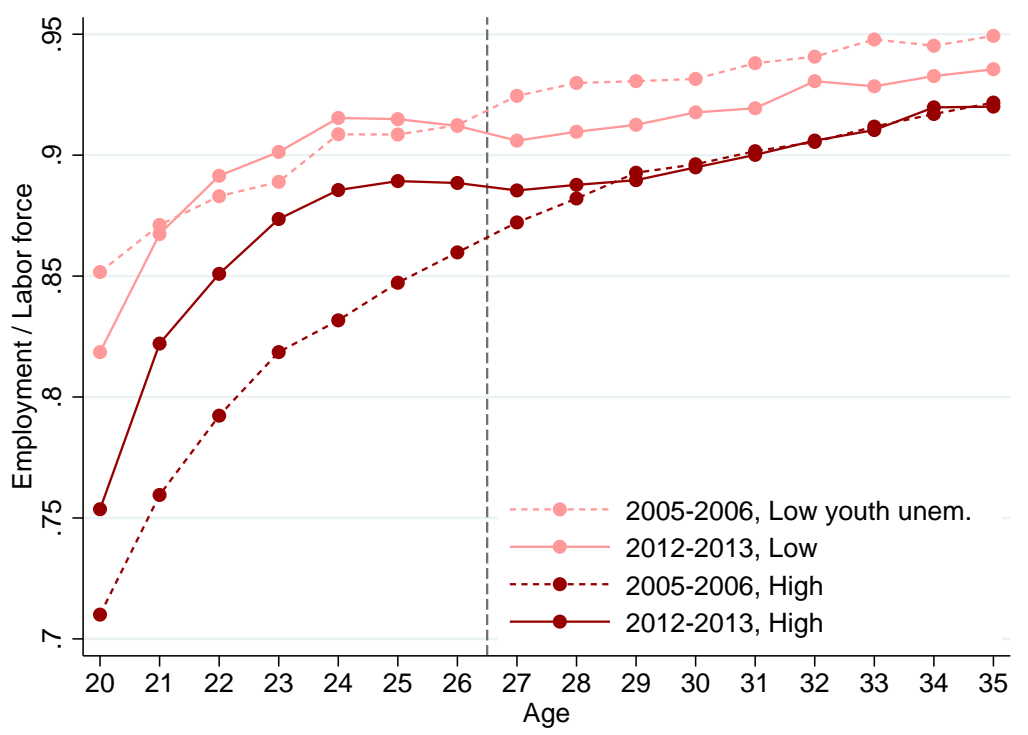

Notes: The top panel depicts the employees to labor force ratio by age and time periods. The employees numerator is all residents employed with annual wage earnings above a small annual threshold (\$4,940 in 2012 and adjusted for inflation in other years). The labor force denominator is defined as all residents who are either (i) employees as just defined for the numerator; (ii) unemployed defined as having registered with the Unemployment Office at any point during the year. The bottom panel shows the share of employees in the labor force by age, pre-reform (2005-2006, in dashed line) and post-reform (2012-2013, in solid line) separately for bottom quintile regions with the lowest 2006 youth unemployment rate (10.5-12.4\%, in light color) and top quintile regions with highest 2006 youth unemployment (20-23.3\%, in dark color). See Appendix Figure A7 for a map of the regions. The top panel shows a strong effect of the reform in increasing the employment rate of young targeted workers (corresponding estimates in Table 2). The bottom panel shows that the employment effects of the payroll tax cut appear much larger in the high unemployment regions than in the low unemployment regions (corresponding estimates in Table 3). 
Figure 7: Employment Effects and Hiring vs. Separation Decomposition

(a) Employment effects by age

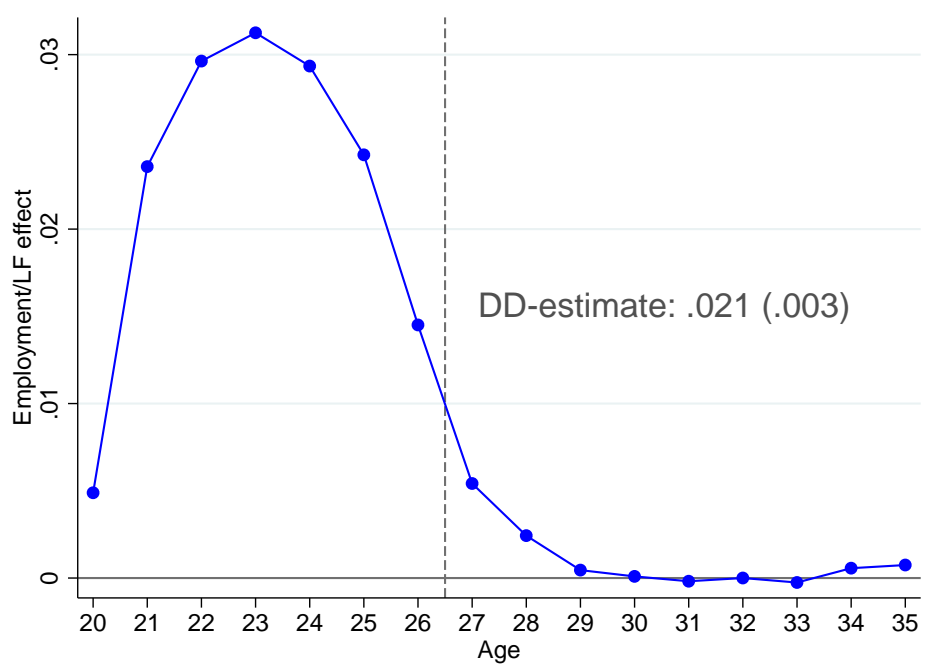

(b) Employment effects by age: hiring vs. separation

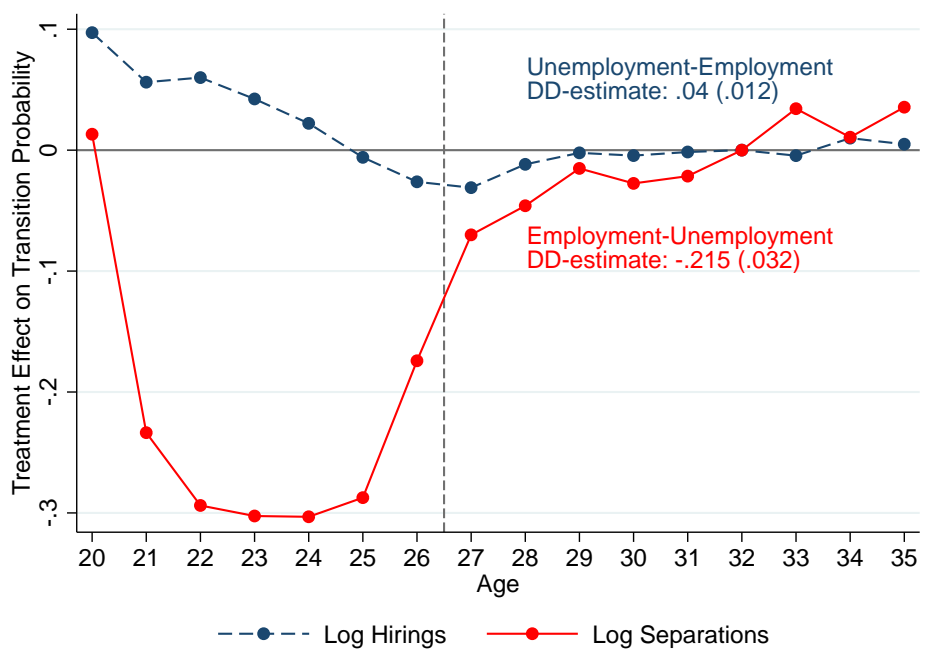

Notes: The top panel depicts the change in employment rates pre-reform (2002-6) vs. post-reform (2009-2013) by age. Using the time series depicted in Figure 6, we regress employment / LF on age dummies, period dummies and age dummies interacted with a dummy for the post-reform period for ages 20-35. The last set of dummies are shown in this graph (age 32 is the omitted category). The reported DD-estimate is simply the difference between the treatment group (age group 20-26) and the control group (age group 27-35) weighted by the labor force at each age in 2005-6 (corresponding to first row of Table 2). The bottom panel decomposes these employment effects into a hiring effect and a separation effect. The hiring effect is estimated as follows. We compute the share of unemployed individuals in year $t-1$ who find a job in year $t$ and estimate the treatment effect on the $\log$ of that share using the same specification as for the top panel. The separation effect is estimated as follows. We compute the share of employed individuals in year $t-1$ who transition into unemployment in year $t$ and again estimate the reform-effect on the log of that share. The reported DD-estimates are the differences between the treatment and control group before (2002-2006) and after the reform (2009-2013). The bottom panel shows that almost $4 / 5$ of the employment effects from the top panel are due to a reduction in the separation rate of young workers and that about $1 / 5$ of the employment effects from the top panel are due to an increase in the hiring rate of young workers. 


\section{Figure 8: Dividing Firms by Pre-Reform Share Young in Payroll}

(a) Density of share young in payroll across firms in 2006

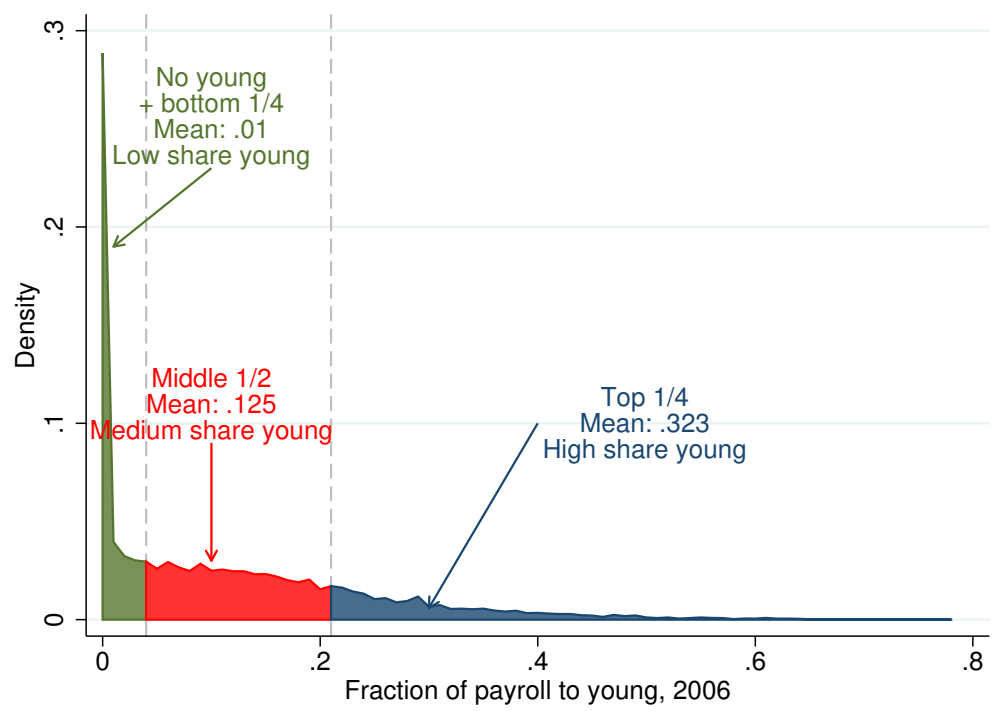

(b) Evolution of share young, by 2006 share young groups

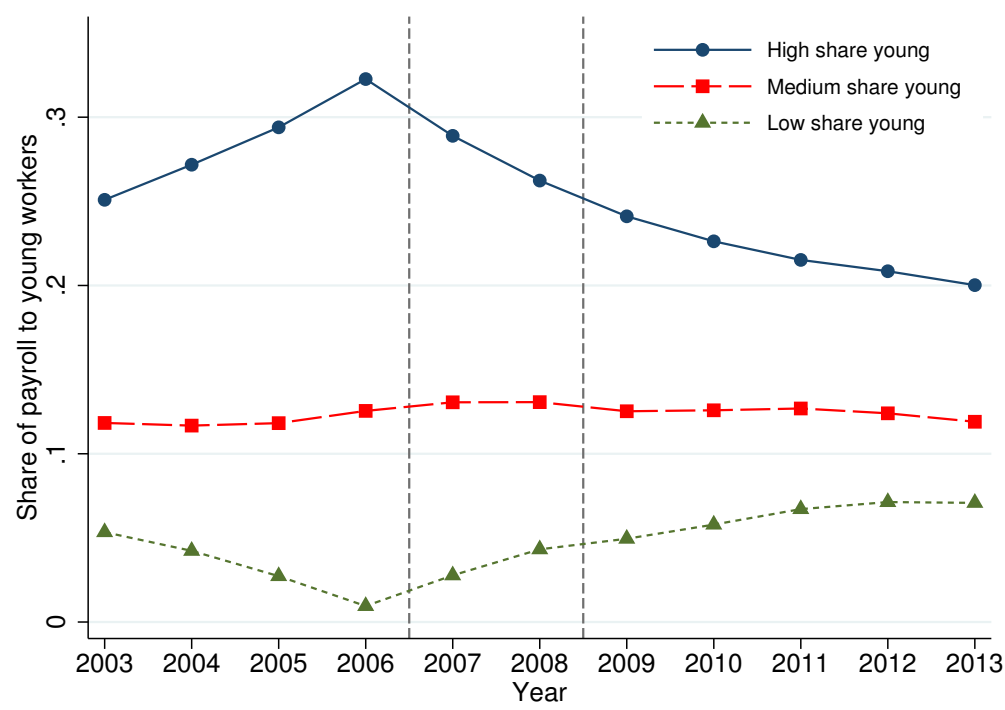

Notes: This figure considers a balanced panel of firms active in every single year from 2003 to 2013 and with more than 3 employees in each year. We only include corporations (excluding the public sector, and foreign owned corporations). We split firms into 3 groups based on the share of payroll paid to young workers (aged 19-25) in 2006 that we call share young. The top panel depicts the density distribution of share young. The high share young group (in blue) are firms in the top quartile share young (among firms with at least one young worker in 2006). The medium share young group (in red) are firms in the middle two quartiles share young (among firms with at least one young worker in 2006). The low share young is the rest (firms in the bottom quartile share young and firms with zero young workers depicted as a spike at zero in the figure). The bottom panel depicts the longitudinal average share young in each year for each of the three groups of firms. The spike/trough pattern around 2006 is due to mean reversion: firms with high share young in 2006 tend to have a lower share young before and after. There is substantial persistence in the share young across years implying that the tax windfall received by firms with a large share young in 2006 persists in subsequent years. 


\section{Figure 9: Firm-level Effects of Payroll Tax Cut on Number of Employees}

(a) Growth in employees over time by 2006 share young

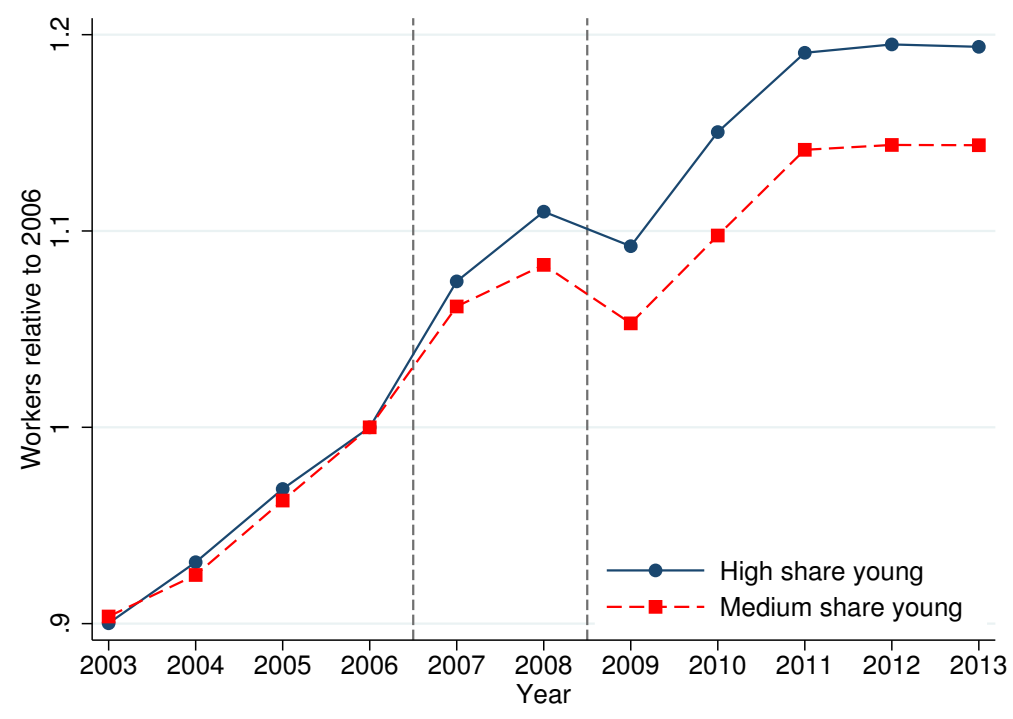

(b) Treatment Intensity: splitting further the high share young group

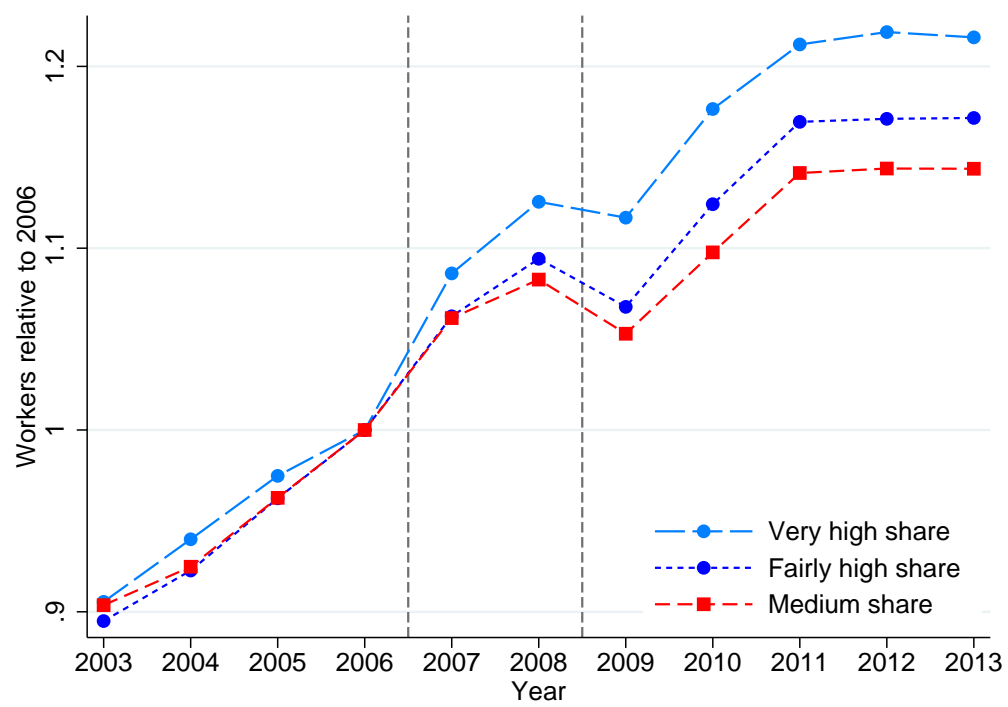

Notes: This figure depicts the (unweighted) average number of full-time-employees (normalized for each firm to the 2006 number of employees) across a balanced sample of firms over time by groups of firms defined by share young in payroll in 2006 (see Figure 8). In the top panel, we consider two groups as in Figure 8 (1) firms in the middle two quartiles of share young in 2006 (medium share young, 12.5\% on average in 2006) and (2) firms in the top quartile of share young in 2006 (high share young, 32.3\% on average in 2006). In the bottom panel, we further split the top quartile group into two equally sized groups: (2a) firms in the top 1/8 of share young in 2006 (very high share young, 39.6\% on average in 2006), (2b) firms in the next 1/8 of share young in 2006 (fairly high share young, 25\% on average in 2006). Both panels show that there is a parallel trend in the growth of employees before 2006 across groups. After the reform, firms with a higher share young in 2006 experience a faster growth of employees. The bottom panel shows that this faster growth is quantitatively related to the initial share young in 2006. This implies that the payroll tax cut stimulated employee growth among the most treated firms. Corresponding estimates are provided in Table 5. 
Figure 10: Firm-level Effects of Payroll Tax Cut on Business Growth

(a) Capital: Total Assets

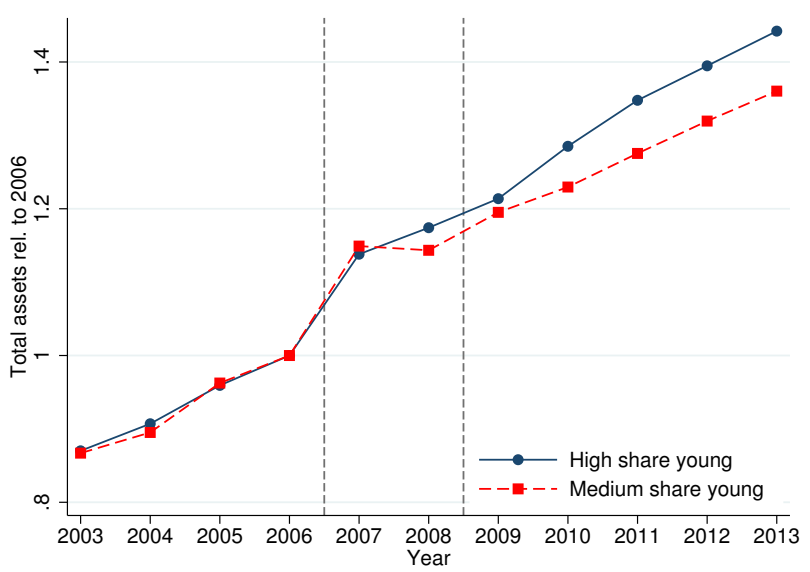

(c) Value Added

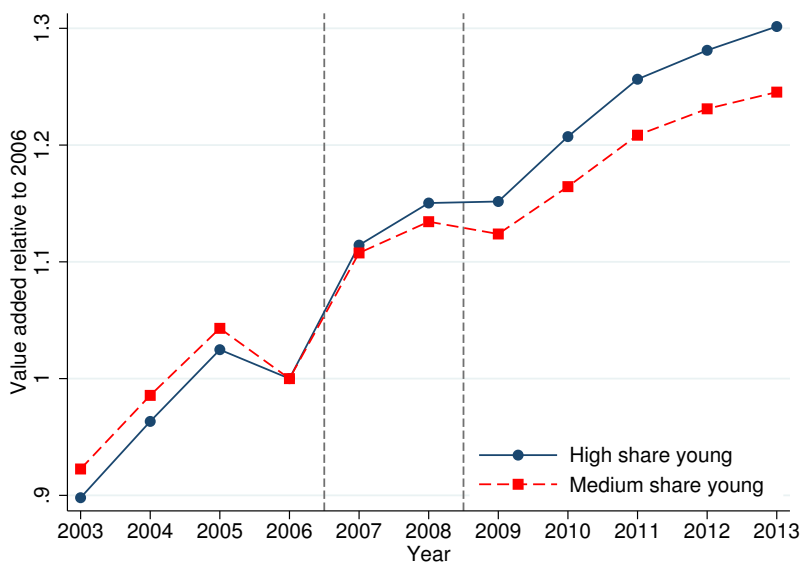

(b) Sales

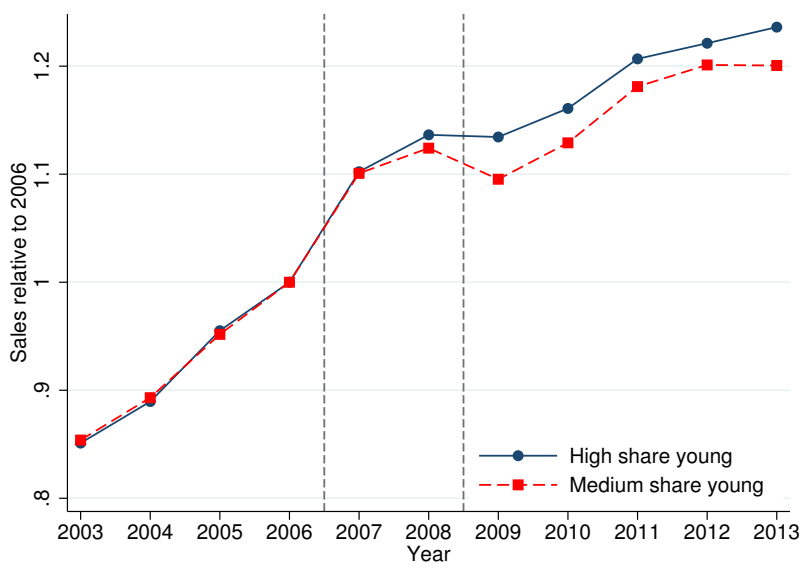

(d) Profits

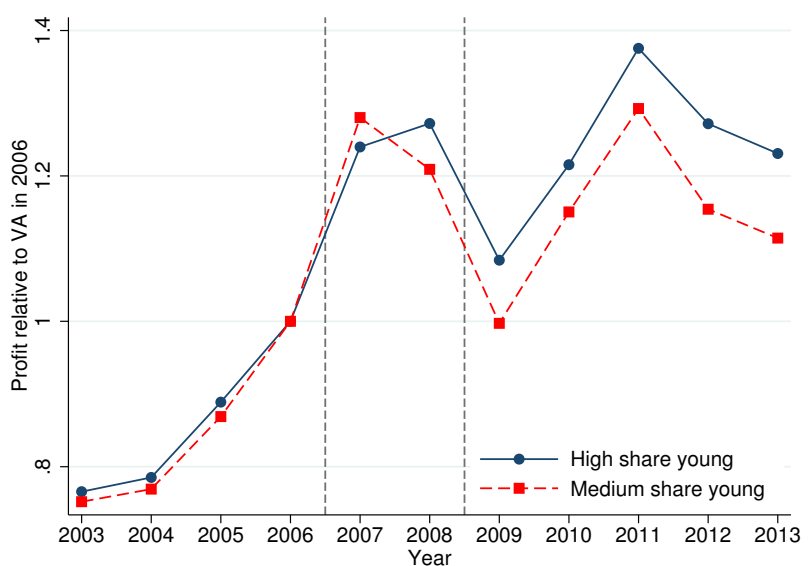

Notes: This figure traces out various longitudinal outcomes of firms (relative to 2006) across a balanced sample of firms (operating in all years 2003-2013 with more than 3 employees in all years) by groups of firms. In each panel, we consider two groups of firms as in Figure 8. (1) firms in the middle two quartiles of share young in 2006 (medium share young) and (2) firms in the top quartile of share young in 2006 (high share young). Each panel depicts the (unweighted) average of the following outcomes (normalized for each firm to the 2006 value) over time by groups of firms: (a) total assets, (b) total sales, (c) value added (defined as sales minus all purchases of intermediate goods and capital goods), (d) profits defined as EBIT (earnings before interest and taxes). For Panel (d), as profits can be negative, we normalize profits by value added in the firm in 2006 and then adjust the two series multiplicatively (so that they are normalized to 1 in 2006). All four panels show that the two groups of firms have parallel pre-reform trends and the group with the largest young share (and hence largest tax windfall) experiences faster growth in assets, sales, value added, and profits after the reform. Corresponding estimates are provided in Table 5 . 
Figure 11: Effect of Payroll Tax Cut on Firm Survival

(a) Fraction of firms operating (unweighted)

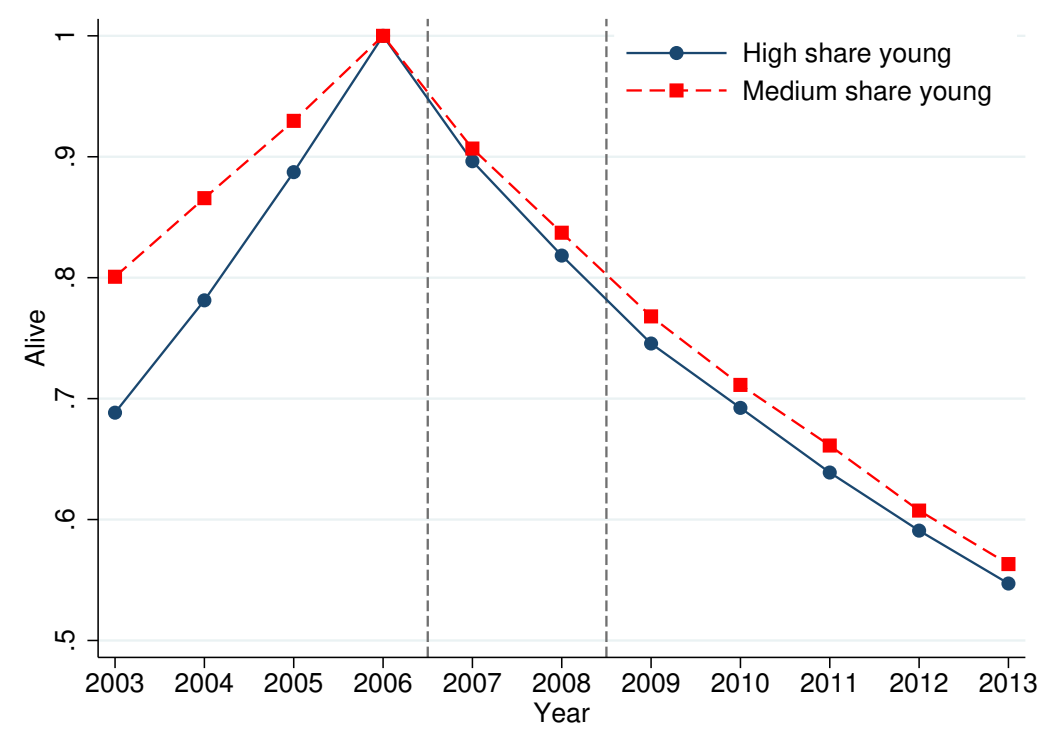

(b) Fraction operating after DFL reweighting by age in 2006

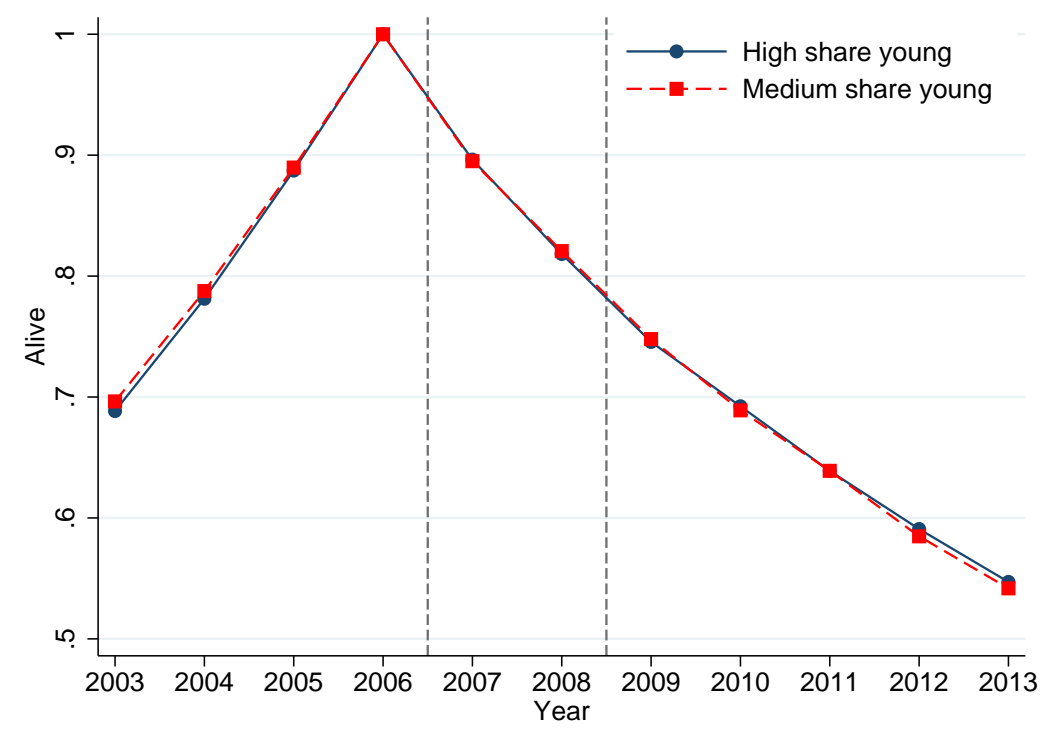

Notes: The figure analyses firm survival using the sample of all firms present in 2006 and operating with more than 3 workers in 2006, regardless of whether they operate in other years. We consider again firms with a high share young in 2006 vs. firms with a medium share young in 2006. Panel (a) plots the fraction of firms operating in each group for years 2003 to 2013. By definition of the sample, this fraction is equal to one in 2006. The panel shows that firms with high share young are younger (less likely to operate before 2006) and slightly less likely to survive (less likely to operate after 2006) than firms with medium share young. Therefore, to be able to analyze compellingly whether the reform affects survival, in Panel (b) we DFL reweigh firms in the medium share young group to align their 2006 age distribution to the high share young group. We do so by partitioning each group into 8 age based subsets and reweighting each subset so that, after reweighting, the fraction of firms in each age subset is equal across the two groups. We then plot again fraction of firms operating in each group for years 2003 to 2013 in Panel (b). The panel shows that post-reform survival rates across the two groups are identical suggesting that the reform does not differentially affect survival. 
Figure 12: Firm-level Effects on Net Wages, Payroll taxes, and Gross Wages per Worker

(a) Net wage earnings per worker

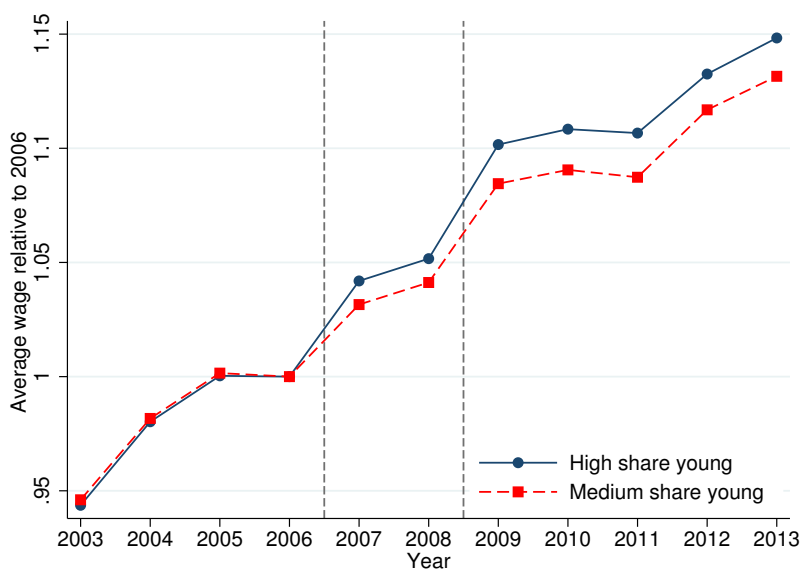

(b) Payroll tax per worker

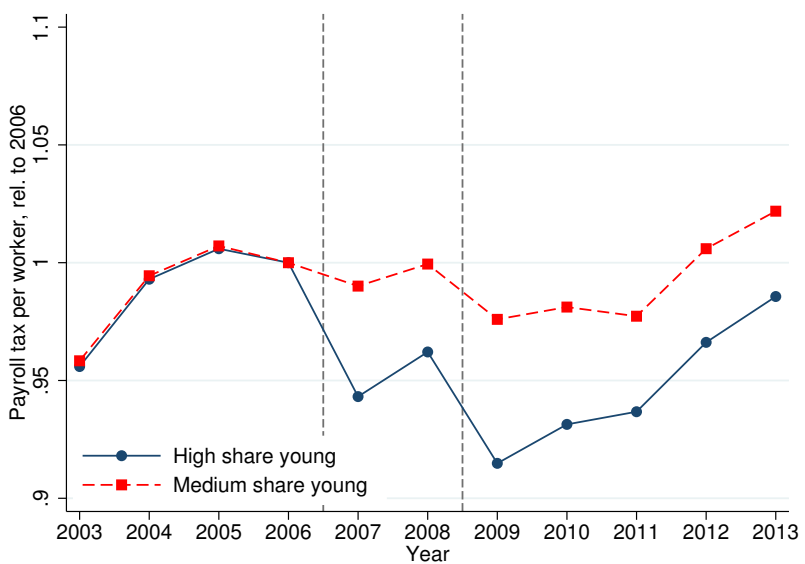

(c) Gross wage earnings per worker

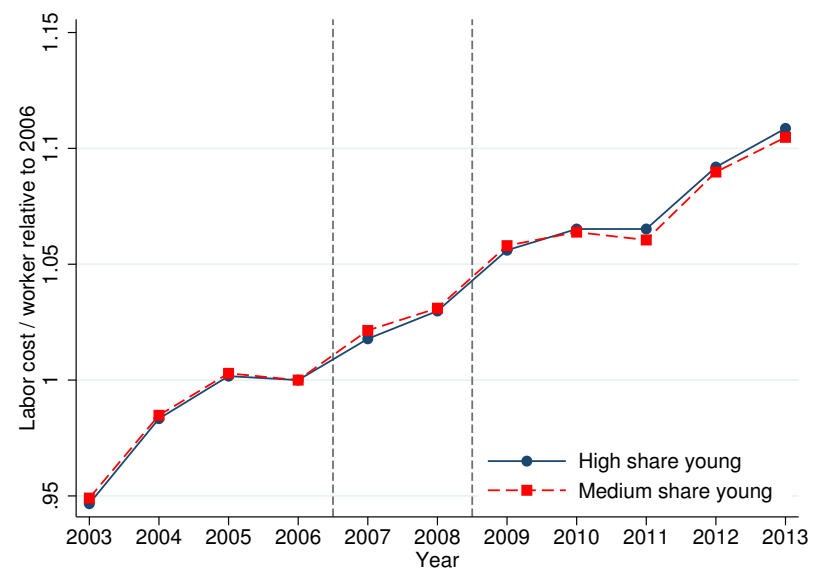

Notes: This figure traces out outcomes of net wage earnings, payroll taxes, and gross wage earnings per worker (relative to 2006) across a balanced sample of firms over time by groups of firms. In each panel, we consider two groups of firms as in Figure 8 (1) firms in the middle two quartiles of share young in 2006 (medium share young) and (2) firms in the top quartile of share young in 2006 (high share young). Panel (a) depicts the evolution (relative to 2006) of the average net wage earnings per worker in the firm (i.e., earnings net of payroll taxes). Panel (b) depicts the evolution (relative to 2006) of the average payroll taxes per worker in the firm. Panel (c) depicts the evolution (relative to 2006) of the average gross wage earnings per worker in the firm (i.e., earnings gross of payroll taxes). Averages are taken across each group of firms in the balanced panel (but the composition of workers in each firm vary from year to year). The figure shows that firms with the largest young share (and hence the largest tax windfall) experience a faster increase in net wage earnings per worker, a lower payroll tax per worker, and in net experience no faster increase in gross wage earnings. This suggests that the windfall payroll tax cut allows firms to pay higher wages on average but that, thanks to the payroll tax cut, the labor cost per worker does not increase on average. Corresponding estimates are provided in Table 5. 
Figure 13: Effects of Payroll Tax Cut on Longitudinal Individual Net Wage Earnings

(a) High share young vs. medium share young

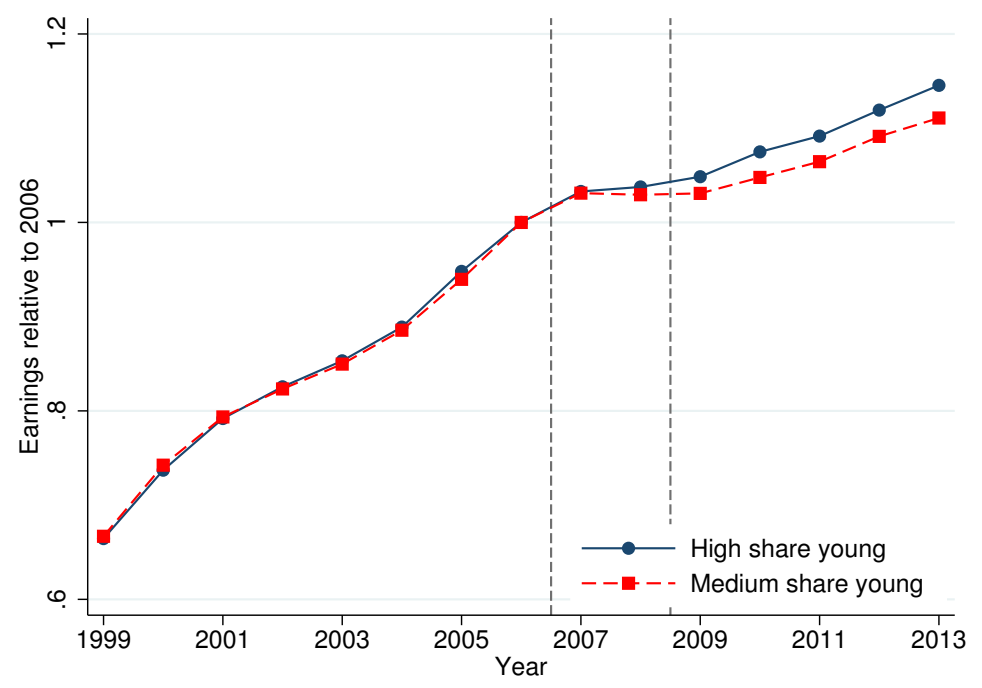

(b) Very high share young and fairly high share young

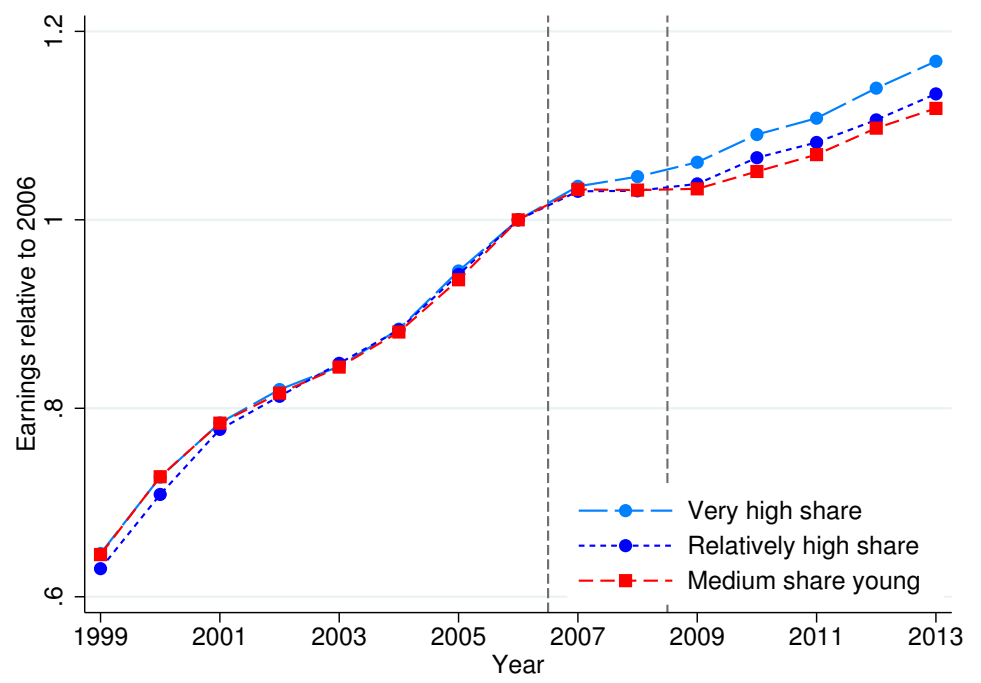

Notes: This figure traces out longitudinal individual net wage earnings (relative to 2006) based on share young at the firm the individual was working at in 2006. We consider the same balanced panel of firms as in Figure 8 . We follow individual workers employed in these firms as of 2006 regardless of whether individuals change jobs or work (non workers are assigned zero earnings). In the top panel, we consider two groups of individuals: (1) individuals working in a medium share young firm in 2006 and (2) individuals working in a high share young firm in 2006. In the bottom panel, we further split the high share young group into two subgroups: (2a) individuals working in a fairly high share young, $(2 \mathrm{~b})$ individual working in a very high share young. Both panels depicts the evolution (relative to 2006) of average individual earnings for all individuals aged 25-60 as of 2006. In both graphs, we DFL reweight by 5 year $\times$ gender cells to control for the age structure across groups (as groups are selected based on fraction young and hence are not balanced in terms of the age distribution). Both panels show that individuals working in 2006 (just before the reform) in a firm with a large share young (and hence largest tax windfall) experience a faster increase in net wage earnings after the reform. Note that all these workers are too old to be directly affected by the payroll tax cut. Corresponding estimates are provided in Table 7 
Figure 14: Effects on Longitudinal Individual Net Wage Earnings: High vs. Low Earners

(a) High earners (above firm median in 2006)

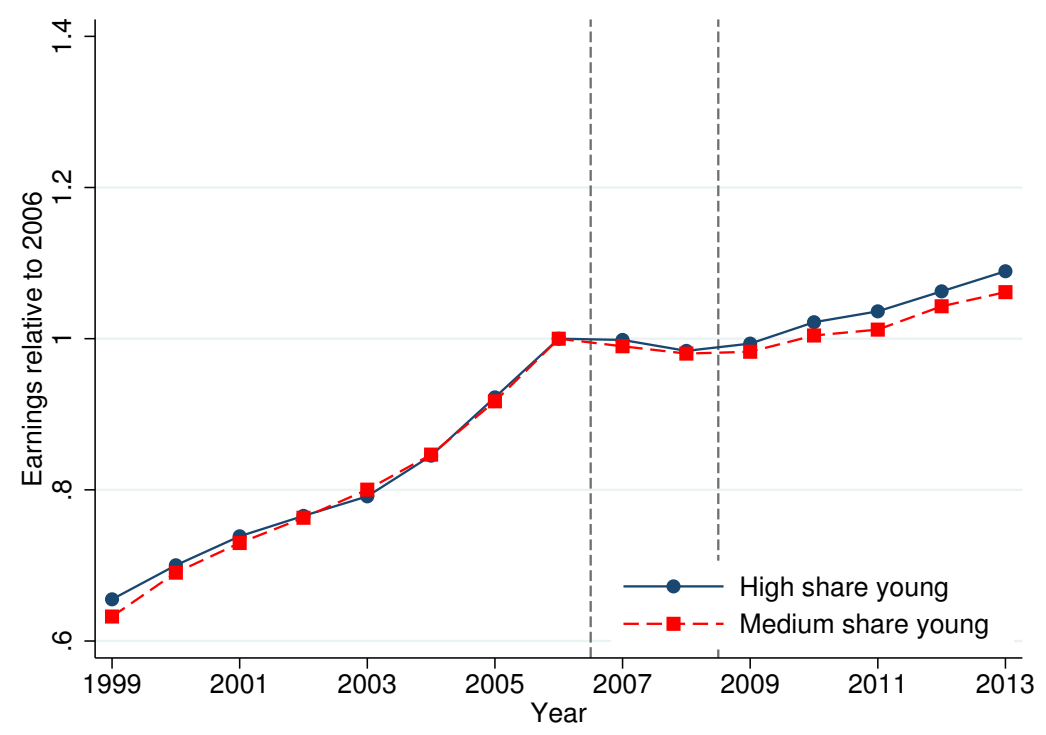

(b) Low earners (below firm median in 2006)

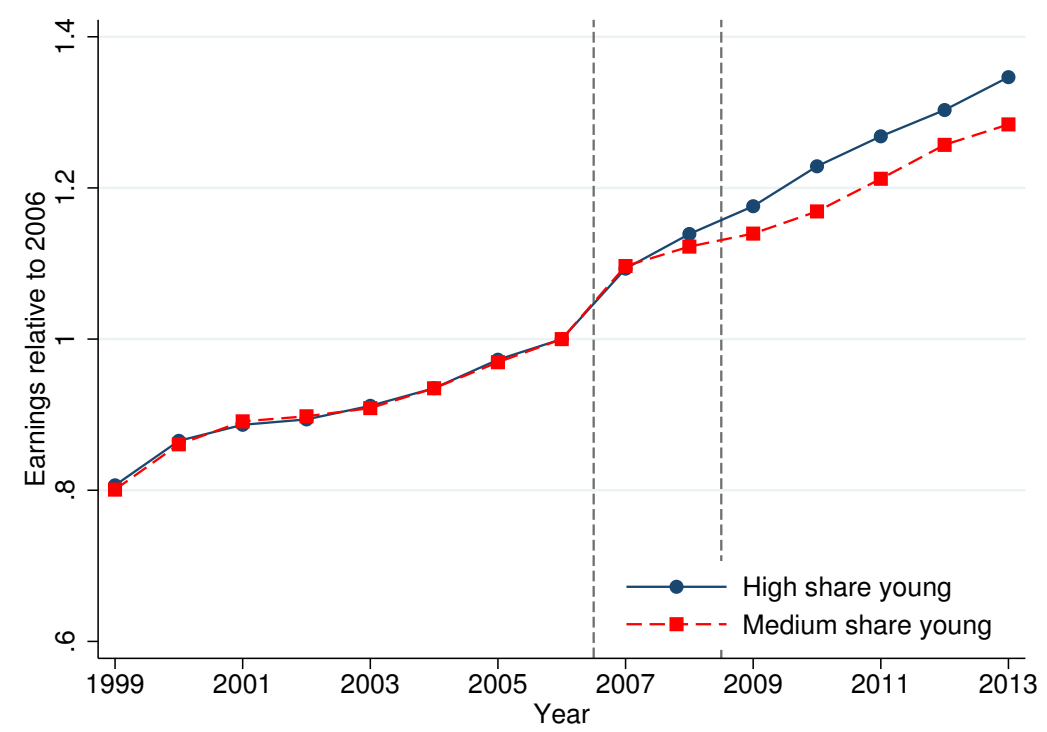

Notes: This figure is built like Figure 13 but considers a narrower group of workers aged 31-40 (in 2006) and splits this sample into high earners (top panel) vs. low earners (bottom panel). Low (resp. high) earners are defined as workers with earnings below (resp. above) the median at the firm they were working in as of 2006 . The median is defined relative to all workers (of any age) at the firm in 2006. The graphs show that individuals working in 2006 (just before the reform) in a firm with a large share of young workers (and hence largest tax windfall) experience a faster increase in net wage earnings after the reform. These positive earnings effects are more pronounced for low earnings workers (bottom panel) than for high earnings workers (top panel). This suggests that the collective tax incidence rent sharing following the tax windfall benefits low earning workers relatively more. Corresponding estimates are provided in Table 7 
Table 1: Incidence on Monthly Wages

\begin{tabular}{lcc}
\hline \hline & $(1)$ & $(2)$ \\
& Short run & $\begin{array}{c}\text { Medium run } \\
\text { Benchmark }\end{array}$ \\
\hline Panel A: All workers & & \\
Net wages & -1.551 & -31.625 \\
Gross wages & $(5.976)$ & $(6.749)$ \\
& -209.154 & -404.698 \\
Pass-through to firms & $(27.677)$ & $(7.528)$ \\
& 1.007 & 1.085 \\
Panel B: Monthly birth data & $(0.269)$ & $(0.046)$ \\
Net wages & 0.995 & -4.831 \\
Gross wages & $(3.745)$ & $(3.537)$ \\
Pass-through to firms & -167.300 & -390.675 \\
& $(15.491)$ & $(4.543)$ \\
Panel C: Top 20 \% & 0.994 & 1.013 \\
Net wages & $(0.185)$ & $(0.025)$ \\
Gross wages & & \\
Pass-through to firms & 23.489 & 13.555 \\
& $(16.083)$ & $(11.601)$ \\
Panel D: New hires & -238.699 & -451.869 \\
Net wages & $(39.232)$ & $(15.970)$ \\
Gross wages & 0.910 & 0.971 \\
& $(0.291)$ & $(0.072)$ \\
\hline \hline & & \\
& -20.226 & -29.208 \\
& $(5.450)$ & $(5.763)$ \\
& -228.673 & -391.232 \\
& $(28.106)$ & $(5.529)$ \\
& 1.097 & 1.081 \\
& $(0.284)$ & $(0.036)$ \\
\hline
\end{tabular}

Notes: This table displays results on the incidence of the payroll tax cut for different subsamples of the data. This regression analysis is based on aggregate time series as depicted in the figures. We take the mean of the contracted monthly wage, including fringe benefits, fixed components, piece-rate and performance pay, by age and time period (two pre-reform periods: 2002-2004 and 2005-2006; and three post-reform periods: 2007-2008; 2009-2011 and 2012-2013) for ages 20-32 (in Panel B we focus on workers turning 24-28 during the year). We regress either the net wage (=monthly wage exclusive of payroll tax) or the gross wage (=monthly wage inclusive of payroll tax) on period-dummies, a dummy for being below the age-eligibility cutoff, age-dummies and the interaction of being below the age-cutoff and the year being post-reform (see text and equation (1) for the exact specification). The table shows coefficients on the last regressor. We divide our analysis into short-run effects (2007-2008) in Column (1) and medium-run effects (2009-2013) in Column (2). Pass-through to firms is defined as the fraction of the payroll tax cut that benefits the employer. It is computed as the gross wage-coefficient divided by the gross wage-coefficient net of the net-wage-coefficient. Standard errors are computed using the delta-method. Panel A focuses on all workers; Panel B on all workers using monthly birth data; Panel C on the top $20 \%$ wage earners (defined within each age $\times$ year cell) and Panel D on new hires. Number of observations in Panel B are 180 (column (1)) and 240 (column (2)). Outcomes are expressed in CPI-adjusted US dollars 
Table 2: Effect of Payroll Tax Cut on Employment Measures

\begin{tabular}{lcc}
\hline \hline & $\begin{array}{c}(1) \\
\text { Effect }\end{array}$ & $\begin{array}{c}(2) \\
\text { Elasticity }\end{array}$ \\
& $\begin{array}{c}\text { (percentage points) } \\
\text { Employment / Labor Force (LF) }\end{array}$ & 0.21 \\
Employment / (LF+students) & $(0.0026)$ & $(0.026)$ \\
Employment / Population & 0.023 & 0.27 \\
& $(0.0040)$ & $(0.047)$ \\
Labor force / Population & 0.014 & 0.23 \\
& $(0.0039)$ & $(0.066)$ \\
Unemployment-Employment transitions & -0.0096 & -0.11 \\
& $(0.0034)$ & $(0.038)$ \\
Employment-Unemployment transitions & 0.011 & 0.23 \\
& $(0.0039)$ & $(0.082)$ \\
& -0.012 & -2.26 \\
$N$ & $(0.0014)$ & $(0.26)$ \\
\hline \hline
\end{tabular}

Notes: This table presents effects of the payroll tax cut on various employment measures (by row) using the aggregated times series by age and time periods displayed in the figures. We regress each outcome variable on 16 age dummies (ages 20 to 35), a post-reform dummy, and the interaction of the post-reform dummy and an age eligibility (ages 20-26) dummy. The table shows coefficients on the last regressor. The time periods used are 2002-04 and 2005-06 (pre-reform) and 2009-2011 and 2012-13 (post-reform), which is our benchmark frame. We exclude years 2007 and 2008 when the reform not yet fully phased-in. Each regression is based on $16 \times 4=64$ observations and we report conventional OLS standard errors. The first column shows percentage point effects and the second transforms these effects into elasticities by dividing the percentage point-effect by the 2005-2006 average of the outcome variable within the treatment group and by the percent reduction in labor costs induced by the reform (which is $12.1 \%$ ). The treatment effect provides an average effect across ages, weighted by age using the age distribution of the labor force in 2006. Labor force (LF) is defined as all residents who are either (i) employed with annual wage earnings above a small annual threshold ( $\$ 4,940$ in 2012 and adjusted for inflation in other years); or (ii) unemployed (defined as having registered with the Unemployment Office at any point during the year). Employment is defined as having annual wage earnings above the small annual threshold. In the second row, we add students (registered in any higher education institution during the year) to the labor force denominator. Unemployment-Employment transitions are defined as the share of unemployed in year $t-1$ who become employed in year $t$ and Employment-Unemployment transitions are defined as the share employed in year $t-1$ who enter unemployment in year $t$. 
Table 3: Effects on Employment across Areas by Level of Initial Youth Unemployment Rate

\begin{tabular}{|c|c|c|c|c|c|}
\hline & $\begin{array}{c}(1) \\
\text { Youth } \\
\text { unempl. rate }\end{array}$ & $\begin{array}{c}(2) \\
\text { Empl. / LF } \\
\text { Benchmark }\end{array}$ & $\begin{array}{c}(3) \\
\text { Pass-through } \\
\text { to firms }\end{array}$ & $\begin{array}{l}\text { (4) } \\
\text { Youth unempl. } \\
\text { rate, placebo }\end{array}$ & $\begin{array}{c}\text { (5) } \\
\text { Empl. / LF } \\
\text { Placebo }\end{array}$ \\
\hline Lowest quintile & 0.108 & $\begin{array}{c}0.010 \\
(0.0033)\end{array}$ & $\begin{array}{c}1.22 \\
(0.095)\end{array}$ & 0.099 & $\begin{array}{l}-0.0058 \\
(0.0082)\end{array}$ \\
\hline Second quintile & 0.124 & $\begin{array}{c}0.011 \\
(0.0018)\end{array}$ & $\begin{array}{c}1.10 \\
(0.10)\end{array}$ & 0.115 & $\begin{array}{c}0.00063 \\
(0.0076)\end{array}$ \\
\hline Third quintile & 0.148 & $\begin{array}{c}0.012 \\
(0.0032)\end{array}$ & $\begin{array}{c}1.13 \\
(0.091)\end{array}$ & 0.143 & $\begin{array}{l}0.00081 \\
(0.0079)\end{array}$ \\
\hline Fourth quintile & 0.184 & $\begin{array}{c}0.029 \\
(0.0032)\end{array}$ & $\begin{array}{c}1.14 \\
(0.066)\end{array}$ & 0.174 & $\begin{array}{c}0.00037 \\
(0.0086)\end{array}$ \\
\hline Top quintile & 0.213 & $\begin{array}{c}0.034 \\
(0.0037)\end{array}$ & $\begin{array}{c}1.13 \\
(0.058)\end{array}$ & 0.190 & $\begin{array}{c}0.0030 \\
(0.0084)\end{array}$ \\
\hline
\end{tabular}

Notes: This table presents the effects of the payroll tax cut on employment / labor force by quintiles of local youth unemployment in 2006. We divide the 21 Swedish counties into five quintile groups by size of the youth (age 16-25) unemployment rate in 2006 (pre-reform) and weighting each county by the size of labor force aged 16-25 in 2006. The map of the counties is presented in Figure A7. Youth unemployment rates for each quintile are reported in column (1). Within each quintile, we follow the methodology from Table 2 and run a simple OLS regression of the aggregated time series (2002-2004; 2005-2006; 2009-2011 and 2012-2013) on 16 age dummies (ages 20-35), a post-reform dummy and the interaction of the post-reform dummy and an age eligibility dummy (ages 20-26). The number of observations per row are thus 64. Employment effects expressed in percentage points are reported in column (2). Employment effects are all significantly positive and larger in places with higher youth unemployment. Column (3) presents the estimates of the pass-through of the payroll tax cut to firms following the tax incidence methodology from Table 1. Columns (4) and (5) replicate columns (1) and (2) for a placebo reform in 2003 comparing years 1998-2002 vs 2003-2006. The placebo employment effects are all very small and insignificant. 
Table 4: Firm Descriptive Statistics by Share Young, 2006

\begin{tabular}{lccc}
\hline \hline Share young: & $\begin{array}{c}(1) \\
\text { Low } \\
\text { No young+ } \\
\text { bottom 1/4 }\end{array}$ & $\begin{array}{c}(2) \\
\text { Medium } \\
\text { Middle 1/2 }\end{array}$ & $\begin{array}{c}(3) \\
\text { High } \\
\text { Top 1/4 }\end{array}$ \\
\hline Fraction young & 0.01 & 0.13 & 0.32 \\
Number of workers & 9.46 & 14.06 & 13.46 \\
Gross annual wage earnings per employee & 35.23 & 31.46 & 27.99 \\
Total assets & 713.09 & 868.23 & 670.86 \\
Value added & 701.27 & 887.57 & 743.94 \\
Sales & 1249.69 & 1827.04 & 1821.04 \\
Profits (EBIT) & 68.73 & 83.79 & 66.13 \\
Financial constraints & & & \\
FC: below median liquid assets / TA & 0.47 & 0.53 & 0.50 \\
FC: below median sales & 0.58 & 0.42 & 0.49 \\
FC: below median firm age & 0.45 & 0.46 & 0.55 \\
Industries & & & \\
Agriculture and mining & 0.04 & 0.05 & 0.07 \\
Manufacturing & 0.19 & 0.18 & 0.11 \\
Construction & 0.15 & 0.21 & 0.16 \\
Wholesale and retail & 0.23 & 0.27 & 0.34 \\
Hotel and restaurants & 0.02 & 0.05 & 0.13 \\
Transport and communication & 0.11 & 0.11 & 0.07 \\
Property management, B2B & 0.16 & 0.08 & 0.06 \\
Education & 0.02 & 0.02 & 0.01 \\
Healthcare (not pharmaceutic firms) & 0.05 & 0.02 & 0.00 \\
Public services & 0.02 & 0.03 & 0.05 \\
\hline Observations & 5698 & 5265 & 2632 \\
\hline \hline
\end{tabular}

Notes: This table provides statistics for a balanced panel of firms active in every single year from 2003 to 2013 and with more than 3 employees in each year. It partitions this sample into three groups based on the share of payroll paid to young workers (aged 19-25) in 2006 as depicted in Figure 8. The first group (low share young) includes firms with zero young workers in 2006 and the bottom quartile (unweighted) of firms with at least one young worker in 2006. The second group (medium share young) includes firms in the middle two quartiles (unweighted) of firms with at least one young worker in 2006. The third group (high share young) includes firms in the top quartile (unweighted) of firms with at least one young worker in 2006. Non-corporate businesses (such that sole proprietorships or partnerships) are excluded. Public sector firms and firms part of a corporate group are also excluded. Statistics for each group are displayed in each of the three columns. All statistics are for year 2006. All monetary variables expressed in 1000 USD (converted from SEK at the exchange rate 8.9 SEK/USD). 
Table 5: Effect of Payroll Tax Cut on Firm Outcomes

\begin{tabular}{lcccc}
\hline \hline & $(1)$ & $(2)$ & $(3)$ & $(4)$ \\
& $\begin{array}{c}\text { Benchmark: } \\
\text { high vs. medium } \\
\text { share young }\end{array}$ & $\begin{array}{c}\text { Fairly high } \\
\text { vs. medium } \\
\text { share young }\end{array}$ & $\begin{array}{c}\text { Very high } \\
\text { vs. medium } \\
\text { share young }\end{array}$ & $\begin{array}{c}\text { Unbalanced panel: } \\
\text { high vs. medium } \\
\text { share young }\end{array}$ \\
\hline Number of Workers & 0.046 & 0.028 & 0.065 & 0.033 \\
Total assets & $(0.0034)$ & $(0.0034)$ & $(0.0043)$ & $(0.0042)$ \\
Sales & 0.058 & 0.039 & 0.077 & 0.016 \\
Value Added & $(0.013)$ & $(0.015)$ & $(0.012)$ & $(0.024)$ \\
Profits (EBIT) & 0.031 & 0.021 & 0.041 & 0.026 \\
Payroll tax per worker & $(0.0041)$ & $(0.0029)$ & $(0.0064)$ & $(0.0072)$ \\
& 0.061 & 0.040 & 0.082 & 0.040 \\
Gross wage per worker & $(0.0073)$ & $(0.0072)$ & $(0.0081)$ & $(0.0073)$ \\
& 0.081 & 0.046 & 0.12 & 0.21 \\
Net wage per worker & $(0.012)$ & $(0.019)$ & $(0.019)$ & $(0.021)$ \\
& -0.044 & -0.025 & -0.063 & \\
& $(0.0051)$ & $(0.0036)$ & $(0.0068)$ & \\
\hline \hline
\end{tabular}

Notes: The table presents the effects of the payroll tax cut on various firm outcomes (by row) using the aggregated longitudinal times series by firm groups and year displayed in Figures 9, 10, and 12. Outcomes at the firm level are always measured relative to 2006 outcomes so that they are naturally normalized to one. The exception is profits which are normalized by value added in 2006 (as profits are often negative). For profits, we renormalize the aggregated time-series of profits/value added in 2006 by its value in 2006 within each group to be able to interpret coefficients as percent effects. In columns (1)-(3), we consider a balanced panel of firms from 2003 to 2013 and with more than 3 employees in each year and at least one young employee in 2006. Column (4) focuses on firms with more than 3 employees in 2006 independent of whether they are alive or not before or after. In this column, we reweight the age distribution of firms in the medium-share young group to match that of the high share young group. For inactive firms, we replace missing outcome variables with zeros. Medium share young is defined as firms in the middle two quartiles of share young in 2006 (among firms with positive share young in 2006). High share young is defined as firms in the top quartile of share young in 2006. Very high share young is defined as firms in the top 1/8 of share young in 2006. Fairly high share young is defined as firms in the next $1 / 8$ of share young in 2006 (i.e., the top quartile excluding the top 1/8). In columns (1) and (4), we compare the high share young firms to medium share young firms. In column (2) we compare the fairly high share young firms to medium share young firms. In column (3) we compare the very high share young firms to medium share young firms. In all cases, the medium share young group is the "control" group and the other group is the "treatment" group. We use years 2003-2006 and 2009-2013 (excluding years 2007-2008 when the reform was only partially phased-in). We regress each outcome variable on year dummies, a treatment dummy, and an interaction of the post-reform period dummy (2009+) and the treatment dummy. The coefficient on the interaction is reported. Each regression is based on 18 observations. Conventional OLS standard errors in parentheses. 
Table 6: Firm Effects of Payroll Tax Cut by Financial Constraint Proxies

\begin{tabular}{|c|c|c|c|}
\hline & $\begin{array}{l}\text { (1) } \\
\text { FC proxy: } \\
\text { Age of firm }\end{array}$ & $\begin{array}{c}(2) \\
\text { FC proxy: } \\
\text { Liquid assets/Total Assets }\end{array}$ & $\begin{array}{c}(3) \\
\text { FC proxy: } \\
\text { Sales }\end{array}$ \\
\hline \multicolumn{4}{|c|}{ Panel A: Outcome: Workers relative to 2006} \\
\hline Less financially constrained & $\begin{array}{c}0.017 \\
(0.004)\end{array}$ & $\begin{array}{c}0.032 \\
(0.005)\end{array}$ & $\begin{array}{c}0.044 \\
(0.004)\end{array}$ \\
\hline More financially constrained & $\begin{array}{c}0.054 \\
(0.004)\end{array}$ & $\begin{array}{c}0.060 \\
(0.005)\end{array}$ & $\begin{array}{c}0.049 \\
(0.004)\end{array}$ \\
\hline $\begin{array}{l}\text { F-test for equal effects } \\
\text { P-value for F-test }\end{array}$ & $\begin{array}{c}43.265 \\
0.000\end{array}$ & $\begin{array}{c}16.638 \\
0.001\end{array}$ & $\begin{array}{l}0.850 \\
0.372\end{array}$ \\
\hline \multicolumn{4}{|c|}{ Panel B: Outcome: Assets relative to 2006} \\
\hline Less financially constrained & $\begin{array}{c}0.040 \\
(0.015)\end{array}$ & $\begin{array}{c}0.043 \\
(0.014)\end{array}$ & $\begin{array}{c}0.034 \\
(0.016)\end{array}$ \\
\hline More financially constrained & $\begin{array}{c}0.053 \\
(0.015)\end{array}$ & $\begin{array}{c}0.068 \\
(0.014)\end{array}$ & $\begin{array}{c}0.075 \\
(0.016)\end{array}$ \\
\hline $\begin{array}{l}\text { F-test for equal effects } \\
\text { P-value for F-test }\end{array}$ & $\begin{array}{l}0.395 \\
0.540\end{array}$ & $\begin{array}{l}1.561 \\
0.232\end{array}$ & $\begin{array}{l}3.199 \\
0.095\end{array}$ \\
\hline \multicolumn{4}{|c|}{ Panel C: Difference in share young in 2006} \\
\hline Less financially constrained & 0.190 & 0.202 & 0.192 \\
\hline More financially constrained & 0.203 & 0.191 & 0.201 \\
\hline
\end{tabular}

Notes: This table displays the effects of the payroll tax cut on employment (Panel A) and total assets (Panel B) for financially constrained and unconstrained firms separately following the methodology of Table 5 . We first divide firms based on share young in 2006 and compare firms with high share young to firms with medium share young. Second, we divide firms by financial constraint proxies: Column (1) divides firms above (unconstrained) and below (constrained) median age in 2006; (2) into above (unconstrained) median of liquid assets / total assets in 2006 and below; and (3) divides firms into above (unconstrained) median sales in 2006 and below. We compute the mean outcome by year, treatment-control and financial constraint. We then regress the outcome on treatment, year-dummies and the interaction of treatment and post 2006 where all regressors are interacted with financial constraint-dummy, on the aggregate time series data (the complete graphical evidence is presented in Appendix Figures A11 and A12). We compare years 2009-2013 to years 1999-2006 (omitting the transitory years 2007-2008). Conventional OLS standard errors are reported in parentheses. In each panel and column, the table displays the treatment-effect for less constrained firms (first row) and for more constrained firms (second row) as well as the F-test and the associated p-value for the null of equal effects across constrained and unconstrained (third row). Panel C displays the difference in the 2006-share of payroll to young between high share and medium share firms to verify that the strength of the first stage is nearly identical in constrained vs. unconstrained firms. 
Table 7: Collective Incidence of Payroll Tax Cut on Individual Earnings

\begin{tabular}{lccc}
\hline \hline & $\begin{array}{c}(1) \\
\text { Benchmark: } \\
\text { High vs. medium } \\
\text { share young }\end{array}$ & $\begin{array}{c}(2) \\
\text { Fairly high } \\
\text { vs. medium } \\
\text { share young }\end{array}$ & $\begin{array}{c}(3) \\
\text { Very high } \\
\text { vs. medium } \\
\text { share young }\end{array}$ \\
\hline All ages (25-60) & 0.026 & 0.015 & 0.037 \\
Ages 25-30 & $(0.0028)$ & $(0.0043)$ & $(0.0031)$ \\
Ages 31-40 & 0.034 & 0.017 & 0.046 \\
& $(0.0089)$ & $(0.010)$ & $(0.011)$ \\
Ages 41-50 & 0.028 & 0.0063 & 0.051 \\
& $(0.0036)$ & $(0.0030)$ & $(0.0055)$ \\
Ages 51-60 & 0.030 & 0.026 & 0.034 \\
& $(0.0020)$ & $(0.0028)$ & $(0.0039)$ \\
\hline Earnings below within-firm median & 0.0048 & -0.0019 & 0.012 \\
& $(0.0031)$ & $(0.0048)$ & $(0.0039)$ \\
\hline Earnings above within-firm median & 0.041 & 0.015 & 0.068 \\
& $(0.0049)$ & $(0.0047)$ & $(0.0084)$ \\
& $(0.018$ & 0.015 & 0.025 \\
& & $(0.0046)$ & $(0.0035)$ \\
\hline \hline
\end{tabular}

Notes: This table shows effects on average individual net wage earnings (relative to 2006 earnings) at the workerlevel of having been working in a firm with a high share young in 2006 (just before the reform). In Column (1) we compare workers in high share young firms to workers in medium share young while Columns (2) and (3) compares workers in very high and fairly high share young (respectively) to workers in medium share young. The first row shows effects on net wage earnings for those workers aged 25-60 in year 2006. The next four rows split the sample into different age groups. In the last two rows we instead split the sample of individuals aged 31-40 into below-median earnings in 2006 vs. above. In all estimations, we DFL-reweight the age-distribution of the workers in firms with medium-share young to match the age-distribution of those working in firms with a high share young, using 5-year age-categories. All the estimates are based on a basic regression using solely the aggregated time series depicted in Figures A15 and 14. We compare years 2009-2013 to years 1999-2006. Conventional OLS standard errors in parentheses. 
Table 8: Distributive Incidence of Payroll Tax Cut on Individual Earnings

\begin{tabular}{lcc}
\hline \hline & $(1)$ & $(2)$ \\
Earnings percentile & Benchmark & Placebo reform in 2003 \\
\hline P-20 & 0.064 & -0.010 \\
& $(0.008)$ & $(0.007)$ \\
P-30 & 0.057 & 0.005 \\
& $(0.010)$ & $(0.006)$ \\
P-40 & 0.040 & -0.002 \\
& $(0.007)$ & $(0.003)$ \\
P-50 & 0.032 & 0.003 \\
& $(0.004)$ & $(0.004)$ \\
P-60 & 0.023 & 0.002 \\
& $(0.003)$ & $(0.002)$ \\
P-70 & 0.018 & 0.002 \\
& $(0.002)$ & $(0.002)$ \\
P-80 & 0.013 & 0.004 \\
& $(0.001)$ & $(0.004)$ \\
P-90 & 0.014 & 0.009 \\
& $(0.002)$ & $(0.005)$ \\
\hline \hline
\end{tabular}

Notes: This table shows effects on various percentiles of the individual net wage earnings distribution (relative to 2006) at the worker-level for having been working in a firm with a high share young in 2006 (just before the reform). Estimates are constructed as in Table 7 but, instead of considering averages, we consider various percentiles P-20, P-30,.., P-90. Column (1) compares workers in high share young firms to workers in medium share young while Columns (2) and (3) compare workers in very high and fairly high share young (respectively) to workers in medium share young. All the estimates are based on a basic regression using solely the aggregated time series depicted in Figure A16. We exclude estimates for P-10 as low percentiles are noisy (see the P-10 graphical representation on Figure A16). We compare years 2009-2013 to years 1999-2006. Conventional OLS standard errors in parentheses. 


\section{Online Appendix}

\section{A.1 Benchmarking implied cash effects}

A full model and assessment of the financial channel is beyond the scope of this paper and limited by the strong effects we find even for firms that our imperfect proxies classify as less constrained. However, we can evaluate our firm-level findings quantitatively by investigating whether the size of our treatment effect for the average firm could be entirely rationalized by a credit constraints channel only. While our sample and particular design differ from existing U.S. analyses with publicly traded, very large firms, our back of the envelope calculation suggests that our effects are of the same order of magnitude, and that the cash channel could play an important role in the firm-level effects.

The standard estimation in the corporate finance literature obtains a dollar-for-dollar effect of a cash flow shock on capital investment (and thereby the capital stock) by regressing capital investment (or change) over lagged capital stock $\left(\frac{\mathrm{K}}{\overline{\mathrm{K}}}\right.$ or $\left.\frac{\mathrm{CapX}}{\overline{\mathrm{K}}}\right)$ on (endogenous or exogenous) cash flow shifts divided by the lagged capital stock $\left(\frac{\mathrm{CF}}{\overline{\mathrm{K}}}\right)$.

To benchmark our effects, we cast our treatment effect into an implied "dollar for dollar" version by rescaling appropriately. We then compare that implied effect to the range of existing estimates in the corporate finance literature for capital. 77

The total-asset differential between the top group and the middle group opens up to $6 \%$ following the reform, i.e. $\Delta \frac{\mathrm{K}}{\overline{\mathrm{K}}}=6 \%$. The initial liquidity injection from the payroll tax cut corresponds to a $2.4 \%$ differential in total labor cost reduction for the top vs. the middle groups, i.e. $\Delta \frac{\mathrm{LC}}{\overline{\mathrm{LC}}}=2.4 \% .78$

Our tax windfall is a differential percentage shift in labor costs of $2.4 \%$. We rescale it by firms' payroll-asset ratio in 2006 to obtain a dollar-for-dollar measure of the capital effect from the tax windfall that can be benchmarked against the standard estimates: $\frac{\overline{\mathrm{LC}}}{\overline{\mathrm{K}}} \cdot \Delta \frac{\mathrm{LC}}{\overline{\mathrm{LC}}}=\Delta \frac{\mathrm{LC}}{\overline{\mathrm{K}}}$.

For our sample of firms, the median labor cost-asset ratio is $\frac{\overline{\mathrm{LC}}}{\overline{\mathrm{K}}}=0.7$; the mean ratio is around .9 with or without winsorization; going forward we use the mid-point of .8 .79

This simple rescaling links the $6 \%$ shift in assets with a $0.8 \cdot 2.4 \%=1.92 \%$ labor cost over asset shift, such that a $\$ 1.92$ in - annual - labor cost reduction - and thus a cumulative liquidity injection from the tax windfall of $\$ 11.52$ by the end of the six-year reform -, would be associated with the $\$ 6$ increase in the final stock of total assets, six years into the reform. Read through

\footnotetext{
${ }^{77}$ The literature has not estimated a coherent set of effects for employment, so we restrict our benchmarking to capital.

${ }^{78}$ The calculation is as follows: the payroll tax cut corresponds to $12.1 \%$ of youth labor costs in year one (assuming no wage changes or scale changes, which would amplify the implied effect). The initial difference in share young between these two groups is 19.8 percentage points. The product implies a $2.4 \%$ differential in total labor cost reduction for the top vs. the middle groups.

${ }^{79}$ We obtain similar ratios when we compute descriptive statistics for Swedish firms with similar sample restrictions (firm size) for 2006 using Bureau van Dijk data.
} 
the lens of credit constraints only, our estimate therefore implies an $\$ 0.52$ capital stock-cash flow sensitivity. This compares to around $\$ .2$ to $\$ .6$ that the literature finds for publicly traded Compustat firms in the US (see e.g., Fazzari, Hubbard, and Petersen, 1988 for a classic study).

There are five reasons that may explain why our implied effect - if indeed due to credit constraints - falls in the upper range of existing estimates. First, our sample contains many small firms, whereas the benchmark estimates refer to publicly traded Compustat firms in the U.S., which presumably are much less constrained 80 Second, as discussed above, the tax reform not only generated an inframarginal cash injection but also lowered marginal costs and may lead to expansion up through a conventional scale effect on top of the financial mechanism. Third, the benchmark estimates arise from variation in unexpected transient - i.e. one-time - shocks to cash flow, whereas we consider a persistent, expected series of tax windfalls. Such liquidity injections may imply considerably larger effects because they may increase the constrained firm's credit worthiness ex ante. Fourth and relatedly, our medium-run analysis revealed that firms scale up, which would generate additional resources starting year 2 through an indirect multiplier effect. Relatedly, the literature considers capital investment, our medium-run treatment requires a cumulative measure of capital stock growth. A short-run impact of incremental investment adds one to one to the capital stock (i.e. the cash flow sensitivities are similar whether capital stock or investment is the dependent variable, both normalized by lagged capital stock), whereas steady-state shifts are mediated by the depreciation rate. Fifth, note that our measure (total assets) also includes financial assets besides productive assets. While we find similar (yet noisier) percentage growth of fixed assets (and fixed tangible assets) in unreported specifications, the ratio of gross labor costs to those asset subtypes is considerably larger, which would imply a proportionately smaller dollar-for-dollar effect of the tax windfall into such subcategories of total assets. Concretely, the median labor cost/fixed asset ratio is 2.75, and the labor cost/fixed tangible asset ratio is 3.75. Accordingly, the implied dollar-for-dollar effect would then fall to the order of $\$ 0.10-0.15$.

In conclusion, our estimates may indeed reflect an interesting medium-run change in resources that constrained firms use to expand their business, and this implied effect is quantitatively consistent with the range of existing investment-cash flow sensitivities. Specifically, our effects would correspond to a $\$ 0.1-\$ 0.5$ effect on capital per dollar of tax windfall, which spans the range of existing estimates for the investment cash flow sensitivity of U.S. firms. While our firm activity findings could therefore be primarily driven by financial effects, we note that a conventional scale effect from marginal costs may also help explain the business growth patterns (albeit not the heterogeneity by financial constraints).

\footnotetext{
${ }^{80}$ For example, Zwick and Mahon (2017) investigate a broader cross section of U.S. firms including smaller private firms (resembling our sample), and find smaller firms exhibit dramatically larger responses to investment incentives than Compustat firms, which the authors attribute to credit constraints.
} 


\section{A.2 A Simple Model with Pay Equity Constraints}

We present a parsimonious labor market model that can account for most of our key findings. It adds one departure from the standard competitive model: a pay equity constraint that compresses net wages between worker types (here: young vs. old), and largely plays out within firms.

This pay equity constraint pushes the youth wage above the market-clearing level, which is below the old wage as the young are less productive than the old. (The old are on their labor supply curve and pin down everyone's net wage.) Hence, youth labor supply is rationed, youth unemployment emerges, and prevailing youth employment is labor-demand-determined.

The model accounts for the following nonstandard payroll tax facts we document: (i) The incidence of an employer payroll tax cut for the young falls fully into their labor costs, while (ii) their net wages do not change. (iii) Youth employment increases even if labor supply elasticities are small and despite a zero shift in net wages for the young. Augmenting the model with two firm types (youth intensive vs. old age intensive firms) can also replicate our cross-sectional firm-level effect, where (iv) high share young firms expand scale and (v) these firms raise wages by more in response to a payroll tax cut for the young, ${ }^{81}$

In this environment, moving from homogeneous to age-dependent employer payroll taxes can offset the labor cost distortion from the equity constraint on net wages, and implement the frictionless age gradient of employment.

We first present the model with a representative firm and household that will account for the market-level findings. As a benchmark, we first discuss the model without the wage friction as a frictionless benchmark, where labor demand and supply will be equilibrated and standard incidence predictions are borne out. We then discuss how pay equity constraints affect the labor market, as well as the effects of age-dependent payroll taxes. Labor demand comes from a wage-taking representative firm. Next, we augment this model with two types of firms and a firm-specific labor supply curve (monopsony) to account for the firm-level results on top of the market-level results.

\section{A.1 Households: Labor Supply}

For young and old households $i \in\{y, o\}$, of equal mass, utility is quasi-linear in consumption $c_{i}$ and employment $n_{i}$ :

$$
u\left(c_{i}, n_{i}\right)=c_{i}-\phi_{i}^{-1 / \xi} \cdot \frac{n_{i}^{1+\frac{1}{\xi}}}{1+\frac{1}{\xi}}
$$

$\xi$ guides Marshallian, Hicksian and Frischian labor supply elasticities ${ }^{22} \phi_{i}$ is the taste for work.

\footnotetext{
${ }^{81}$ Four additional empirical findings are beyond the scope of our model. First, rent sharing in our model works through a monopsony mechanism (firm-specific labor supply curve), which stands in for richer mechanisms of rent sharing of tax windfalls. Second, credit constraints are not active, such that the marginal cost channel drives labor demand responses, and we do not model capital. Third, since our pay-equity constraint is specialized to be fully binding, we cannot generate the progressive wage effects within firms, although a slight extension to partial wage flexibility may do so. Fourth, we do not explicitly model worker flows through separations and hiring but consider net quantities, which stand in for long-term jobs.

${ }^{82}$ In line with our evidence, we model the extensive margin on employment $n_{i}$ but preclude an intensive hours choice. $\xi$ then captures the distribution of labor disutility in the respective age groups.
} 
Labor supply is a function of the wage $w_{i}$, and tastes $\phi_{i}$ and $\xi$ :

$$
n_{i}^{s}=\phi_{i} w_{i}^{\xi}
$$

\section{A.2 Representative Firms and Labor Demand}

CES production with young and old workers. The production functions is:

$$
F\left(n_{y}, n_{o}\right)=\left(x_{y} \gamma_{y} n_{y}^{\alpha}+x_{o} \gamma_{o} n_{o}^{\alpha}\right)^{\frac{\beta}{\alpha}}
$$

where $\beta$ denotes overall return to scale. $\gamma_{i}$ is the productivity parameter of a given worker-age type $i$, where we assume $\gamma_{y}<\gamma_{o}$, i.e. younger workers are less productive than the old ${ }^{83} x_{i}$ is the production weight of type $i$, i.e. $\sum_{i=y, o} x_{i}=1$. We introduce both $\gamma_{i}$ and $x_{i}$ because, when we turn to a version with multiple firm types with different weights $x_{i}^{f}$ for each firm type $f$, reflecting technological bias.

Labor demand sets input $i$ 's marginal product equal to its gross wage (incl. payroll tax):

$$
\beta x_{i} \gamma_{i} n_{i}^{\beta-1}\left[x_{j} \gamma_{j}\left(\frac{n_{j}}{n_{i}}\right)^{\alpha}+x_{i} \gamma_{i}\right]^{\frac{\beta}{\alpha}-1}=\left(1+\tau_{i}\right) w_{i}
$$

With CES, the ratio of these labor demand conditions implies: pins down desired input ratio $\frac{n_{j}}{n_{i}}$ as a function of labor costs:

$$
\frac{n_{j}}{n_{i}}=\left[\frac{x_{j}}{x_{i}} \frac{\gamma_{j}}{\gamma_{i}} \frac{\left(1+\tau_{i}\right) w_{i}}{\left(1+\tau_{j}\right) w_{j}}\right]^{\frac{1}{1-\alpha}}
$$

Plugging in for $\frac{n_{j}}{n_{i}}$ in A4 with the desired skill ratio A5 , we obtain $n_{i}$ only as a function of the parameters of the production function and gross wages:

$$
n_{i}^{d}=\left(\frac{\beta x_{i} \gamma_{i}}{\left(1+\tau_{i}\right) w_{i}}\right)^{\frac{1}{1-\beta}}\left[x_{j} \gamma_{j}\left[\frac{x_{j}}{x_{i}} \frac{\gamma_{j}}{\gamma_{i}} \frac{\left(1+\tau_{i}\right) w_{i}}{\left(1+\tau_{j}\right) w_{j}}\right]^{\frac{\alpha}{1-\alpha}}+x_{i} \gamma_{i}\right]^{\left(\frac{\beta}{\alpha}-1\right)\left(\frac{1}{1-\beta}\right)}
$$

\section{A.3 Benchmark: Frictionless Equilibrium - No Equity Constraints}

Age gradients of labor market outcomes. Now consider the frictionless equilibrium without pay equity constraints. Our CES set-up could be extended to more than two age groups (rather than young and old) to trace out the worker ages corresponding to the empirical marketlevel age cuts, e.g. Figure 2 for employment and Figure 6 for net wages. Indeed, our analysis follows a difference-in-difference analysis, so we do not speak to aggregate absolute levels. So it is useful to not only focus on levels (end of this Section) but rather on the age gradient of labor market outcomes. This perspective is particularly convenient since our empirical analysis considers a shift in the payroll tax rate age profile, and because we will later on consider

\footnotetext{
${ }^{83}$ Note that the productivity parameters do not map into observables. In fact, in our model with equal labor costs, the marginal product of old and young workers are equal with pay-equity constraints by labor demand due to homogeneous gross wages.
} 
whether in general an age-dependent payroll tax regime may fully offset the wage friction (and thus restore the frictionless equilibrium we describe below as our benchmark).

To obtain the equilibrium, consider again the age gradient of labor demand from (A5):

$$
\frac{n_{i}^{d}}{n_{j}^{d}}=\left[\frac{x_{j}}{x_{i}} \frac{\gamma_{j}}{\gamma_{i}} \frac{\left(1+\tau_{i}\right) w_{i}}{\left(1+\tau_{j}\right) w_{j}}\right]^{-\frac{1}{1-\alpha}}
$$

The age gradient of labor supply arises from $n_{i}^{s}=\phi_{i} w_{i}^{\xi}$ :

$$
\frac{n_{i}^{s}}{n_{j}^{s}}=\frac{\phi_{i}}{\phi_{j}}\left(\frac{w_{i}}{w_{j}}\right)^{\xi}
$$

We first derive the age gradient of equilibrium net wages, which is the model analogue of our empirical market-level Figure 2. Panel (a) shows an upward-sloping employment profile, which we will rationalize with productivity differences (or taste differences $\phi$ ):

$$
\frac{w_{i}^{e q}}{w_{j}^{e q}}=\left[\frac{x_{i}}{x_{j}} \frac{\gamma_{i}}{\gamma_{j}}\right]^{\frac{1}{\xi(1-\alpha)+1}} \cdot\left[\frac{1+\tau_{i}}{1+\tau_{j}}\right]^{-\frac{1}{\xi(1-\alpha)+1}} \cdot\left(\frac{\phi_{i}}{\phi_{j}}\right)^{-\frac{1-\alpha}{\xi(1-\alpha)+1}}
$$

The wage path is affected by three factors: productivity differences, taste differences, and the payroll tax gradient. Taste differences can only affect wages if worker types aren't perfect substitutes $(\alpha=1)$, in which case labor demand is perfectly elastic between worker types. Productivity differences determine the wage gradient even if workers are perfect substitutes, in which case wages perfectly trace the differences in the productivity terms.

In terms of payroll tax incidence into net wages, the payroll tax gradient acts exactly as the productivity gradient. As in the standard incidence framework, with elastic labor demand between worker groups $(\alpha \approx 1)$, workers' relative net wages bear the full incidence of payroll tax differences in the cross-section. This case is our benchmark and our prior for our empirical analysis, since around the age discontinuity, workers should be close to perfect substitutes. For $\alpha<1$, labor demand is not perfectly elastic for a given age group, and then labor supply elasticities $\xi$ will mediate the incidence: if $\xi \rightarrow 0$, then relative net wages absorb age-dependent payroll taxes, without any employment effect, irrespectively of the labor demand elasticity. But the closer $\alpha$ to one, the less relevant labor supply factors become for incidence into net wages.

The model's age gradient of equilibrium gross wages captures the flip side of the net wage incidence results. With elastic labor supply, gross wages take the incidence of payroll taxes. When labor demand is cross-sectionally perfectly elastic ( $\alpha$ close to one), then gross wages are invariant in payroll tax rates:

$$
\frac{\left(1+\tau_{i}\right) w_{i}^{e q}}{\left(1+\tau_{j}\right) w_{j}^{e q}}=\left[\frac{x_{i}}{x_{j}} \frac{\gamma_{i}}{\gamma_{j}}\right]^{\frac{1}{\xi(1-\alpha)+1}} \cdot\left[\frac{1+\tau_{i}}{1+\tau_{j}}\right]^{\frac{\xi(1-\alpha)}{\xi(1-\alpha)+1}} \cdot\left(\frac{\phi_{i}}{\phi_{j}}\right)^{-\frac{1-\alpha}{\xi(1-\alpha)+1}}
$$

Figure 2 Panel (b) shows incidence for the age gradient of gross wages. We rejects the zero/small incidence into gross wages predicted by inelastic labor supply and elastic labor demand.

Finally, we consider the age gradient of equilibrium employment, the empirical analogue of which we trace our in market-level Figure 6. That Figure shows an upward-sloping employment profile. Our model-equivalent replicates this empirical fact if productivity factors 
increase in age (and if workers' tastes for work do not decline in an offsetting way):

$$
\begin{aligned}
\frac{n_{i}^{e q}}{n_{j}^{e q}} & =\frac{\phi_{i}}{\phi_{j}}\left(\frac{w_{i}}{w_{j}}\right)^{\xi} \\
& =\left[\frac{x_{i}}{x_{j}} \frac{\gamma_{i}}{\gamma_{j}}\right]^{\frac{\xi}{\xi(1-\alpha)+1}} \cdot\left[\frac{1+\tau_{i}}{1+\tau_{j}}\right]^{-\frac{\xi}{\xi(1-\alpha)+1}} \cdot\left(\frac{\phi_{i}}{\phi_{j}}\right)^{\frac{1}{\xi(1-\alpha)+1}}
\end{aligned}
$$

The employment incidence of payroll tax differences are limited by low assumed labor supply elasticities even when labor demand is very elastic. We do find differential employment impacts around the discontinuity that imply an equilibrium employment elasticity of around 0.21 (Table 2 ). With $\alpha=1$, this would imply a labor supply elasticity (assuming a counterfactual equilibrium economy in which net wages increased) of 0.22 , a realistic value. The tension is of course that the empirical results find a zero rather than $12 \%$ incidence on net wage differentials for treated young workers (see Figure 2 Panel (a)). A model with incidence along a standard, even moderately elastic labor supply is therefore not a good candidate for our facts.

Levels of age-specific labor market outcomes. Our empirical analysis of market-level effects exploits difference-in-difference analyses, and therefore examines relative shifts in the employment and wage profiles rather than absolute effects. For completeness we also present the closed forms of the level of equilibrium employment and wages, on which comparative statics could be performed:

$$
\begin{gathered}
n_{i}^{e q}=\left(\frac{\beta x_{i} \gamma_{i} \phi_{i}^{\frac{1}{\xi}}}{1+\tau_{i}}\left[x_{j} \gamma_{j}\left(\left[\frac{x_{j}}{x_{i}} \frac{\gamma_{j}}{\gamma_{i}}\right]^{\frac{\xi \alpha}{\xi(1-\alpha)+1}} \cdot\left[\frac{1+\tau_{j}}{1+\tau_{i}}\right]^{-\frac{\xi \alpha}{\xi(1-\alpha)+1}} \cdot\left(\frac{\phi_{j}}{\phi_{i}}\right)^{\frac{\alpha}{\xi(1-\alpha)+1}}\right)+x_{i} \gamma_{i}\right]^{\frac{\beta}{\alpha}-1}\right)^{\frac{1}{\frac{1}{\xi}+(1-\beta)}} \\
w_{i}^{e q}=\left(\phi_{i}^{-1} n_{i}^{e q}\right)^{\frac{1}{\xi}} \\
\left(1+\tau_{i}\right) w_{i}^{e q}=\left(1+\tau_{i}\right)\left(\phi_{i}^{-1} n_{i}^{e q}\right)^{\frac{1}{\xi}}
\end{gathered}
$$

Standard incidence predictions are borne out because we are in the competitive labor market. Level analysis of incidence in this environment is only slightly more complicated than crosssectional incidence in the age gradients 84

\section{A.4 A Labor Market with Equity Constraints on Net Pay}

We now show how a labor market with constraints provides a parsimonious refinement that helps the model account for the empirical facts. Wages for the young are constrained to equal those of the old workers due to pay equity constraints $\left(w_{i}=w_{j}\right)$. Old labor supply and demand

${ }^{84}$ Most simply, with infinitely elastic labor demand $(\alpha=1$ and $\beta=1)$, the expressions collapse to:

$$
\begin{aligned}
n_{i} & =\left(x_{i} \gamma_{i}\right)^{\xi} \cdot\left(1+\tau_{i}\right)^{-\xi} \cdot \phi_{i} \\
w_{i} & =\left(x_{i} \gamma_{i}\right) \cdot\left(1+\tau_{i}\right)^{-1} \\
\left(1+\tau_{i}\right) w_{i} & =\left(x_{i} \gamma_{i}\right)
\end{aligned}
$$

Gross wages are constant; net wages take the full incidence; employment responses depend on $\xi$. 
are in equilibrium and pin down the market-clearing old wage, which, due to our friction, also pin down youth wages. Such pay equity constraints distort the age gradient of net and gross wages, generating youth unemployment and nonstandard tax incidence patterns.

Equity-constrained net wages. The friction lies in the differentiation of net wages. While we could consider a variety of plausible reduced-form representations that capture this phenomenon (e.g. wage compression, a constraint on adjacent age group's maximal wage gap,...), we consider an exposition with identical wages:

$$
\frac{w_{i}}{w_{j}}=1
$$

Old workers are on their labor supply curve, such that their labor market clears:

$$
\phi_{o} w_{o}^{\xi}=n_{o}^{s}
$$

By contrast, youth labor supply exceeds the prevailing employment, given by labor demand:

$$
\phi_{y} w_{o}^{\xi}=n_{y}^{s}>n_{y}^{d}
$$

Labor demand for factor $i$ is:

$$
n_{i}^{d}=\left(\frac{\beta x_{i} \gamma_{i}}{\left(1+\tau_{i}\right) w_{i}}\right)^{\frac{1}{1-\beta}}\left[x_{j} \gamma_{j}\left[\frac{x_{j}}{x_{i}} \frac{\gamma_{j}}{\gamma_{i}} \frac{\left(1+\tau_{i}\right) w_{i}}{\left(1+\tau_{j}\right) w_{j}}\right]^{\frac{\alpha}{1-\alpha}}+x_{i} \gamma_{i}\right]^{\left(\frac{\beta}{\alpha}-1\right)\left(\frac{1}{1-\beta}\right)}
$$

Since wages are constrained to be identical, this expression becomes:

$$
n_{i}^{d}=\left(\frac{\beta x_{i} \gamma_{i}}{\left(1+\tau_{i}\right) w_{i}}\right)^{\frac{1}{1-\beta}}\left[x_{j} \gamma_{j}\left[\frac{x_{j}}{x_{i}} \frac{\gamma_{j}}{\gamma_{i}} \frac{1+\tau_{i}}{1+\tau_{j}}\right]^{\frac{\alpha}{1-\alpha}}+x_{i} \gamma_{i}\right]^{\left(\frac{\beta}{\alpha}-1\right)\left(\frac{1}{1-\beta}\right)}
$$

Equilibrium employment, net wages and gross wages of the old. We can now pin down the equilibrium employment level of the old, and therefore the old net and gross wages, which in turn pins down prevailing (disequilibrium) employment for the young and unemployment. By assumption, the old are on their labor supply curve, such that $w_{o}=\left(\phi_{o}^{-1} n_{o}^{s}\right)^{\frac{1}{\xi}}$. Plugging this in A23 for $i=o, j=y$, we obtain equilibrium employment for the old and their net and gross wages:

$$
\begin{aligned}
n_{o}^{e q} & =\left(\frac{\beta x_{o} \gamma_{o} \phi_{o}^{\frac{1}{\xi}}}{\left(1+\tau_{o}\right)}\left[x_{y} \gamma_{y}\left[\frac{x_{y}}{x_{o}} \frac{\gamma_{y}}{\gamma_{o}} \frac{\left(1+\tau_{o}\right)}{\left(1+\tau_{y}\right)}\right]^{\frac{\alpha}{1-\alpha}}+x_{o} \gamma_{o}\right]^{\frac{\beta}{\alpha}-1}\right)^{\frac{1}{1+\frac{1}{\xi}-\beta}} \\
w_{o}^{e q} & =\left(\phi_{o}^{-1} n_{o}^{e q}\right)^{\frac{1}{\xi}} \\
\left(1+\tau_{o}\right) w_{o}^{e q} & =\left(1+\tau_{o}\right)\left(\phi_{o}^{-1} n_{o}^{e q}\right)^{\frac{1}{\xi}}
\end{aligned}
$$

In contrast to employment level in the frictionless benchmark, the current expression does not contain any youth labor supply features (e.g. taste parameters) since they are off their labor supply curve. 
Prevailing youth employment is labor-demand-determined, because net wages constrained to be equal (but are too high to clear the market because the young are less productive $\left(\gamma_{y}<\gamma_{o}\right)$, and therefore moves in lock-step with old equilibrium employment given firm's optimal skill mix from (A5):

$$
n_{y}^{\text {diseq }}=n_{y}^{d}=\left[\frac{x_{y}}{x_{o}} \frac{\gamma_{y}}{\gamma_{o}} \frac{\left(1+\tau_{o}\right)}{\left(1+\tau_{y}\right)}\right]^{\frac{1}{1-\alpha}} \cdot \underbrace{\left(\frac{\beta x_{o} \gamma_{o} \phi_{o}^{\frac{1}{\xi}}}{\left(1+\tau_{o}\right)}\right)^{\frac{1}{1+\frac{1}{\xi}-\beta}}\left[x_{y} \gamma_{y}\left[\frac{x_{y}}{x_{o}} \frac{\gamma_{y}}{\gamma_{o}} \frac{\left(1+\tau_{o}\right)}{\left(1+\tau_{y}\right)}\right]^{\frac{\alpha}{1-\alpha}}+x_{o} \gamma_{o}\right]^{\left(\frac{\beta}{\alpha}-1\right)\left(\frac{1}{1+\frac{1}{\xi}-\beta}\right)}}_{=n_{o}^{e q}}
$$

Even the youth employment terms do not depend on youth labor supply terms (i.e. $\phi_{y}$ ), unlike in the frictionless benchmark.

Age gradients. It is interesting to examine how the age gradients for employment, net wages and gross wages contrast with the frictionless equilibrium benchmark. We then turn to the incidence of age-dependent payroll taxes, and their potential to offset the underlying wage friction.

By construction, the friction manifests itself as a flattened age gradient of net wages:

$$
\frac{w_{y}}{w_{o}}=1
$$

Since net wages are compressed due to the friction, the age gradient of net wages is always equal to one and are invariant in payroll tax differentials. (The wage level will endogenously change as pinned down by incidence in the old labor market.)

As a result, any payroll tax rate gradient therefore solely drives the age gradient of gross wages:

$$
\frac{\left(1+\tau_{y}\right) w_{y}}{\left(1+\tau_{o}\right) w_{o}}=\frac{1+\tau_{y}}{1+\tau_{o}}
$$

The age gradient of employment is, for any given equilibrium old employment level $n_{o}^{e q}$, directly given by the firm's labor demand preferences facing equal net wages yet potentially different payroll tax rates:

$$
\frac{n_{y}^{\text {diseq }}}{n_{o}^{e q}}=\left[\frac{x_{y}}{x_{o}} \frac{\gamma_{y}}{\gamma_{o}}\right]^{\frac{1}{1-\alpha}} \cdot\left[\frac{\left(1+\tau_{y}\right)}{\left(1+\tau_{o}\right)}\right]^{-\frac{1}{1-\alpha}}
$$

Comparison: frictionless equilibrium age gradient. Notably, the employment age gradient with equity constraints does not take into account any labor supply taste parameters of the young workers. To see this, compare the equity-constrained employment gradient with the frictionless age gradient for employment (A13).

Age-dependent employer payroll taxes to mimic the frictionless age gradient for gross wages and employment. Interestingly, payroll taxes can be set to have gross wages implement the frictionless age gradient for employment and gross wages (incl. a frictionless equilibrium with an arbitrary combination of payroll tax rates that may have been featured in 
the frictionless equilibrium to momic) 85

$$
\frac{1+\tau_{y}^{*}}{1+\tau_{o}^{*}}=\left[\frac{x_{y}}{x_{o}} \frac{\gamma_{y}}{\gamma_{o}}\right]^{\frac{1}{\xi(1-\alpha)+1}} \cdot\left[\frac{1+\tau_{y}}{1+\tau_{o}}\right]^{\frac{\xi(1-\alpha)}{\xi(1-\alpha)+1}} \cdot\left(\frac{\phi_{y}}{\phi_{o}}\right)^{-\frac{(1-\alpha)}{\xi(1-\alpha)+1}}
$$

Our conceptual framework and the collection of all our findings suggest that some of this age gradient in unemployment is due to insufficient alignment of gross wages with productivity fundamentals along the life cycle, i.e. that the effective labor cost per efficiency unit of labor are decreasing with age. We find that a net-pay equity friction, largely operating within firms, emerges as a plausible underlying friction. The generalization of our results, empirical and theoretical, is that an age-specific employer payroll tax schedule will be an effective and simple way to equalize the employer-facing productivity-adjusted gross wages with wage constraints. ${ }^{86}$ An age-specific employer payroll tax schedule is feasible because age is a fixed and easily observable attribute and therefore a suitable tag for differentiated tax rates. See Weinzierl (2011) for an application to age-dependent income taxes in a Mirrleesian framework.

Payroll tax cuts for the old only. Since the market for the old clears, standard competitive intuitions apply. Tax incidence is guided by relative demand $(\beta, \alpha)$ elasticities and supply elasticities $(\xi)$. With prime-aged workers being inelastic in their labor supply, their net wages will take the incidence - i.e. old net wages will increase -, and labor costs of the old (gross wages) will only slightly decrease. Since the old wages determines the youth wage, this process pushes up the gross wage of the young, making them less attractive to hire.

Encompassing payroll tax cuts. An interesting scenario is an encompassing payroll tax cut, i.e. one that affects $\tau_{y}$ and $\tau_{o}$ equally. Employment for the young is determined by the old's employment and wage levels, which clear the labor market for the old (but not the young if productivity parameters or taste parameters differ). As a result, when both payroll tax rates change, intuitions are guided by standard incidence mechanisms for the old wages (and thus the young wage too, although that market does not clear). This prediction is consistent with aggregate net-wage incidence in response to encompassing payroll tax cuts. As a result, encompassing payroll tax cuts need not be effective even if targeted payroll tax cuts are effective, if equity constraints exist. As a result, targeted payroll tax cuts may be more effective than encompassing ones. This prediction also differentiates a pay-equity friction from a simple wage floor or wage rigidity, where payroll tax cuts would be effective, at least in the short run.

Short-run vs. long-run effects. (Encompassing) employer payroll tax cuts may be effective in the short run under wage rigidities, but may be offset once wages adjust and realize the standard incidence predictions 87 By contrast, in the presence of cross-sectional pay equity constraints, age-graduated payroll taxes might be able to flatten and lift the age gradient of employment for young or otherwise disadvantaged workers even in the long run. In fact, we found no net-wage incidence even six years into the reform, and persistent employment effects.

\footnotetext{
${ }^{85}$ This tax reform need not be revenue-neutral. However, the base tax rate the old can be chosen arbitrarily.

${ }^{86}$ In fact, the prescription depends on some form of wage frictions not only as the source of the distortion but also for net wage incidence to not offset the labor cost reduction due to the payroll schedule.

${ }^{87}$ For this argument, see e.g. Bils and Klenow (2009).
} 
Youth unemployment. In the Swedish case, youth nonemployment manifested itself as unemployment, which gave rise to the policy concerns that ultimately led to the intervention. A standard competitive model without frictions would not feature unemployment 88 Our model generates a basic form of youth unemployment in form of rationed youth labor supply, i.e. the difference between labor supply - at the old wage $w_{y}=w_{o}-$, and labor-demand-determined prevailing employment A30. The presence of unemployment in form of rationed labor supply is a crucial ingredient in our model in that it rationalizes why employment increases can go along without net-wage changes even if labor supply elasticity $\xi$ is very small, which the frictionless economy would struggle to explain.

Concretely, the count of young workers in unemployment is:

$$
u_{y}=n_{y}^{s}-n_{y}^{d i s e q}=\phi_{y} w_{o}^{\xi}-n_{y}^{d i s e q}=\frac{\phi_{y}}{\phi_{o}} n_{o}^{e q}-n_{y}^{d i s e q}
$$

The unemployment rate $\tilde{u}$ is the ratio of the unemployed over the labor force, which here is desired labor supply:

$$
\begin{aligned}
\tilde{u} & =\frac{u_{y}}{n_{y}^{s}}=\frac{n_{y}^{s}-n_{y}^{\text {diseq }}}{n_{y}^{s}}=1-\frac{n_{y}^{\text {diseq }}}{n_{y}^{s}} \\
& =1-\left[\frac{x_{y}}{x_{o}} \frac{\gamma_{y}}{\gamma_{o}}\right]^{\frac{1}{1-\alpha}} \cdot\left[\frac{\left(1+\tau_{y}\right)}{\left(1+\tau_{o}\right)}\right]^{-\frac{1}{1-\alpha}} \frac{n_{o}^{s}}{n_{y}^{s}} \\
& =1-\left[\frac{x_{y}}{x_{o}} \frac{\gamma_{y}}{\gamma_{o}}\right]^{\frac{1}{1-\alpha}} \cdot\left[\frac{\left(1+\tau_{y}\right)}{\left(1+\tau_{o}\right)}\right]^{-\frac{1}{1-\alpha}} \cdot\left(\frac{\phi_{o}}{\phi_{y}}\right)
\end{aligned}
$$

The youth unemployment rate is pinned down by two factors: labor supply (how many workers would like to work at the upward-distorted wage) and labor demand (the, downward-distorted) amount of jobs for the young).

First, tastes for labor supply may differ between the two groups such that when considering any given going - homogeneous - wage (that of the old), the young workers may be less or more included to supply labor than the old (at that wage). This is captured by $\frac{\phi_{o}}{\phi_{y}}$. For the useful benchmark case in which baseline tastes for labor are equal, this ratio is 1 . We find this factor (taste differences explaining participation differences) less interesting because it would not carry over to an employment/population analysis.

The second source of unemployment is due to labor demand. It arises from the firm's upwarddistorted cost of employing a young worker in efficiency units given the pay-equity constraint and the lower productivity fundamentals of the young. For $\phi_{o}=\phi_{y}$ and initially homogeneous tax rates $\tau_{y}=\tau_{o}$, we have youth unemployment as long as the young have lower productivity parameters $x_{i} \gamma_{i}$ than the old.

The following payroll tax regime can eliminate youth unemployment from equity constraints:

$$
\left.\frac{1+\tau_{y}}{1+\tau_{o}}\right|_{\tilde{u}_{y}=0}=\frac{\gamma_{y}}{\gamma_{o}}\left(\frac{\phi_{o}}{\phi_{y}}\right)^{\frac{1}{1-\alpha}}
$$

Interestingly, this is generally not the schedule that would have the economy mimic the fric-

\footnotetext{
${ }^{88}$ While the payroll tax wedge would distort labor demand and supply as a labor wedge, each side of the market is on their respective demand and supply curves given gross and net wages.
} 
tionless equilibrium 89

\section{A.5 Two Types of Firms}

Lastly, we sketch one refinement to the model that helps it account not only for our market-level findings but also the firm-level heterogeneity and employment and wage effects. Paralleling our empirical design, we introduce two types of firms $f \in\{Y, O\}$ : the youth-intense firms $Y$ and old-intense firms $O$. In addition, we assume that the workers have CES preferences for their labor allocation. We sketch the model and point to the relevant mechanisms, but economize on space by not again solving for the full equilibrium. Crucially, the pay equity constraint works within firms, but not across firms.

\section{A.5.1 Households Labor Supply}

Rather than supplying labor to one firm, young households $y$ and old households $o$ supply labor to youth-intense firms $Y$ and old-intense firms $O$, such that:

$$
\begin{aligned}
& n_{y}=n_{y}^{Y}+n_{y}^{O} \\
& n_{o}=n_{o}^{Y}+n_{o}^{O}
\end{aligned}
$$

We preserve quasilinear utility but allow for CES-like aggregation of labor disutilities that generate firm-specific labor supply curves (we suppress taste parameters $\phi_{i}^{f}$ ):

$$
\begin{aligned}
u\left(c_{i}, n_{i}^{O}, n_{i}^{Y}\right) & =c_{i}-\frac{\left[\left[\left(n_{i}^{O}\right)^{1+\frac{1}{\xi}}\right]^{\psi}+\left[\left(n_{i}^{Y}\right)^{1+\frac{1}{\xi}}\right]^{\psi}\right]^{\frac{1}{\psi}}}{1+\frac{1}{\xi}} \\
& =c_{i}-n_{i}^{1+\frac{1}{\xi}} \cdot \frac{\left[\left[\left(\frac{n_{i}^{O}}{n_{i}}\right)^{1+\frac{1}{\xi}}\right]^{\psi}+\left[\left(\frac{n_{i}^{Y}}{n_{i}}\right)^{1+\frac{1}{\xi}}\right]^{\psi}\right]^{\frac{1}{\psi}}}{1+\frac{1}{\xi}}
\end{aligned}
$$

The household incurs the standard $\xi$-guided disutility of total labor supply $n_{i}$, but also has preferences over smoothing out or concentrating labor supply between firm types, as guided by $\psi$. The individual utility maximization FOC gives for $i$ 's labor supply to firms $f$ and $g / f$ :

$$
\left(n_{i}^{s f}\right)^{\frac{1}{\xi}}\left[\left[\left(n_{i}^{s}{ }_{i}^{f}\right)^{1+\frac{1}{\xi}}\right]^{\psi}+\left[\left(n_{i}^{g}\right)^{1+\frac{1}{\xi}}\right]^{\psi}\right]^{\frac{1}{\psi}-1}=w_{i}^{f}
$$

For $\psi=1$, the firm-specific labor supply preferences are separable, which precludes between-firm spillovers through wages, which we will conveniently use for a tractable exposition.

\footnotetext{
${ }^{89}$ The reason is that part of youth unemployment arises from the wage that is "too high", which makes the marginal worker still strictly prefer to work at the net wage that is constrained to equal that of the (more productive) older workers; this component will persist even when payroll taxes achieve the frictionless employment gradient. We find this portion of unemployment less interesting, and in fact a policy-maker could eliminate this residual unemployment by increasing the employee payroll tax in practice.
} 


\section{A.5.2 Labor Demand}

The production functions for a given firm $f$ is:

$$
F^{f}\left(n_{y}, n_{o}\right)=\left(x_{y}^{f} \gamma_{y}\left(n_{y}^{f}\right)^{\alpha}+x_{o}^{f} \gamma_{o}\left(n_{o}^{f}\right)^{\alpha}\right)^{\frac{\beta}{\alpha}}
$$

where $x_{i}^{f}$ now denotes the firm-specific weight in the production function of a given worker-age type $i$. so that $\sum_{i=y, o} x_{i}^{f}=1$. Age-bias $x_{i}^{f}$ will generate the between-firm dispersion in youth intensity of firms in the model.

As before, we can express the labor demand for the old again as follows:

$$
n_{o}^{d_{o}^{f}}=\left(\frac{\beta x_{o}^{f} \gamma_{o}}{\left(1+\tau_{o}\right) w_{o}^{f}}\right)^{\frac{1}{1-\beta}}\left[x_{y}^{f} \gamma_{y}\left[\frac{x_{y}^{f}}{x_{o}^{f}} \frac{\gamma_{y}}{\gamma_{o}} \frac{\left(1+\tau_{o}\right) w_{o}^{f}}{\left(1+\tau_{y}\right) w_{y}^{f}}\right]^{\frac{\alpha}{1-\alpha}}+x_{o}^{f} \gamma_{o}\right]^{\left(\frac{\beta}{\alpha}-1\right)\left(\frac{1}{1-\beta}\right)}
$$

Equilibrium. With the convenient case $\psi=1$, the economy mirrors the representative-agent case discussed above 90 Moreover, with the equity constraint in net pay within firms, we obtain the following equilibrium labor market outcomes:

$$
\begin{aligned}
n_{i}^{e q f} & =\left(\frac{\beta x_{i} \gamma_{i} \psi_{i}^{\frac{1}{\xi}}}{1+\tau_{i}}\left[x_{j} \gamma_{j}\left(\left[\frac{x_{i}}{x_{j}} \gamma_{i} \gamma_{j}^{\frac{\xi \alpha}{\xi(1-\alpha)+1}} \cdot\left[\frac{1+\tau_{i}}{1+\tau_{j}}\right]^{-\frac{\xi \alpha}{\xi(1-\alpha)+1}}\right)+x_{i} \gamma_{i}\right]^{\frac{\beta}{\alpha}-1}\right)^{\frac{1}{\xi}+(1-\beta)}\right. \\
w_{i}^{e q f} & =\left(\psi_{i}^{-1} n_{i}^{e q f}\right)^{\frac{1}{\xi}} \\
\left(1+\tau_{i}\right) w_{i}^{e q f} & =\left(1+\tau_{i}\right)\left(\psi_{i}^{-1} n_{i}^{e q f}\right)^{\frac{1}{\xi}}
\end{aligned}
$$

As in the market-level analysis, the firm-level factor that guides employment and wage effects is (now firm-specific) labor supply elasticity $\xi$. Here, we broadly interpret $\xi$ as a tractable way to model rent-sharing-like patterns in a labor monopsony narrative.

Deriving the labor cost share of young workers as the mediator of the firm-level effects. Crucially for our identification design, we must show that the empirical sorting of firms by their labor-cost share young predicts larger elasticity of (old, but also overall) employment to a shift in the youth payroll tax rate, and in turn into net wages paid by the firm. We do so with a simple comparative static argument of employment to the youth payroll tax: For youth employment we find the following elasticity:

$$
\frac{d \ln \left(n_{y}^{f}\right)}{d \ln \left(1+\tau_{y}\right)}=-\frac{1}{1-\alpha}-\frac{\beta-\alpha}{1-\alpha} \frac{1}{\frac{1}{\xi}+(1-\beta)} \frac{n_{y}^{f} w_{y}^{f}\left(1+\tau_{y}\right)}{\frac{n_{y}^{f} w_{y}^{f}\left(1+\tau_{y}\right)+n_{o}^{f} w_{o}^{f}\left(1+\tau_{o}\right)}{4}}
$$

\footnotetext{
${ }^{90}$ The difference is now that, with $\psi \neq 1$, we cannot directly replace $w_{o}^{f}$ as a function of only $n_{o}^{f}$ from the worker utility function, but there are between-firm-type wage spillovers through the worker's non-separable labor disutility. Since we our cross-sectional difference-in-difference (or dosage treatment) design cannot pick up such spillovers, we here consider $\psi=1$ for clarify of exposition.
} 
For old employment we find the following elasticity:

$$
\frac{d \ln \left(n_{o}^{f}\right)}{d \ln \left(1+\tau_{y}\right)}=-\frac{1}{\frac{1}{\xi}+(1-\beta)} \frac{\beta-\alpha}{1-\alpha} \frac{n_{y}^{f} w_{y}^{f}\left(1+\tau_{y}\right)}{\frac{n_{y}^{f} w_{y}^{f}\left(1+\tau_{y}\right)+n_{o}^{f} w_{o}^{f}\left(1+\tau_{o}\right)}{1}}
$$

Since we cannot observe these structural parameters that ultimately guide the elasticity, the above result (that labor demand implies that the endogenous (optimally chosen) labor cost share equals the structural parameters) is crucial. Therefore, we sort firms by their payroll share young, which precisely determines its exposure and response to the payroll tax cut. This share young is exactly the firm-level variable we plot in Figure 8, the histogram in Panel (a) and its evolution in Panel (b).

$$
\frac{n_{y}^{f} w_{y}^{f}\left(1+\tau_{y}\right)}{n_{y}^{f} w_{y}^{f}\left(1+\tau_{y}\right)+n_{o}^{f} w_{o}^{f}\left(1+\tau_{o}\right)}=\frac{x_{y}^{f} \gamma_{y}\left[\frac{x_{y}^{f}}{x_{o}^{f}} \frac{\gamma_{y}}{\gamma_{o}} \frac{\left(1+\tau_{o}\right)}{\left(1+\tau_{y}\right)}\right]^{\frac{\alpha}{1-\alpha}}}{\left[x_{y}^{f} \gamma_{y}\left[\frac{x_{y}^{f}}{x_{o}} \frac{\gamma_{y}}{\gamma_{o}} \frac{\left(1+\tau_{o}\right)}{\left(1+\tau_{y}\right)}\right]^{\frac{\alpha}{1-\alpha}}+x_{o}^{f} \gamma_{o}\right]}
$$

Total firm employment responses are is the employment-weighted average of two elasticities. Net wage effects are guided by the elasticity of old employment and the labor supply elasticity, and inherit the dependence on the share of youth labor costs in total labor costs:

$$
\frac{d \ln \left(w_{o}^{f}\right)}{d \ln \left(1+\tau_{y}\right)}=\frac{1}{\xi} \frac{d \ln \left(n_{o}^{f}\right)}{d \ln \left(1+\tau_{y}\right)}=-\frac{\frac{1}{\xi}}{\frac{1}{\xi}+(1-\beta)} \frac{\beta-\alpha}{1-\alpha} \frac{n_{y}^{f} w_{y}^{f}\left(1+\tau_{y}\right)}{n_{y}^{f} w_{y}^{f}\left(1+\tau_{y}\right)+n_{o}^{f} w_{o}^{f}\left(1+\tau_{o}\right)}
$$


Figure A1: New Hires in 2000: Job Length by Age

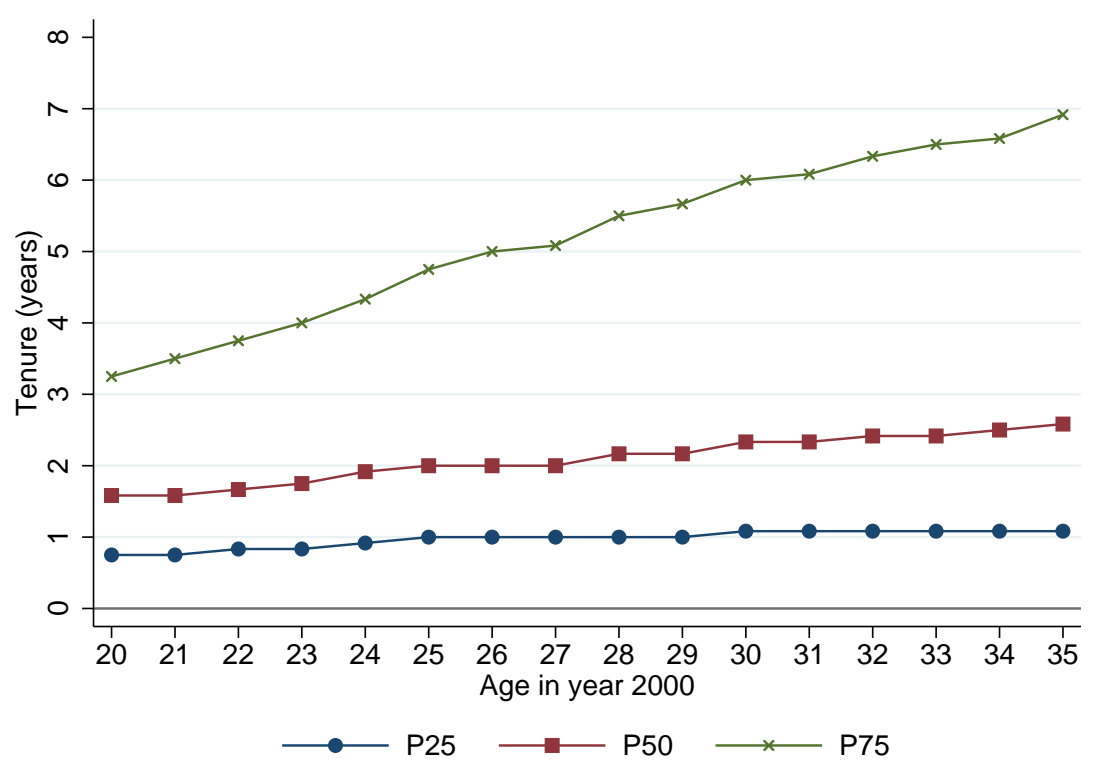

Notes: This figure depicts job length by age of hiring for individuals newly hired in 2000. A newly hired individual is defined as someone who never worked with the firm in the past but starts in 2000. We additionally require that earnings in 2000 from that employer exceed the minimum threshold of $\$ 4,940$ (in 2012 dollars). For individuals with multiple new spells in 2000 exceeding that threshold, we select the spell with highest earnings. We then follow that spell over time and define a separation in year $t$ as having earnings from that same employer (who hired them in 2000) in year $t$ but not in year $t+1$ (the series are only slightly different if we allow for one-year-gaps in the spells, accounting for the generous parental leave system and sickness insurance). Age is defined as the age the person reaches during year 2000. The series depict the 25 th, 50 th and 75 th percentiles of tenure, measured in months, for the work spells among such newly hired by age in 2000 . We do not show the mean as the series are censored in 2013 (the last year of data). For young workers aged 20-26, the median spell is less than 2 years. The series implies that the absence of tax incidence on wages cannot be explained solely by the concern that all young hires will age out of the payroll tax eligibility on the job. 
Figure A2: The Effect of the Payroll Tax Cut on Wages: High vs. Low Turnover Industries

(a) High Turnover Industries: Monthly Net Wages

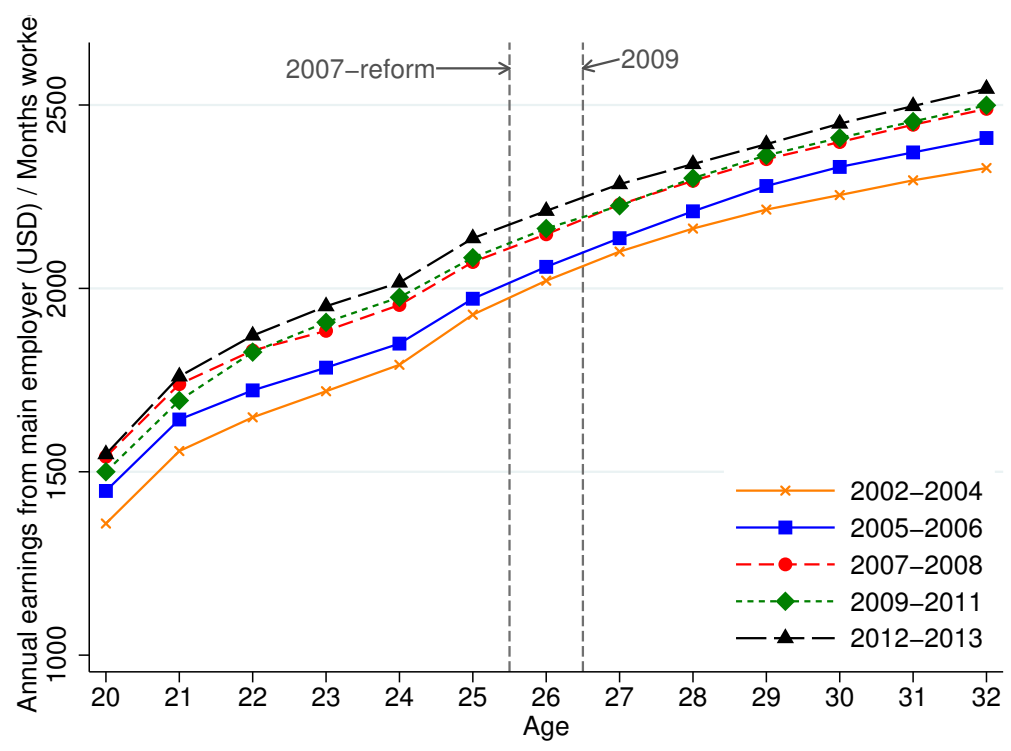

(b) Low Turnover Industries: Monthly Net Wages

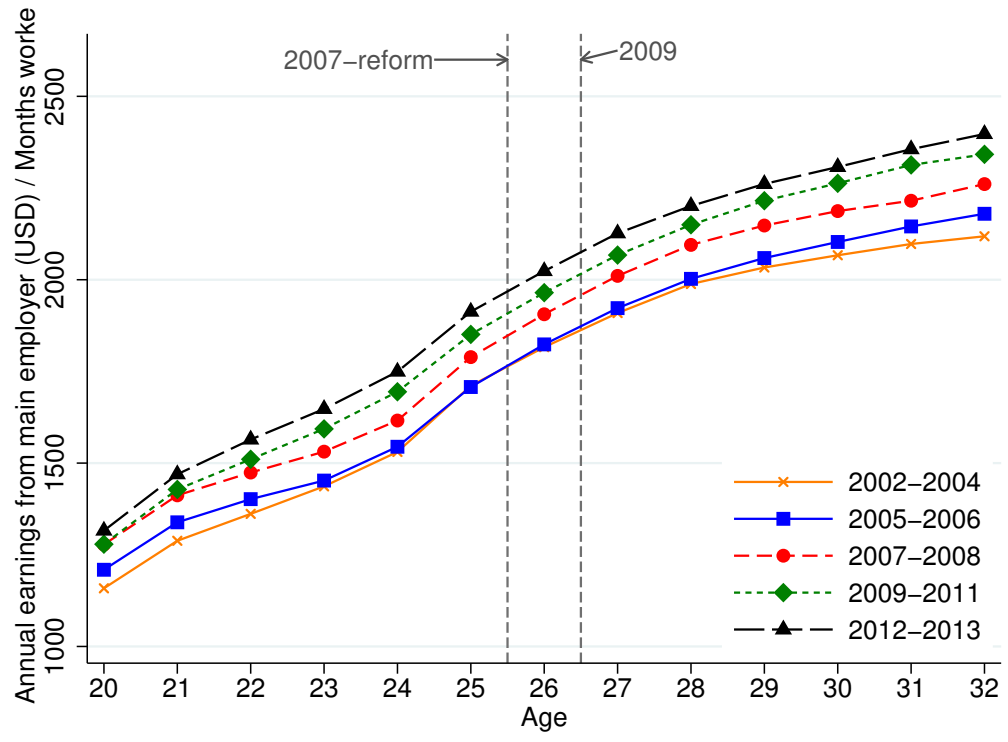

Notes: This figure examines robustness of our market-level wage results by replicating it separately for high and low turnover industries. Our turnover measure is the mean job duration of new job spells in 2000 for workers aged 20-25, within industry for the coarse 10-industry classification. We split industries by median (weighted by 2000 employment). Net wages are continuous at the age thresholds for both high and low turnover industries. The absence of wage incidence even for the high-turnover industries indicates that wage-smoothing in long-term wage contracts is unlikely to be the main explanation for the wage patterns. The wage measure is average monthly net wage (the full-time equivalent contracted monthly wage, net of payroll taxes) in Sweden by age and time periods using the Structure of Earnings Survey data. It is adjusted for inflation (base-year 2003) and converted to US dollars using an exchange rate of 8.9 SEK/USD (as of 4/18/2017). Age is defined as the age turned during the calendar year, which is the relevant concept for the payroll tax cut. The two dashed vertical lines depict the age thresholds under which the payroll tax cuts apply in 2007-08 and 2009-14 respectively. 
Figure A3: Comparing our Employment and Unemployment Measures with Official Statistics

(a) Comparison of the employment rates

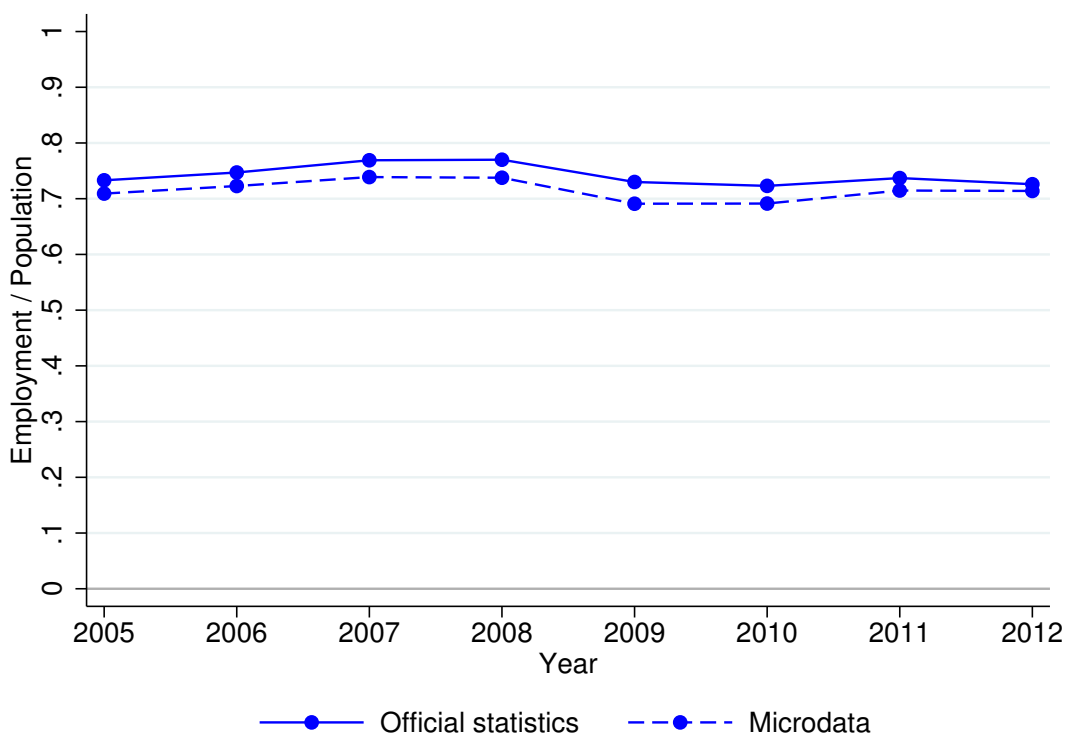

(b) Comparison of the unemployment rates

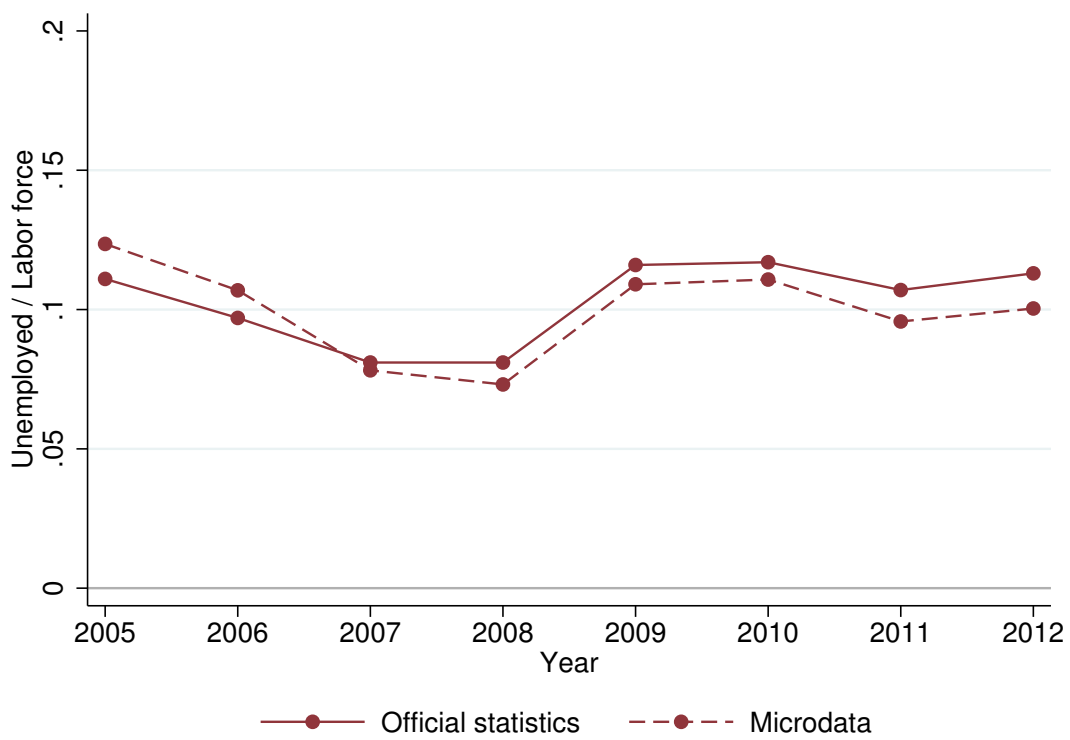

Notes: This figure compares our employment and unemployment measures with official statistics. Our measures are created using administrative full population data while official statistics are created using survey data. The top panel depicts the share of the population aged 20-34 in employment. The bottom panel considers the share of the labor force aged 20-34 (which includes the employed and the unemployed) in unemployment. In our data, a person is defined as employed when annual wage earnings (either from wages or self-employment) are above a minimum threshold of $\$ 4,940$ in 2012 (and adjusted for inflation in other years). In official statistics, a person is defined as employed if he/she works at least one hour during the week of the survey (or has an employment contract, but was absent during the survey week). In our data, a person is defined as unemployed when he/she has zero earnings or earnings below the minimum threshold and has been registered with the unemployment agency for at least one day during the year. In official statistics, an individual is labelled unemployed if he/she is not employed but has applied for at least one job during the past four weeks. 
Figure A4: The Effect of the Payroll Tax Cut on Employment to Labor Force: Robustness

(a) Adding students to labor force

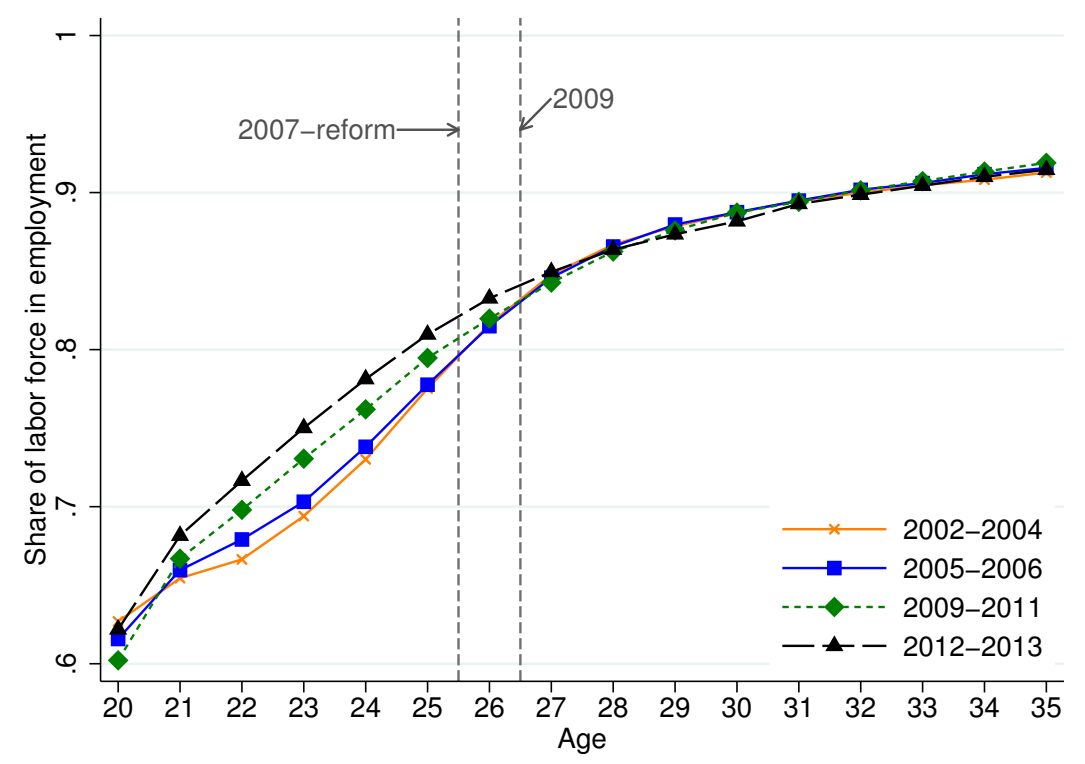

(b) Varying the earnings threshold to define employment

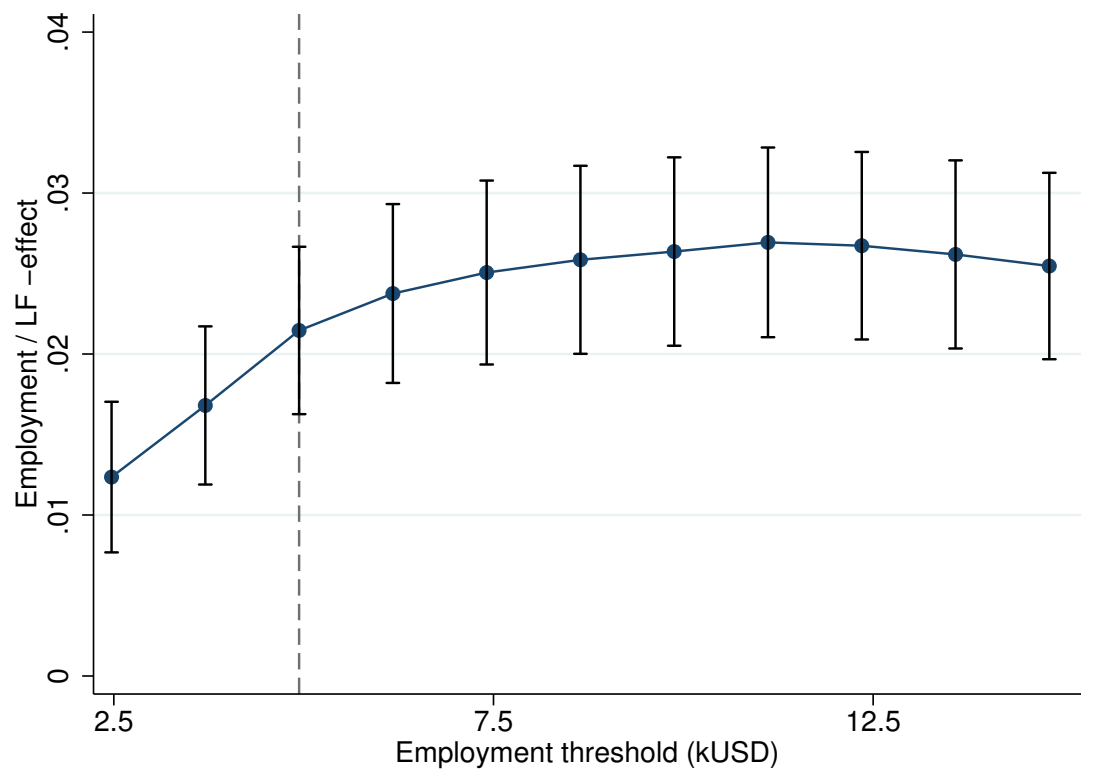

Notes: This figure investigates the robustness of the employment to labor force effects depicted in Figure 6. top panel. In the top panel, we add students to the labor force denominator. In the bottom panel, we keep the labor force constant (using the baseline definition) but vary the earnings threshold required for being labelled as employed. We then estimate the DD-specification in equation (1) and plot the coefficients of the reform-effect along with 95\%-confidence intervals. Both graphs show that the employment effects we have obtained are robust to these alternative definitions. The estimates from adding students to the labor force are presented in row 2 of Table 2. The bottom panel shows that employment to labor force effects are strongest when employment is defined as annual wage earnings above $\$ 10,000$. 
Figure A5: The Effect of the Payroll Tax Cut on Labor Force to Population Ratio

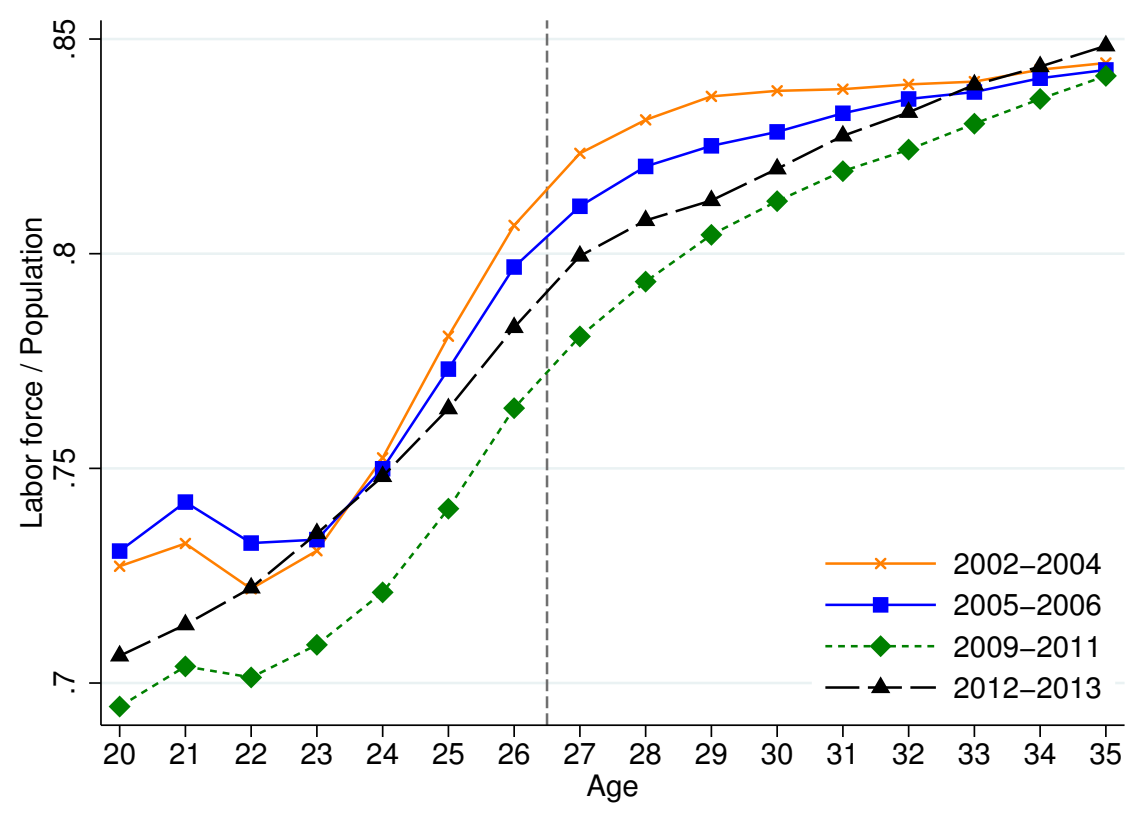

Notes: The figure shows the labor force to population ratio by age and time periods. The labor force numerator is defined as in Figure 6 as all residents who are either (i) employed with annual wage earnings above a small annual threshold; (ii) unemployed defined as having registered with the Unemployment Office at any point during the year. The small annual threshold is equal to $\$ 4,940$ in 2012 (and adjusted for inflation in other years). The population denominator is defined as all residents. The figure does not show a clear impact of the tax cut on labor force to population suggesting no supply side response from individuals (although pre-trends are not very parallel and hence could mask small effects). 
Figure A6: The Effect of the Payroll Tax Cut on Self-Employment

(a) Fraction of the population with self-employment earnings

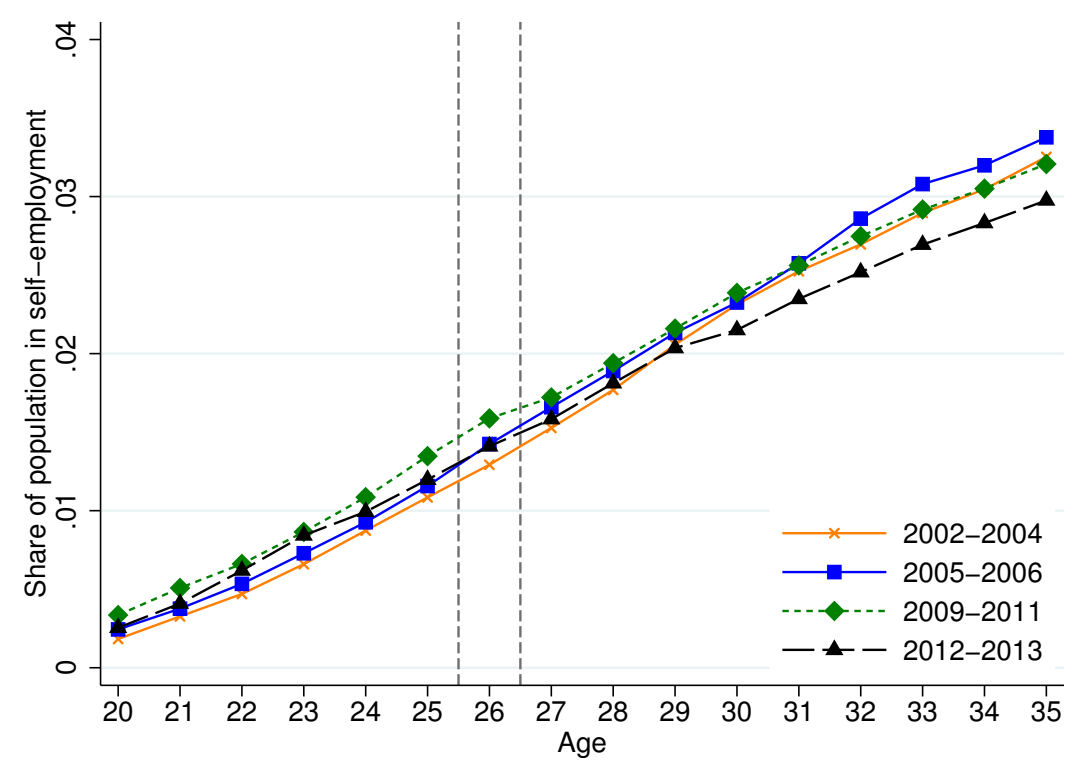

(b) Average self-employment earnings gross of tax (and including zeros)

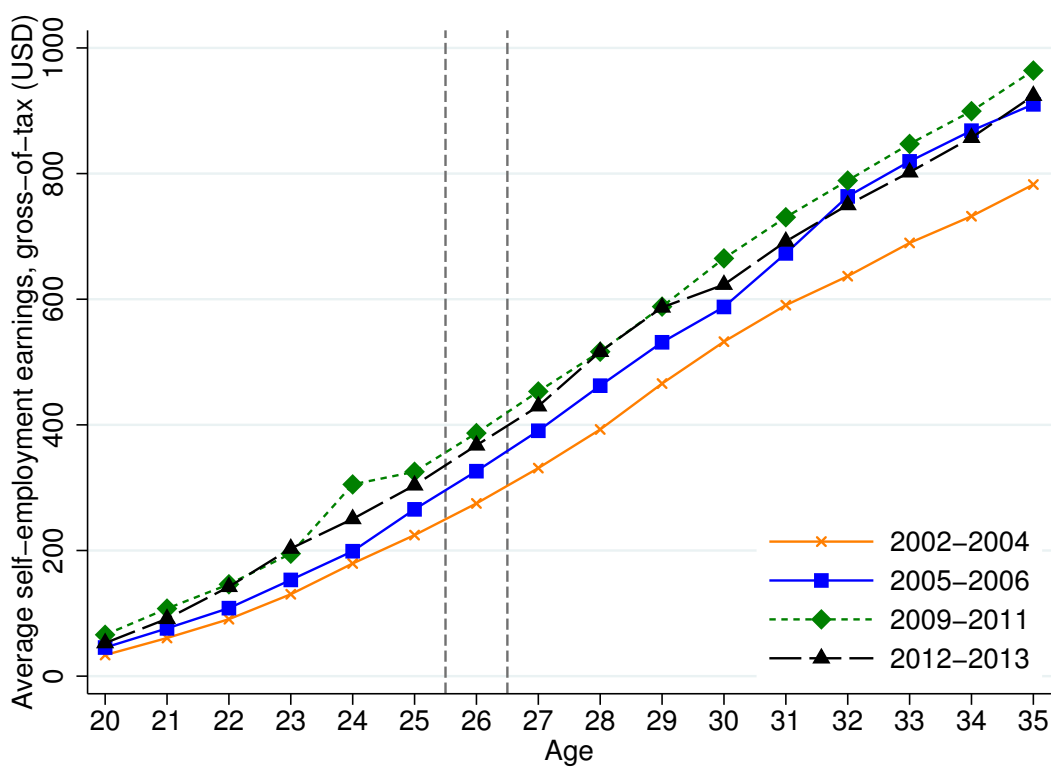

Notes: This figure depicts the effects of the payroll tax cut on self-employment. The top panel plots the share of the population by age and groups of years with annual self-employment earnings above a minimum threshold of $\$ 4,940$ (in 2012 and adjusted for inflation in other years) as used for our wage earnings analysis. The bottom panel plots average self-employment earnings in the full population (hence including zeros) by age and groups of years. Self-employment earnings are before payroll tax so that there is no mechanical effect of the reform. Both graphs suggest relatively modest effects on self-employment of the payroll tax cuts, hereby replicating the findings of Egebark (2016). However, the pre-trends are not as compellingly parallel as in our analysis of wage earnings, so that we have less confidence on the reliability of these self-employment effects. Regression results based on these graphs are somewhat sensitive to the age range chosen (results not reported). 
Figure A7: Youth Unemployment Rate by Region 2006

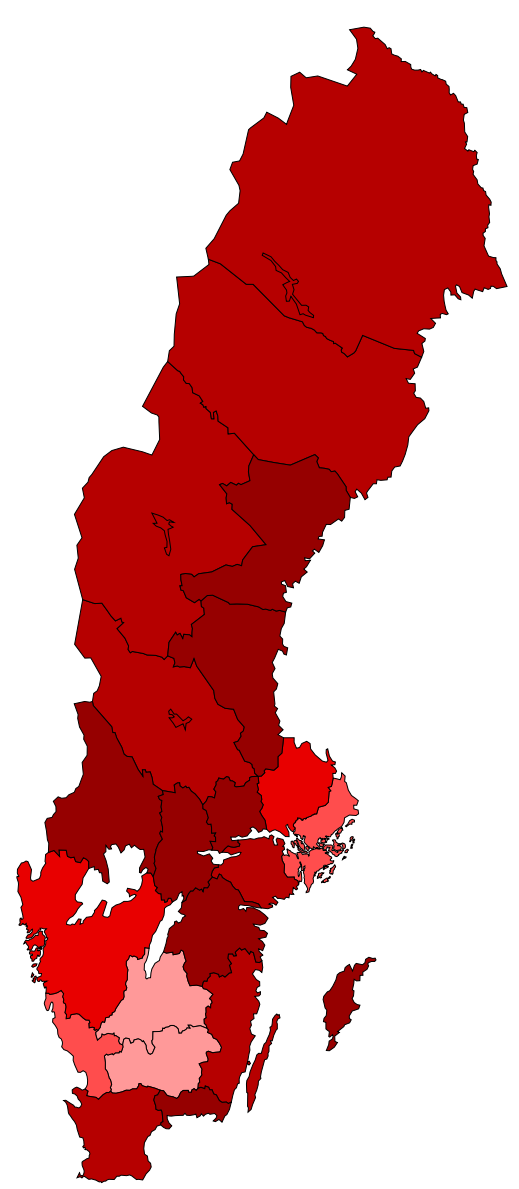

Quintiles of Youth Unemployment Rate in 2006

Q5: Darkest $20-23.3 \%$

Q4: Dark $17.8-20 \%$

Q3: Medium 14.9-17.8\%

Q2: Light $12.4-14.9 \%$

Q1: Lighest $10.5-12.4 \%$

Notes: This figure depicts the heterogeneity in youth unemployment rate in 2006 across Swedish regions. Youth unemployment rate is defined as the unemployment rate (unemployed to labor force) among individuals aged 16-25. We follow the same definition as in our analysis on Figure 6. Panel (a). We divide all 21 regions of Sweden into five quintiles (population weighted) and use a color scale for each quintile from lightest (lowest unemployment rate) to darkest (highest unemployment rate). The legend next to the map displays the ranges of youth unemployment rates across each quintile. This division of regions underlies the analysis of heterogeneous employment effects by size of unemployment rate depicted in Figure 6. Panel (b) and Table 3. 
Figure A8: Firm-level Effects: Very High and Fairly High vs. Medium Share Young

(a) First stage: share young

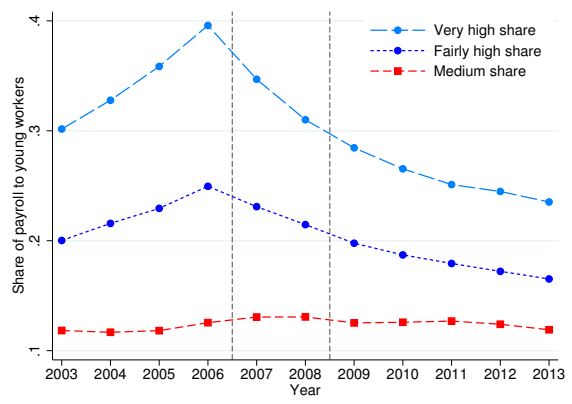

(c) Sales

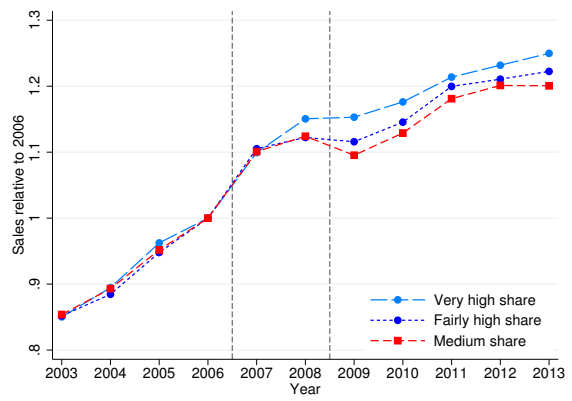

(e) Profits

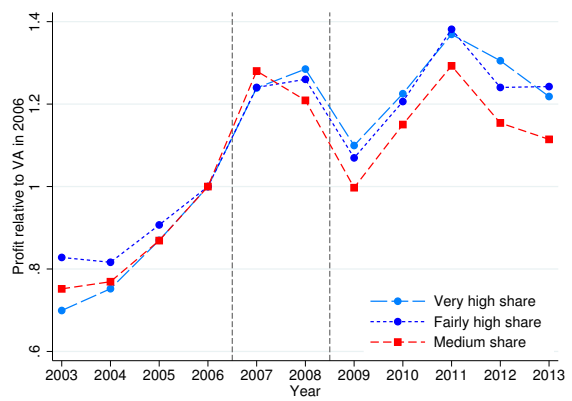

(g) Payroll tax per worker

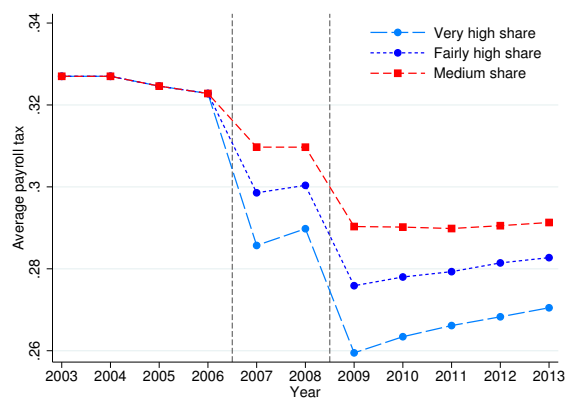

(b) Capital: total assets

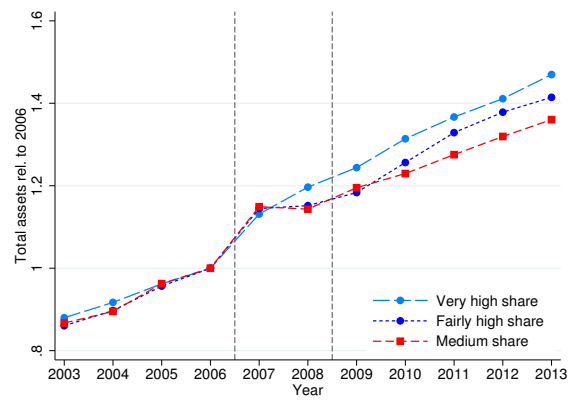

(d) Value added

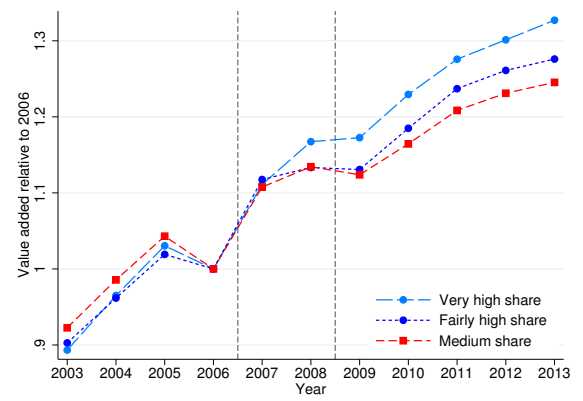

(f) Net wage earnings per worker

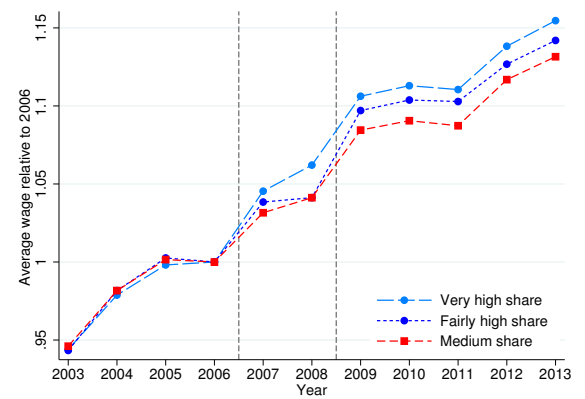

(h) Gross wage earnings per worker

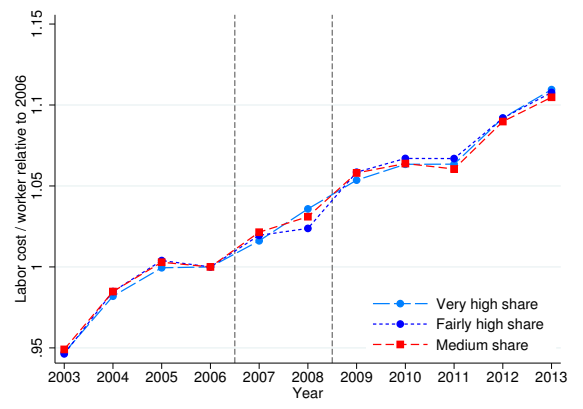

Notes: This figure reproduces the first stage Figure 8 , the firm-level effects on business growth of Figure 10 , and net and gross wages per worker of Figure 12 but further splitting the high share young group into 2 equally sized groups: (a) very high share young, (b) fairly high share young (as done in Panel (b) of Figure 9). All panels show parallel pre-trends (except profits) and larger effects for the very high share young group than for the fairly high share young group. Corresponding estimates are provided in Table 5. 
Figure A9: Firm-level Effects: Robustness to Including Non-operating Firms

(a) Number of workers

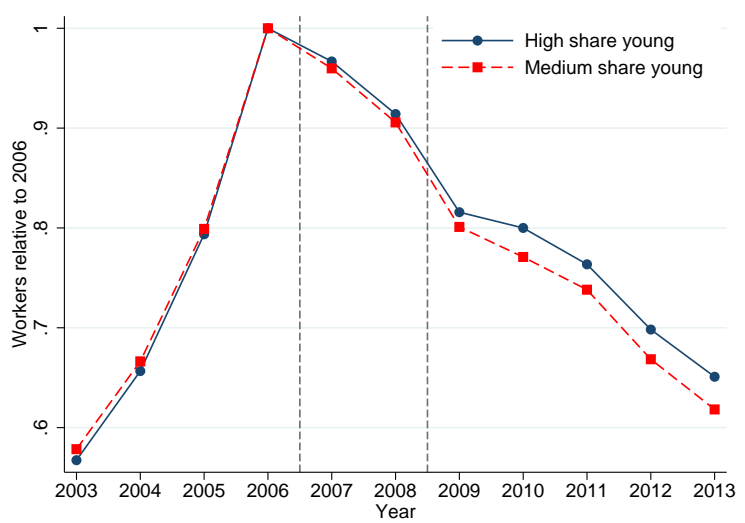

(c) Value added

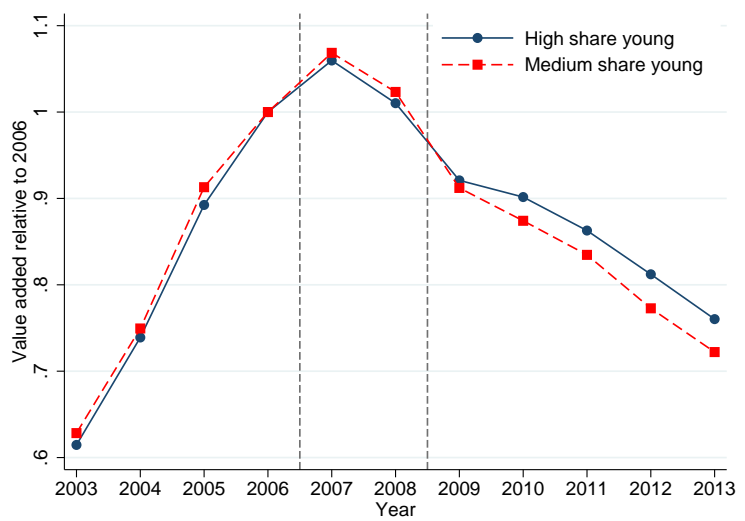

(b) Sales

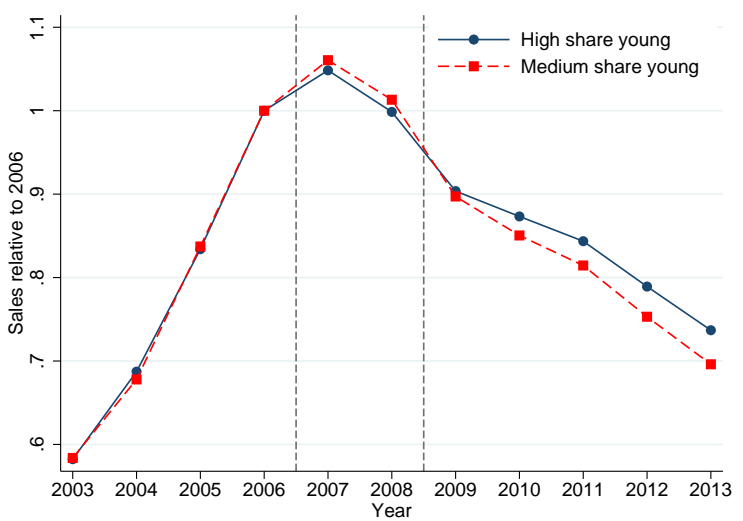

(d) Profits

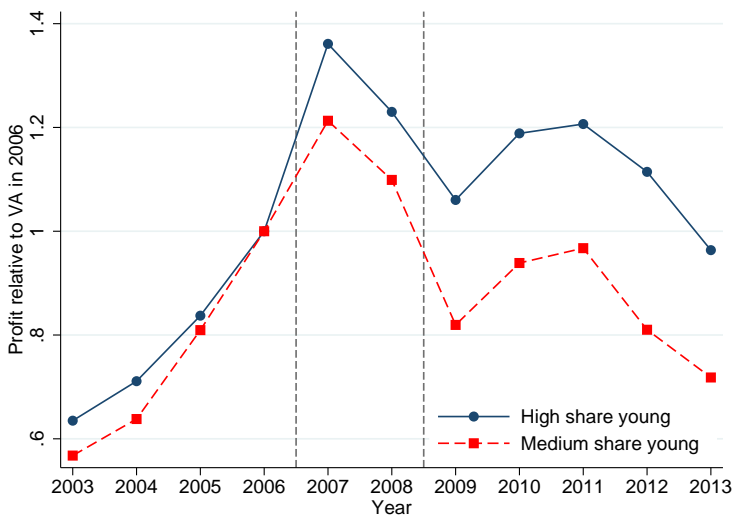

Notes: The figure proposes a robustness check of Figures 9 and 10 by including non-operating firms instead of considering a balanced panel of firms operating in all years 2003-2013 as in the main text. In this graph, we consider all firms present in 2006 and operating with more than 3 workers in 2006, regardless of whether they operate in other years as in Figure 11. Firms are naturally assigned zero values for employment, sales, value added, and profits in years in which they do not operate. We then compare firms with a high share young in 2006 to firms with a medium share young in 2006 as in the main text. As in Panel (b) of Figure 11, we DFL reweight firms based on their age in 2006 in order to make the two groups comparable in terms of pre-trends. Panels (a-d) show that pre-trends are well aligned (except for profits) and that firms with high share young experience faster employment, sales, value added, and profits growth after the reform consistent with the results using the balanced panel of firms in the main text. Corresponding estimates are presented in Table 5 , column (4). 
Figure A10: Firm-level Effects: Robustness to Changing the Base Year from 2006 to 2003

(a) First stage (2006)

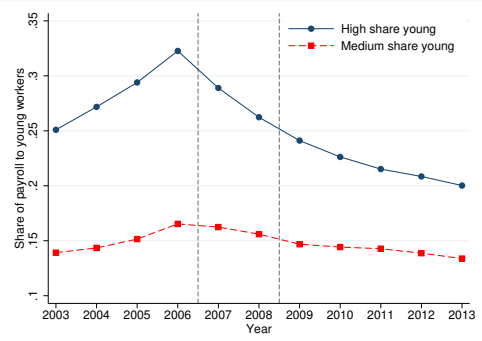

(c) Number of workers (2006)

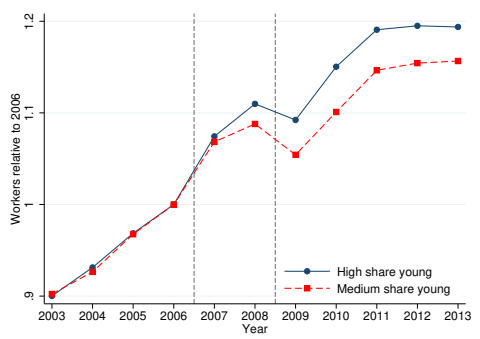

(e) Sales (2006)

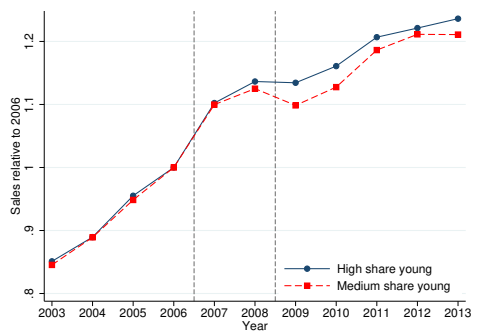

(g) Individual earnings (2006)

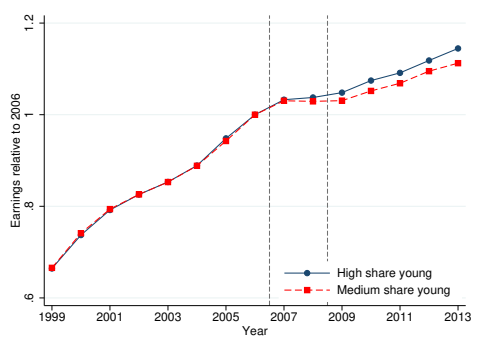

(b) First stage (2003)

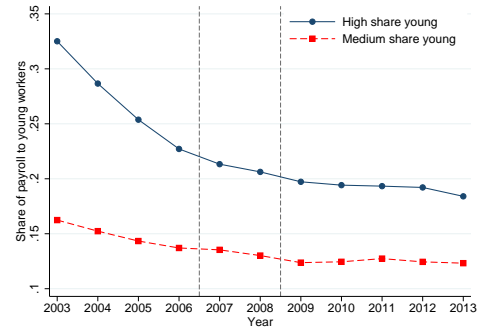

(d) Number of workers (2003)

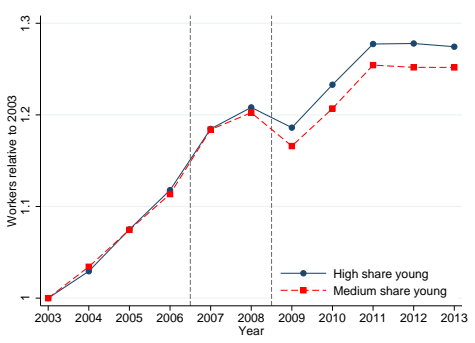

(f) Sales (2003)

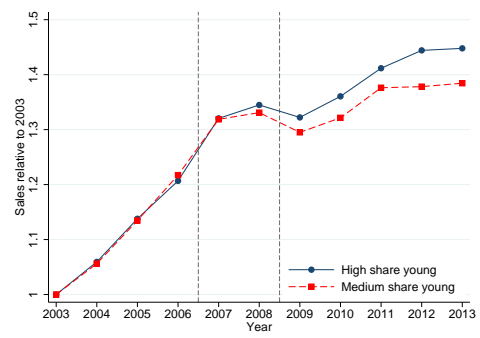

(h) Individual earnings (2003)

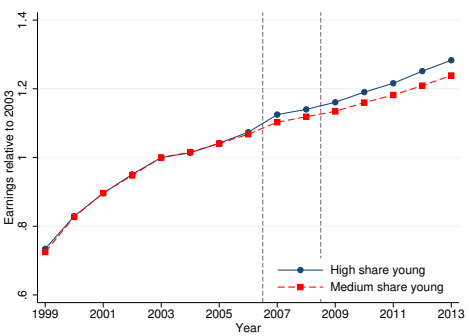

Notes: The figure proposes a robustness check by comparing firms' outcomes when defining the treatment and control groups based on year 2003 instead of year 2006. The left-hand-side panels consider the 2006 base year as in the main text while the right-hand-side panels consider the 2003 base year. In both cases, we still consider the balanced panel of firms operating in all years 2003-2013 as in the main text. For the left (right) side panels, the treatment group is defined as firms in the top quartile of share young in payroll in 2003 (2006) among firms with positive share young; the control group is defined as firms in the second quartile (below the top quartile) of share young in payroll in 2003 (2006). Note that we use here as control group the second quartile instead of the middle two quartiles as in the main text. This is because the bottom of the middle two quartiles does not exhibit parallel trends pre-reform when using the 2003 base year. The side-by-side graphs show that our first stage, and effect on number of workers, sales, and longitudinal individual earnings are robust to changing the base year to 2003. For all outcomes, pre-reform trends are parallel and an effect arises after the reform. 


\section{Figure A11: Firm Employment Effects by Credit Constraint Proxies}
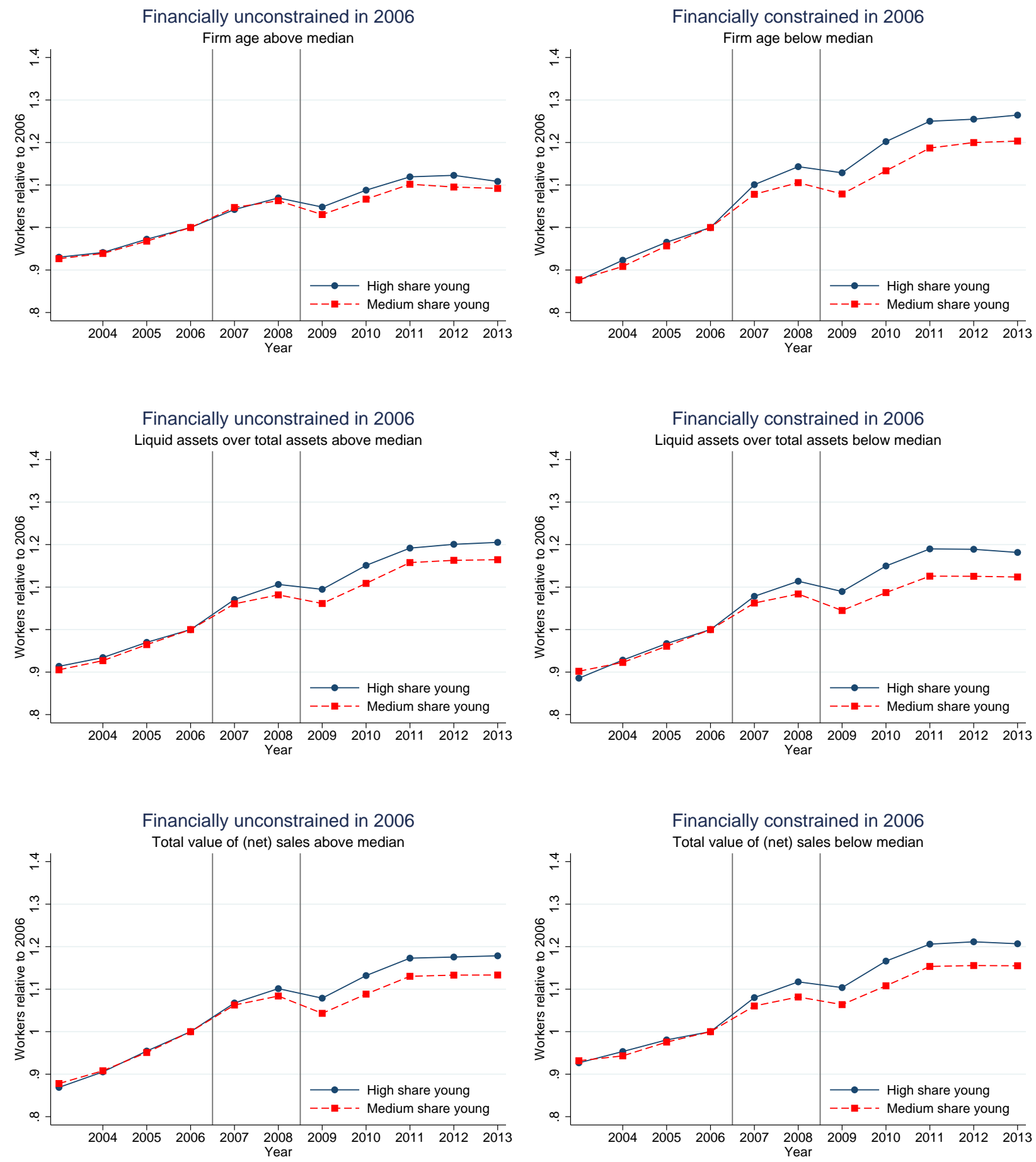

Notes: This figure repeats Figure 9, Panel (b) on the effects on firms of the payroll tax cut on the growth of employment (relative to 2006) but splitting the sample by proxies for credit constraints as of 2006. Each of the three rows considers a specific proxy for credit constraints: (1) age of the firm, (2) liquid assets over total assets, (3) size of firm measured by net sales. In each row, the left panel is for firms with low credit constraints and the right panel for firms with high credit constraint based on the proxy being above or below median (in 2006). In all cases, pre-trends are parallel supporting our identification assumption. Overall, we find employment responses in all types of firms, constrained or not, but responses are larger for firms more likely to be credit constrained based on the proxies (see Table 6 for corresponding estimates). 
Figure A12: Firm Asset Growth Effects by Credit Constraint Proxies
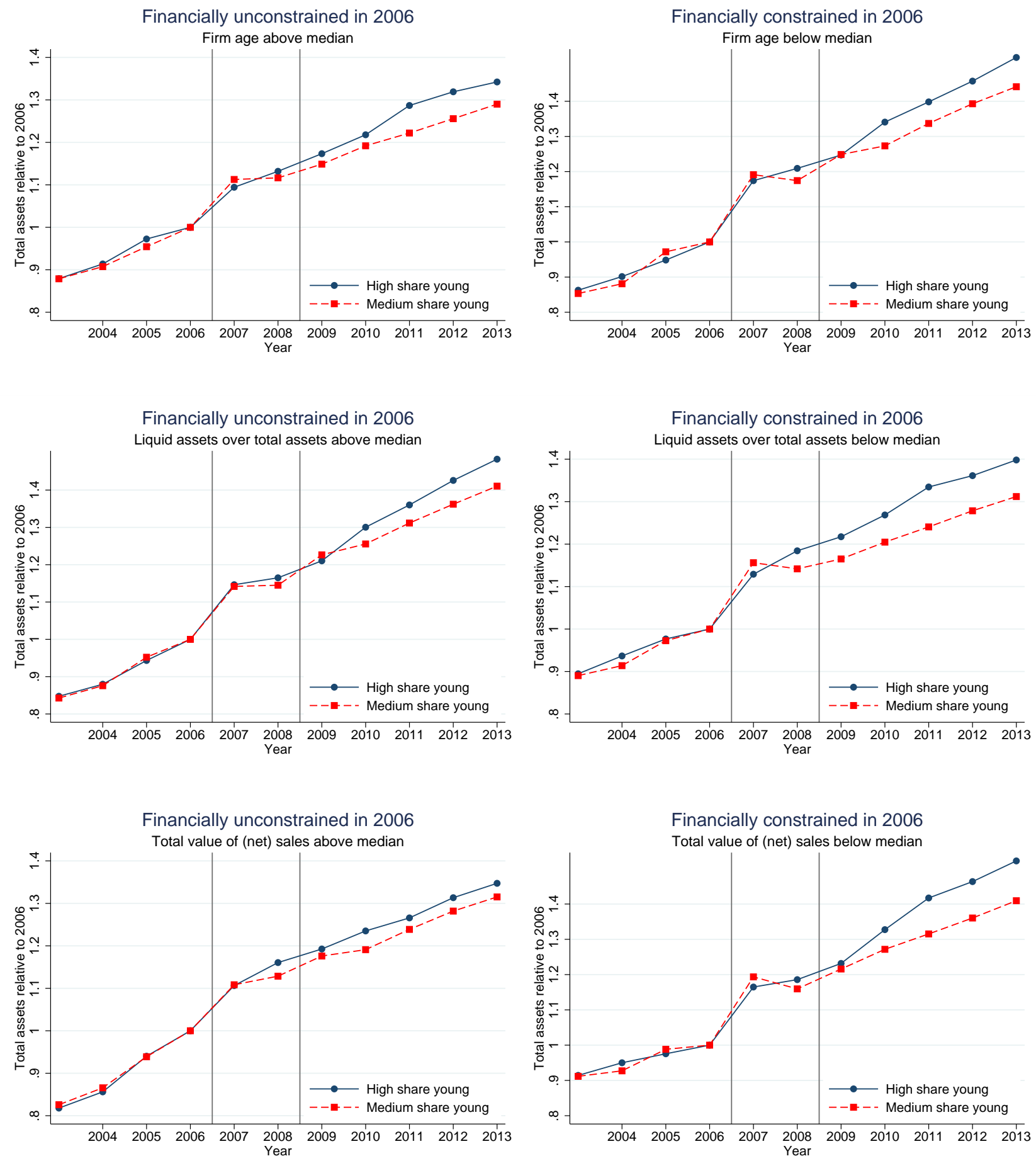

Notes: This figure repeats Figure 10, Panel (a) on the effects on firms of the payroll tax cut on the growth of total assets (relative to 2006) but splitting the sample by proxies for credit constraints as of 2006. Each of the three rows considers a specific proxy for credit constraints: (1) age of the firm, (2) liquid assets over total assets, (3) size of firm measured by net sales. In each row, the left panel is for firms with low credit constraints and the right panel for firms with high credit constraint based on the proxy being above or below median. In all cases, pre-trends are parallel supporting our identification assumption. Overall, we find asset growth in all types of firms, constrained or not, but responses are larger for firms more likely to be credit constrained based on the proxies (see Table 6 for corresponding estimates). 
Figure A13: Individual-level Effects on Extensive Margin Earnings (Employment)

(a) Fraction of individuals working at any firm

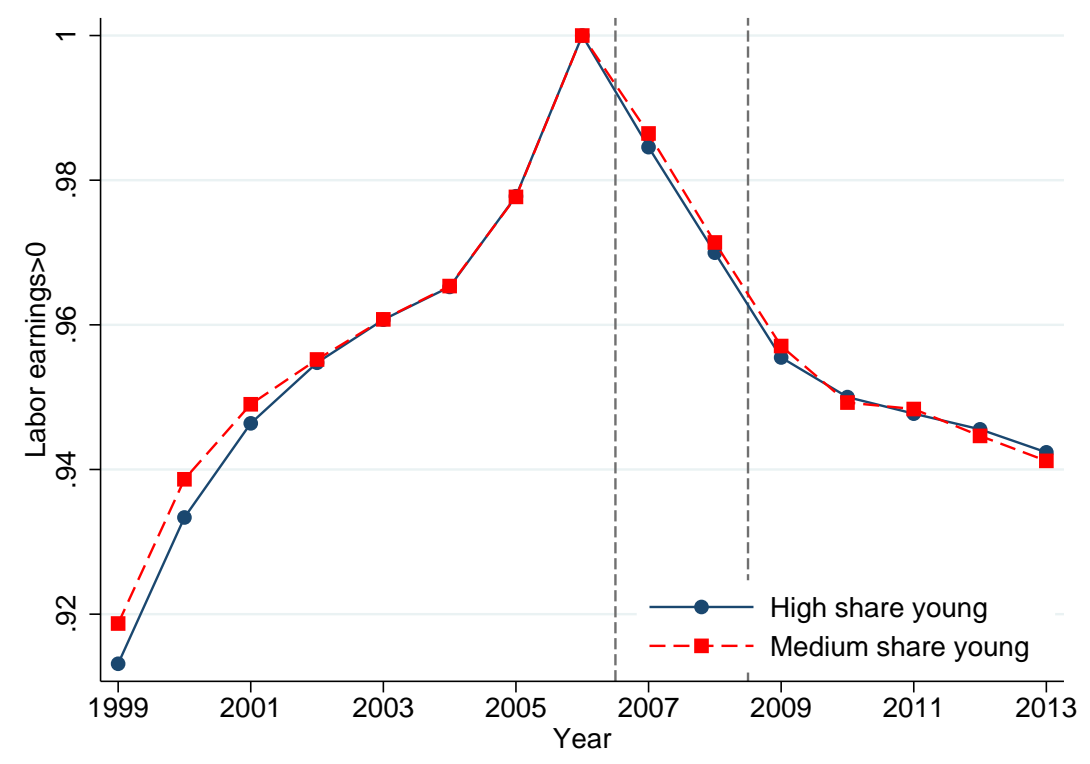

(b) Fraction of individuals working with 2006 employer

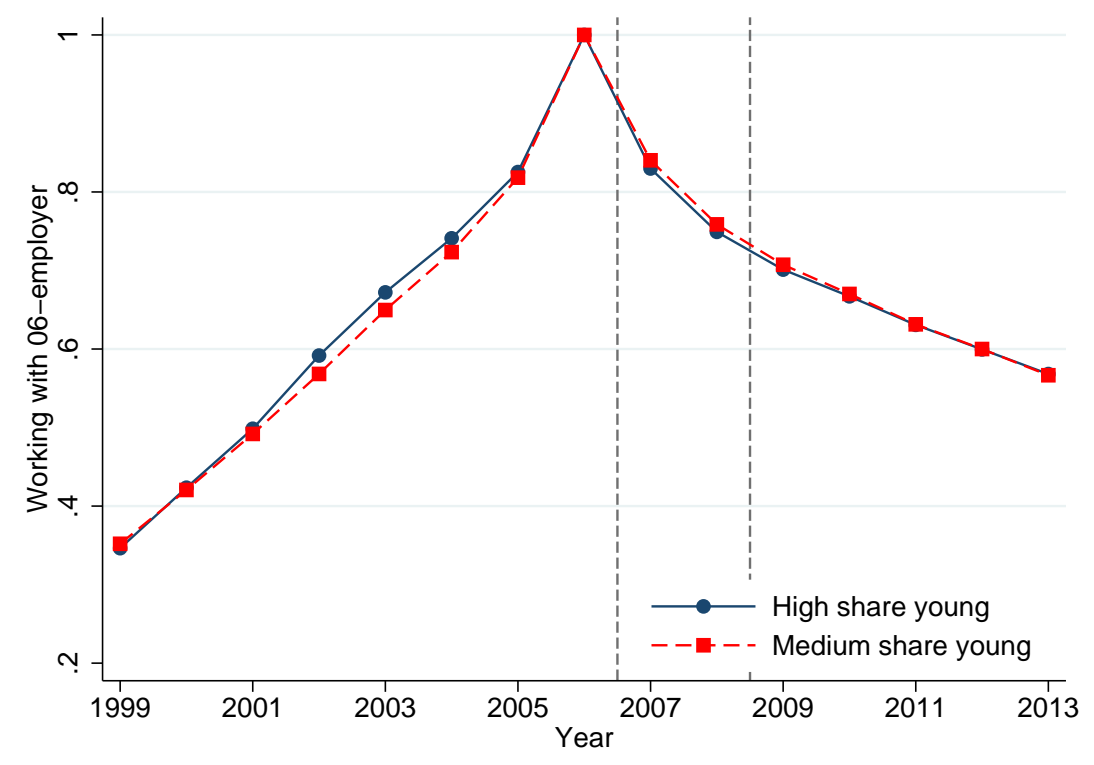

Notes: This figure repeats the setting of Figure 13 where we follow individuals based on share young at the firm they are working at in 2006. We consider two groups of individuals: (1) individuals working in a medium share young firm in 2006 and (2) individuals working in a high share young firm in 2006. In the top panel, we plot the fraction of individuals with positive earnings during the year (regardless of employer). This fraction is equal to 1 in 2006 by definition of the sample. In the bottom panel, we plot the fraction of individuals with positive earnings during the year with the same employer they were working at in 2006. This fraction is also by definition equal to 1 in 2006. Both panels show parallel pre-reform trends. Both panels show that working at the high share young firm in 2006 (relative to medium share young) has no effect post-reform on the extensive margin of overall employment (top panel) or employment at the same firm (bottom panel). Hence, all the effects we uncover are intensive margin effects on earnings. 
(a) Earnings of individuals working at any firm

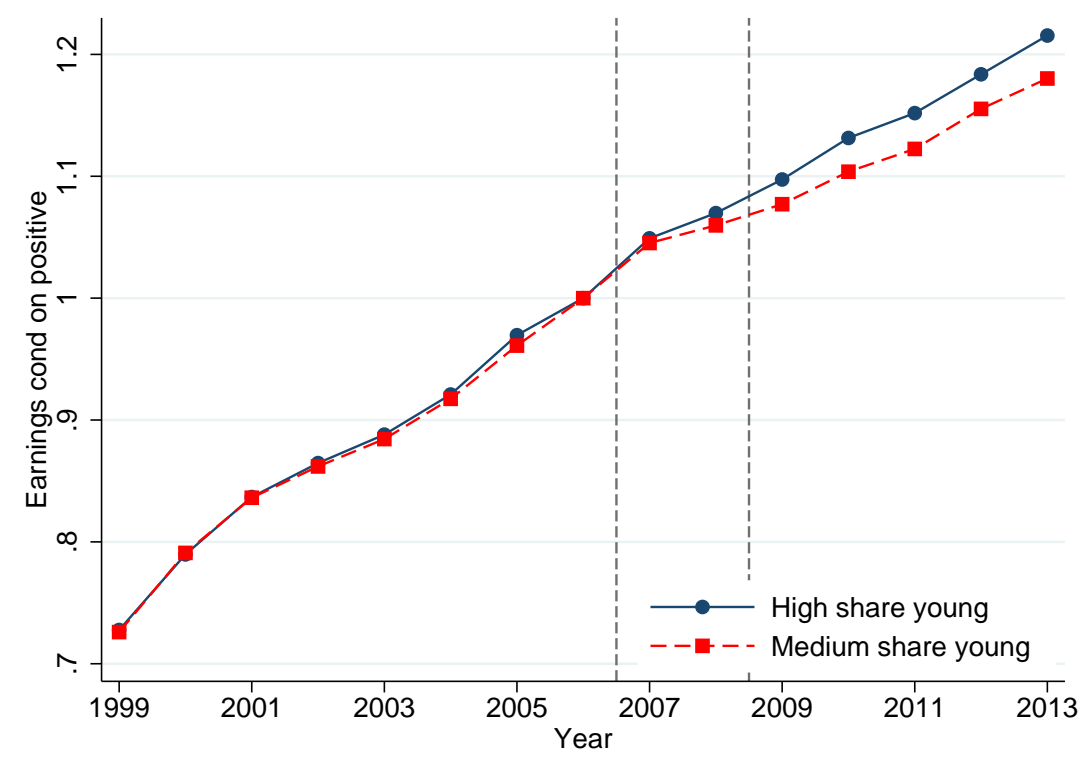

(b) Earnings of individuals working with 2006 employer

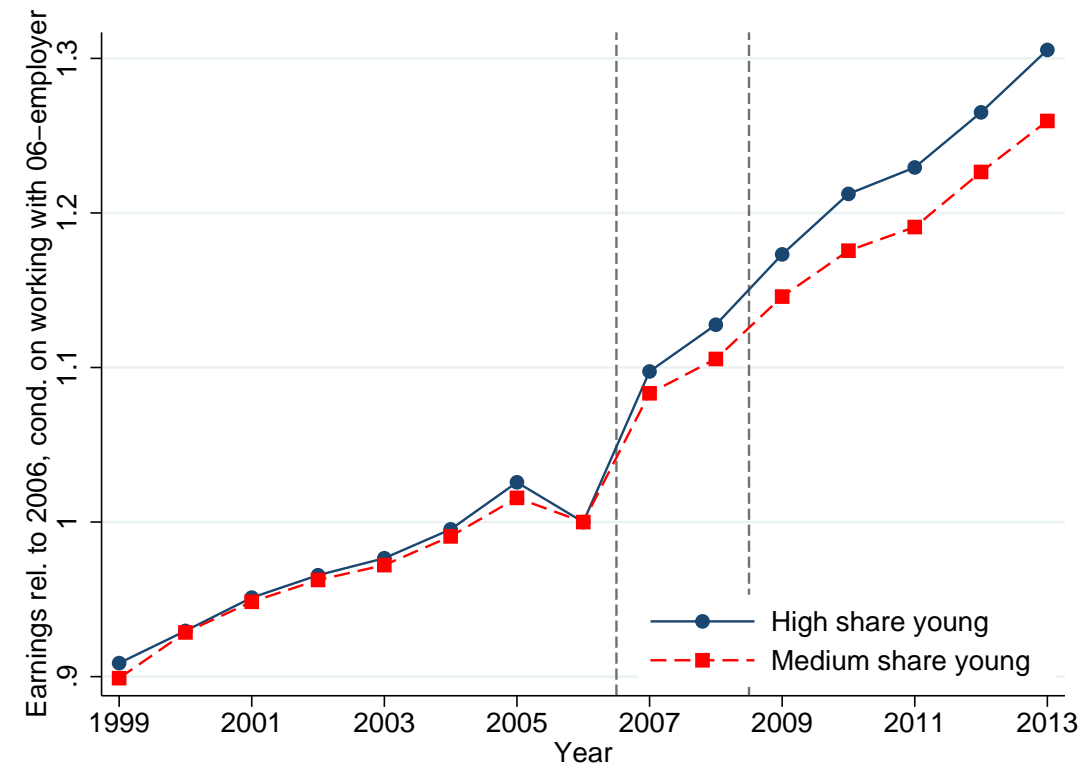

Notes: This figure repeats the setting of Figure 13 where we follow individuals based on share young at the firm they are working at in 2006. We consider two groups of individuals: (1) individuals working in a medium share young firm in 2006 and (2) individuals working in a high share young firm in 2006. In the top panel, we plot the earnings of individuals with positive earnings during the year (regardless of employer), i.e. conditional on employment. In the bottom panel, we plot the earnings of the subset of those individuals that work with the 2006 employer in a given other year, that is only earners with the 2006 employer are plotted. Both panels show parallel pre-reform trends. Both panels show that working at the high share young firm in 2006 (relative to medium share young) has a positive effect post-reform on the intensive margin of earnings (top panel) or on earnings with the 2006 employer (bottom panel). Hence, the effects we uncover are intensive margin effects on earnings and moreover exhibited by workers with the original 2006 employer. 
Figure A15: Individual Net Wage Earnings Effects by Age groups

(a) Ages 25-30

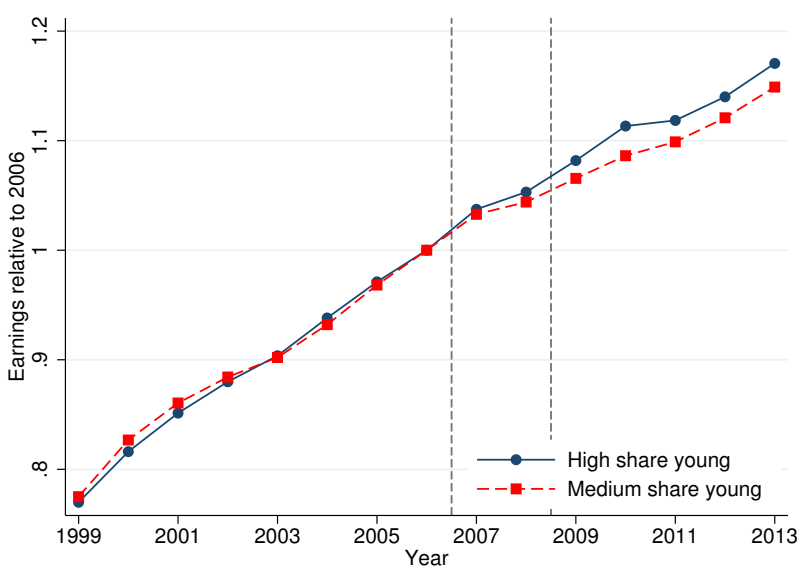

(c) Ages 41-50

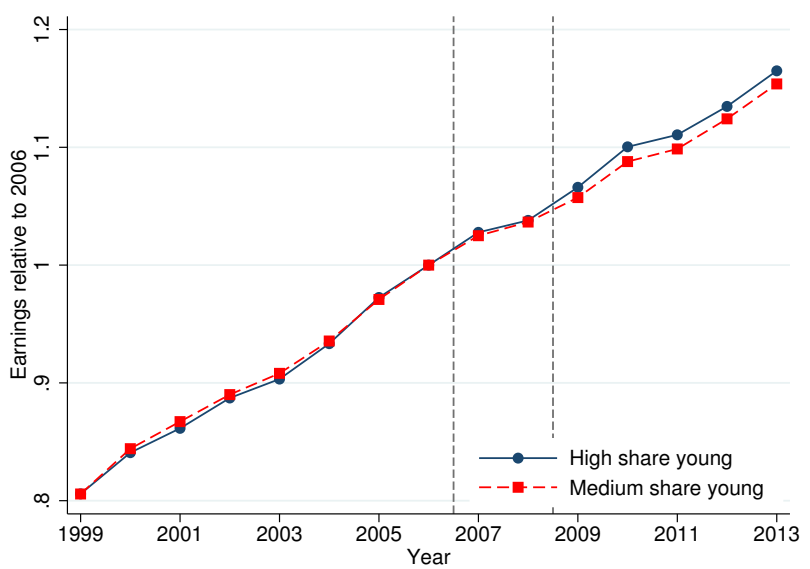

(b) Ages 31-40

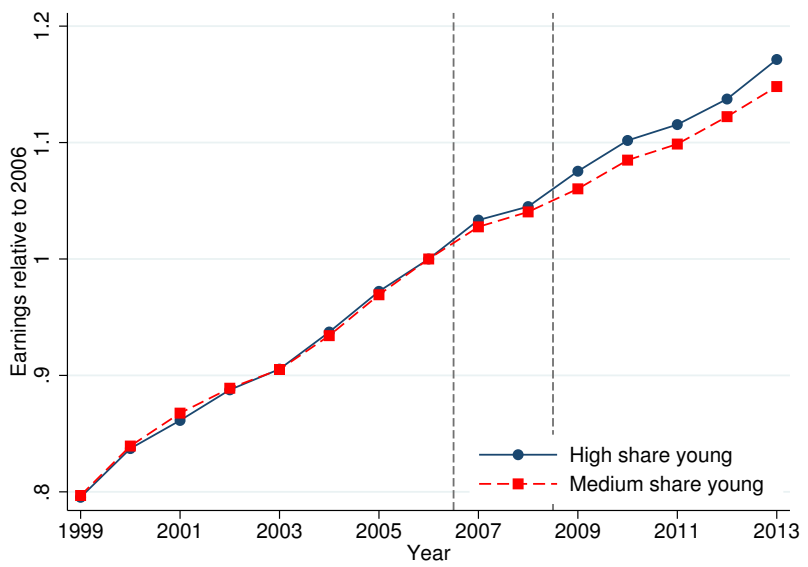

(d) Ages 51-60

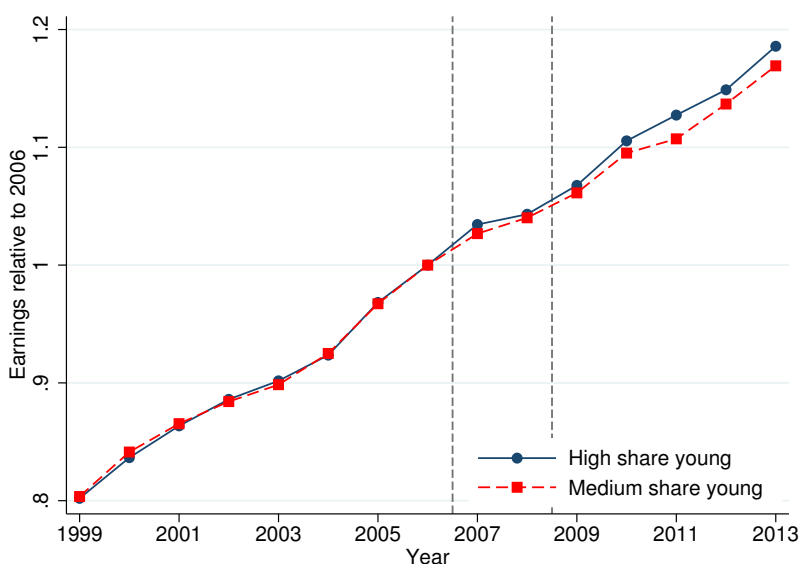

Notes: This figure repeats the average individual earnings longitudinal effects of Figure 13 . Panel (a) but further splits the sample into 4 age groups of 2006. Each age group is depicted in a specific panel: (a) ages 25-30, (b) ages 31-40, (c) ages 41-50, (d) ages 51-60. In each panel, we estimate average individual earnings (relative to 2006) for (1) individuals who worked at a firm with high share young in 2006 and (2) individuals who worked at a firm with medium share young in 2006. All panels show that individuals working in a high share young firm in 2006 (which benefitted from a larger tax windfall) experience faster earnings growth on average. The pre-trends are all parallel. Corresponding estimates are provided in Table 7. 
Figure A16: Individual-level Effects on Net Wage Earnings Percentiles

(a) 10th percentile

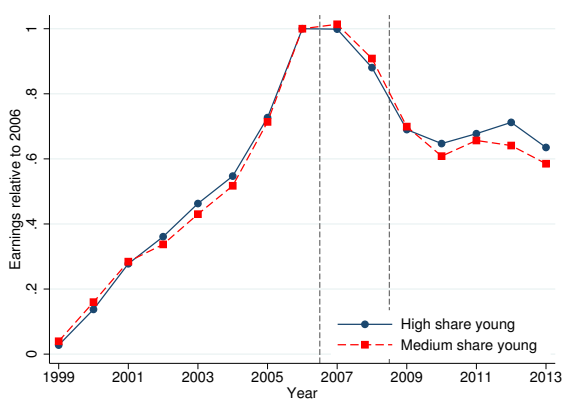

(d) 40th percentile

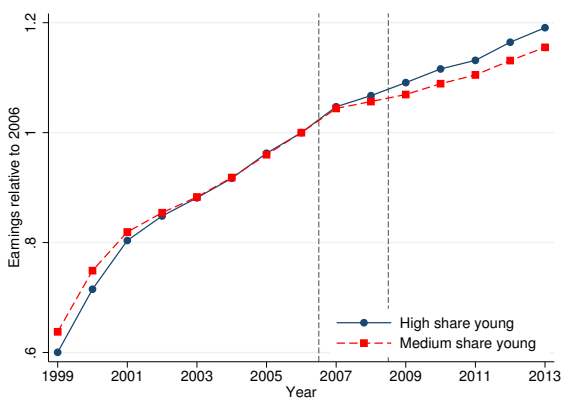

(g) 70th percentile

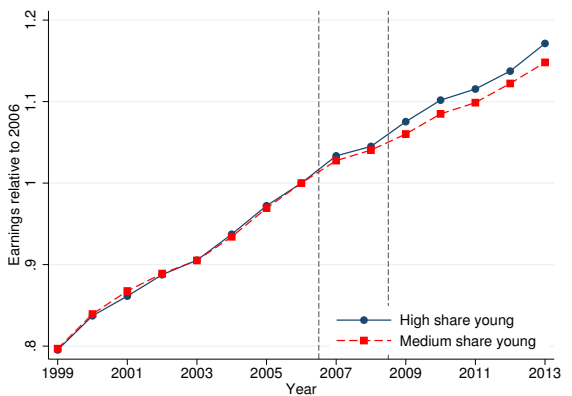

(b) 20th percentile

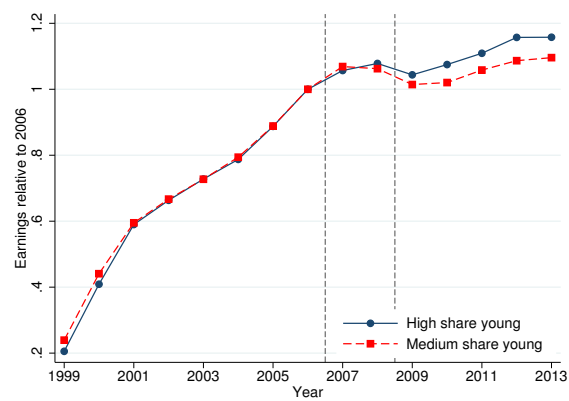

(e) 50th percentile

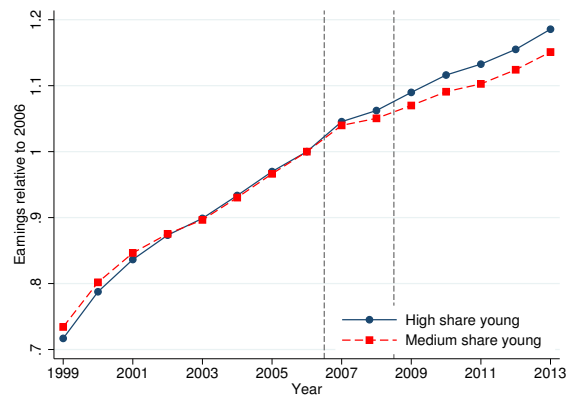

(h) 80th percentile

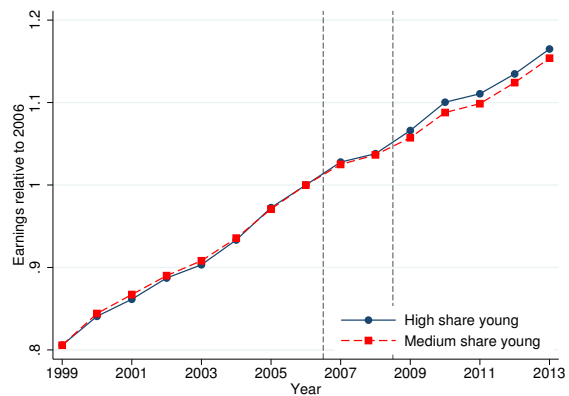

(c) 30th percentile

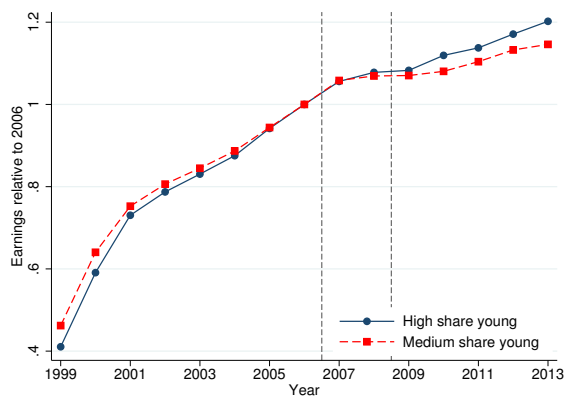

(f) 60th percentile

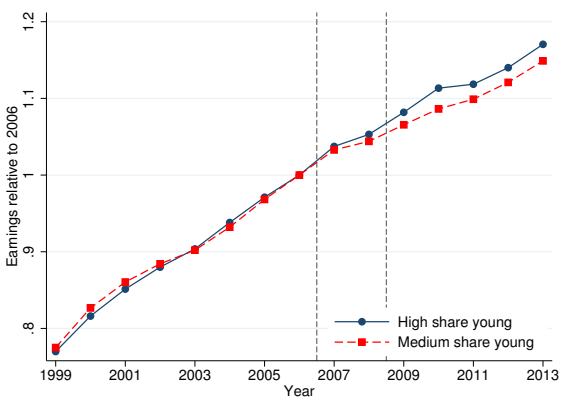

(i) 90 th percentile

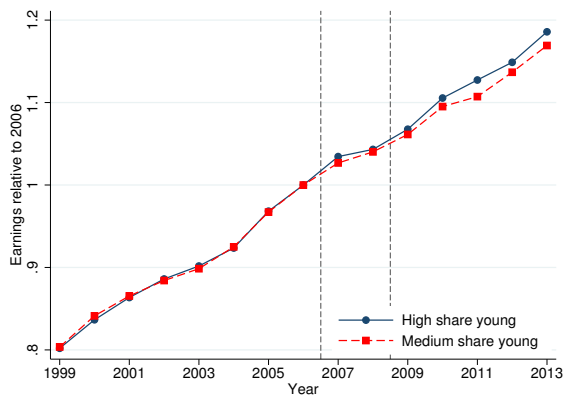

Notes: We repeat the analysis of Figure 13 . Panel (a) but instead of considering average net wage earnings, we consider various percentiles of the net wage earnings distribution among workers based on share young at the firm the individual was working at in 2006. The graphs show that the positive effects on individual earnings of the payroll tax cut are more pronounced at the lower percentiles than at the higher percentiles. This implies that the collective tax incidence rent sharing following the payroll tax cut benefits low earning workers relatively more. Corresponding estimates are provided in Table 8 
Table A1: Short-run Effect of Payroll Tax Cut on Employment Measures

\begin{tabular}{lcc}
\hline \hline & $(1)$ & $(2)$ \\
& Effect (ppt) & Elasticity \\
\hline Employment / Labor Force (LF) & 0.025 & 0.25 \\
Employment / (LF+students) & $(0.0028)$ & $(0.028)$ \\
& 0.035 & 0.41 \\
Employment / Population & $(0.0034)$ & $(0.040)$ \\
& 0.026 & 0.45 \\
Labor force / Population & $(0.0039)$ & $(0.066)$ \\
& 0.0077 & 0.085 \\
Unemployment-Employment transitions & $(0.0038)$ & $(0.042)$ \\
& 0.0040 & 0.084 \\
Employment-Unemployment transitions & $(0.0034)$ & $(0.071)$ \\
& -0.011 & -1.98 \\
$N$ & $(0.0015)$ & $(0.27)$ \\
\hline \hline
\end{tabular}

Notes: This table repeats the analysis of Table 2 but focusing on short-run effects when the reform was only partially phased-in. We compare the 2007-08 period relative to pre-reform periods 2002-2004 and 2005-2006 (the main text table compares periods 2009-2011 and 2012-13 relative to pre-reform periods 2002-2004 and 2005-2006). 